\title{
EXPLORING THE LINK BETWEEN CANADIAN UNIVERSITY ATHLETICS AND EMOTIONALLY INTELLIGENT LEADERSHIP POTENTIAL
}

by

\author{
Robert C. Smart, B.Com
}

\author{
A thesis submitted to \\ The Faculty of Graduate Studies and Research \\ in partial fulfillment of the \\ degree of \\ Master of Business Administration
}

Eric Sprott School of Business

Carleton University

Ottawa, Ontario

July 19, 2004

Ccopyright

Robert C. Smart, 2004 


$\begin{array}{ll}\begin{array}{l}\text { Library and } \\ \text { Archives Canada }\end{array} & \begin{array}{l}\text { Bibliothèque et } \\ \text { Archives Canada }\end{array} \\ \begin{array}{l}\text { Published Heritage } \\ \text { Branch }\end{array} & \begin{array}{l}\text { Direction du } \\ \text { Patrimoine de l'édition }\end{array} \\ \begin{array}{l}\text { 395 Wellington Street } \\ \text { Ottawa ON K1A 0N4 }\end{array} & \begin{array}{l}\text { 395, rue Wellington } \\ \text { Ottawa ON K1A ON4 } \\ \text { Canada }\end{array} \\ \end{array}$

Your file Votre référence ISBN: 0-612-99021-4

Ourfile Notre référence

ISBN: 0-612-99021-4

NOTICE:

The author has granted a nonexclusive license allowing Library and Archives Canada to reproduce, publish, archive, preserve, conserve, communicate to the public by telecommunication or on the Internet, loan, distribute and sell theses worldwide, for commercial or noncommercial purposes, in microform, paper, electronic and/or any other formats.

The author retains copyright ownership and moral rights in this thesis. Neither the thesis nor substantial extracts from it may be printed or otherwise reproduced without the author's permission.
AVIS:

L'auteur a accordé une licence non exclusive permettant à la Bibliothèque et Archives Canada de reproduire, publier, archiver, sauvegarder, conserver, transmettre au public par télécommunication ou par l'Internet, prêter, distribuer et vendre des thèses partout dans le monde, à des fins commerciales ou autres, sur support microforme, papier, électronique et/ou autres formats.

L'auteur conserve la propriété du droit d'auteur et des droits moraux qui protège cette thèse. $\mathrm{Ni}$ la thèse ni des extraits substantiels de celle-ci ne doivent être imprimés ou autrement reproduits sans son autorisation.
In compliance with the Canadian

Privacy Act some supporting forms may have been removed from this thesis.

While these forms may be included in the document page count, their removal does not represent any loss of content from the thesis.
Conformément à la loi canadienne sur la protection de la vie privée, quelques formulaires secondaires ont été enlevés de cette thèse.

Bien que ces formulaires aient inclus dans la pagination, il n'y aura aucun contenu manquant. 


\section{ABSTRACT}

The purpose of this research was to examine the relationship between varsity athletic participation and emotionally intelligent (EI) leadership potential. A cross-sectional model was developed to test for differing levels of EI in students who played a varsity sport during their time at university.

The research sample consisted of 120 Ontario university students ( 60 varsity athletes and 60 non-varsity students). The model was tested using a two (varsity athletic participation: yes/no) by two (gender: male/female) ANOVA for overall EI and MANOVA for the four branches of EI as dependent variables. The instrument used to test EI was the Mayer/Salovey/Caruso Emotional Intelligence Test (MSCEIT). Findings from this research report no significant association between varsity athletic participation and EI levels for university students of either gender. The results of this research will be useful to researchers, administration and employers seeking to valuate the varsity athletic participation experience in hiring and funding decisions. 


\section{ACKNOWLEDGEMENTS}

There are several individuals who I need to thank for making this thesis possible. First and foremost, I would like to say thanks to all of my family. To Mom, Dad, Mike and Jess, thanks for giving me the love of school and sports.

As well, nothing I have done well in school, sports and life would be possible or nearly as fun without the guidance and encouragement of my coach, uncle and friend, Dave. Thanks to my thesis supervisor, Dr. Linda Duxbury. Her patience, knowledge and teaching ability guided me through each step of this thesis. She was a great thesis coach. Thanks to my thesis advisory committee members, Dr. Ian Lee and Dr. Steven Murphy for their guidance on this thesis.

Finally, big thanks to all of my team mates, coaches and support staff who made my university athletic experience possible. It was a good run and I hope everyone had as much fun as I did.

Go Ravens! 


\section{TABLE OF CONTENTS}

1.0 INTRODUCTION

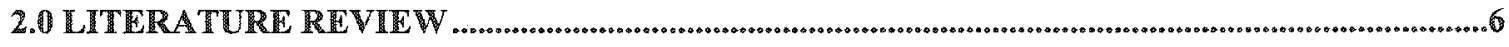

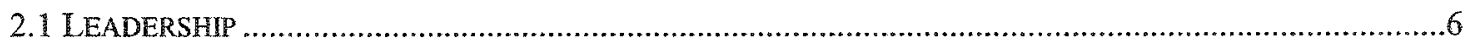

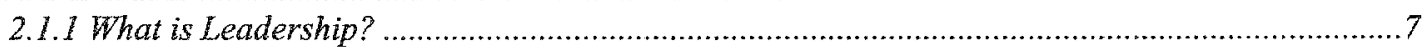

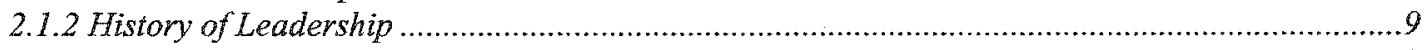

2.1.2.1 Trait Leadership - Early Leadership Theory …………............................................................9

2.1.2.2 Behavioral Leadership Theories..............................................................................................12

2.1.2.3 Situational Leadership Theory ...................................................................................................16

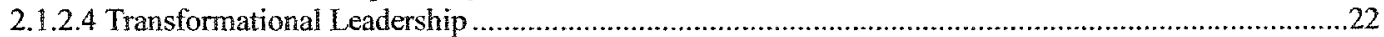

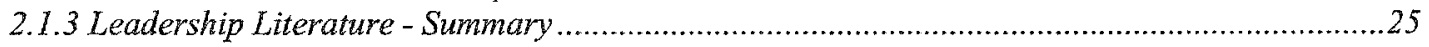

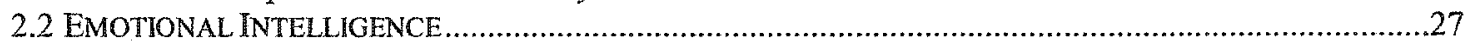

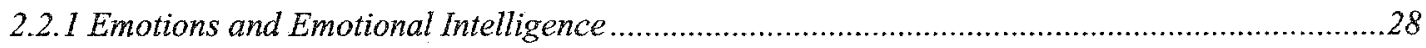

2.2.2 History of Emotional Intelligence ………..........................................................................29

2.2.3 Modern Emotional Intelligence .........................................................................................

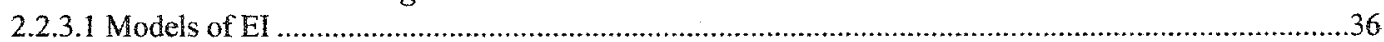

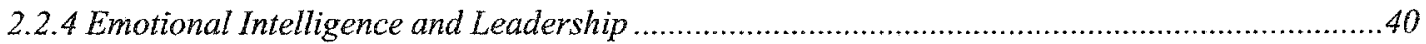

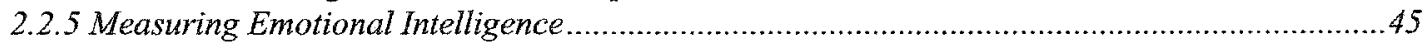

2.2.6 Emotional Intelligence - Summary ……………...........................................................

2.3 DEVELOPMENT OF UNIVERSTTY STUDENTS: THE ROLE OF VARSTTY ATHLETICS ..............................50

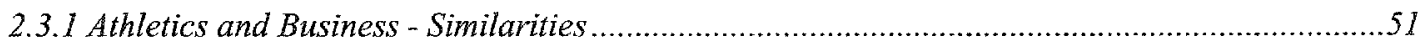

2.3.1.1 Academic Research- Similarities between Sport and Business.........................................................52

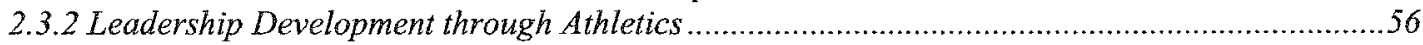

2.3.3 Development of Emotional Intelligence in Students...........................................................6

2.3.4 University Student Athlete Experience - Summary …........................................................62

3.0 RESEARCH QUESTIONS................................................................................................................64

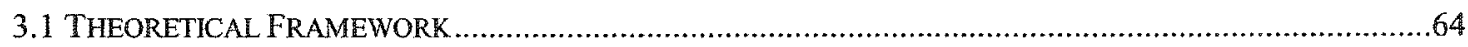

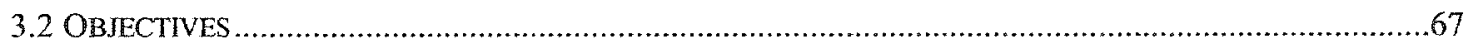

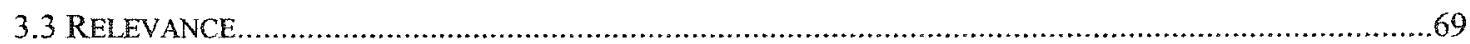

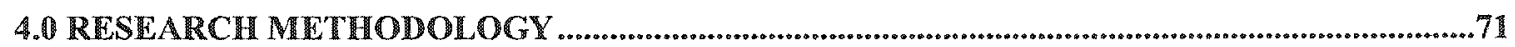

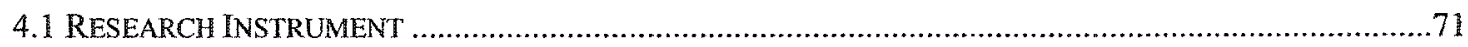

4.1.1 Selecting a Definition and Measure of Emotional Intelligence................................................71

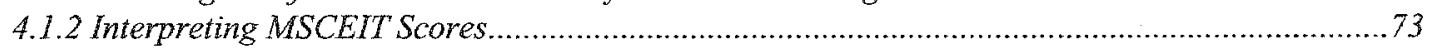

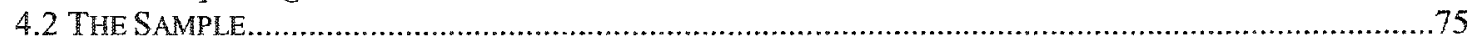

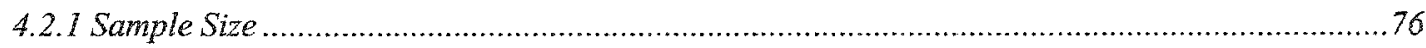

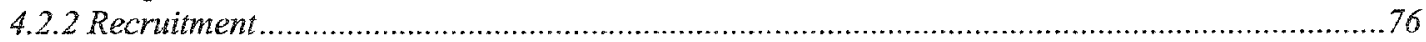

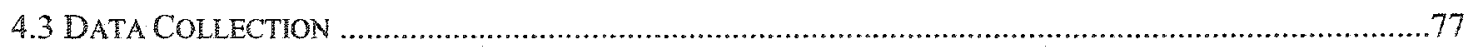

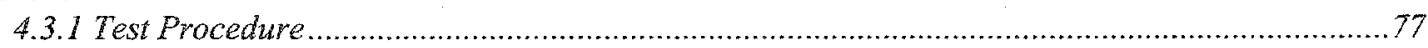

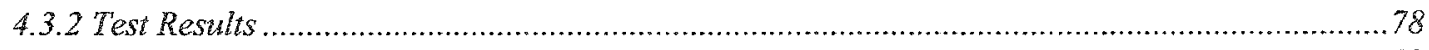

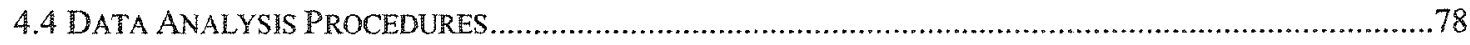

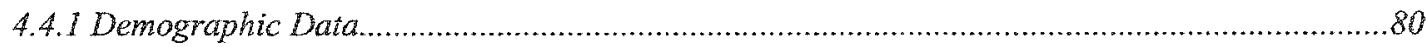

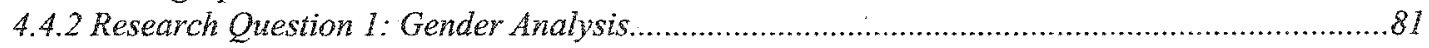

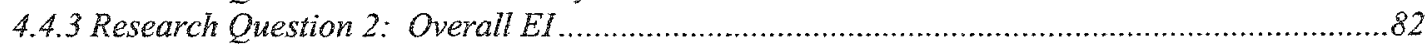

4.4.4 Research Question 3a-d: Four Branches of Emotional Intelligence ......................................82

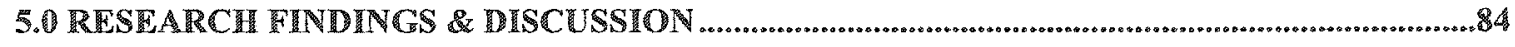

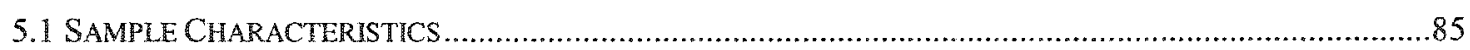

$5.1 .1 \mathrm{Age}$

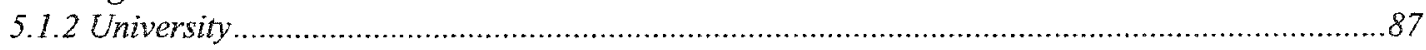

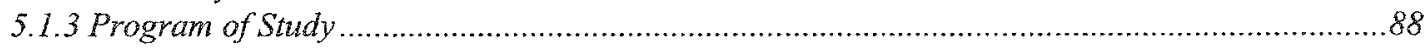


5.1.4 Varsity Sport Information

5.2 DATA ANALYSIS - OVERVIEW

5.3 RESULTS ASSOCIATED WITH RESEARCH QUESTION 1: IS THE RELATIONSHIP BETWEEN VARSTTY ATHLETIC PARTKCIPATLON AND THE EI SCORES OF UNIVERSTYY STUDENTS DIFFERENT FOR MALES AND FEMALES?

5.4 RESULTS ASSOCIATED WITH RESEARCH QUESTION 2: WHAT IS THE RELATIONSHIP BETWEEN VARSITY ATHLETIC PARTICIPATION AND OVERALL EMOTIONAL INTELLIGENCE AMONG UNIVERSITY STUDENTS? ....97

5.5 RESULTS ASSOCIATED WITH RESEARCH QUESTION 3

5.5.1 Results Associated with Research Question 3 a: What is the relationship between varsity athletic participation and a student's ability to perceive and identify emotions?. 101 5.5.2 Results Associated with Research Question 3b: What is the relationship between varsity athletic participation and a student's ability to facilitate and use emotion? 102

5.5.3 Results Associated with Research Question $3 c$ : What is the relationship between varsity athletic participation and a student's ability to understand emotions?

5.5.4 Results Associated with Research Question 3d: What is the relationship between varsity athletic participation and a student's ability to manage emotions?

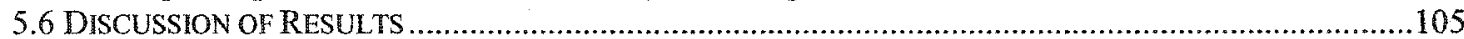

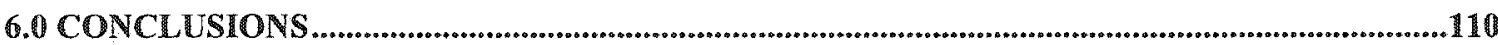

7.0 RETERENCES ... 


\section{LIST OF TABLES}

Table 4.1.2 Guidelines for Interpreting MSCEIT Scores ................................. 74

Table 4.4 - Summary of Analysis of Data .......................................................... 83

Table 5.1 Complete Sample Breakdown......................................................... 85

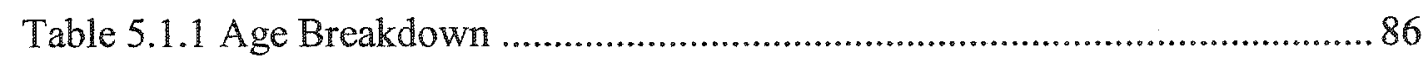

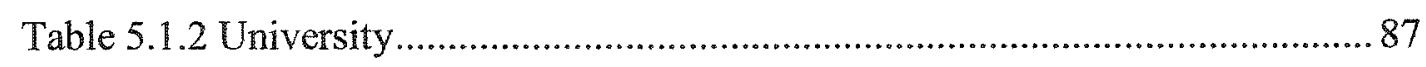

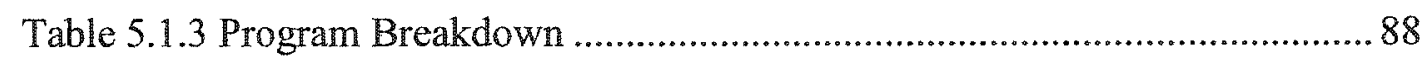

Table 5.1.4 Varsity Sport Breakdown........................................................... 90

Table 5.2 Full Sample Mean EI Scores by Group ...............................................91

Table 5.3a MSCEIT Mean Scores - Sport * Gender.......................................... 95

Table 5.3b Gender * Varsity Athletic Participation Interaction Effect................... 96

Table 5.4 Research Question 2: ANOVA ............................................................. 98

Table 5.5a MSCEIT Four Branches of EI Mean Scores ...................................... 99

Table 5.5b Research Question 3: MANOVA Main Effects................................. 100 


\section{LIST OF FIGURES}

Figure 1: Blake and Mouton's Managerial Grid .................................................. 14

Figure 2: Tannenbaum and Schmidt - Leadership Model.......................................... 17

Figure 3: Hersey-Blanchard Situational Leadership Model....................................... 18

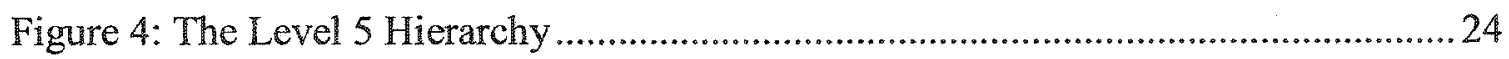

Figure 5: Goleman's Model of Emotional Intelligence ...............................................35

Figure 6: Cooper and Sawaf Model of Emotional Intelligence .................................... 37

Figure 7: MSC Model of Emotional Intelligence .................................................... 38

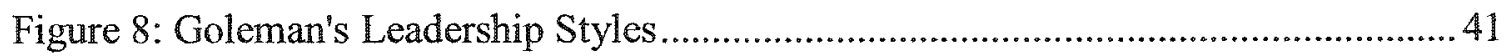

Figure 9: Framework Linking Emotionally Intelligent Leadership and University Athletic

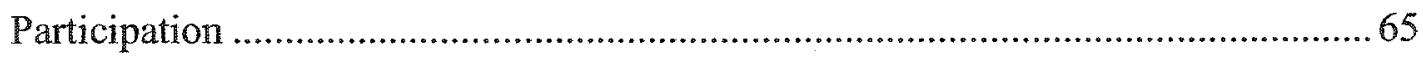

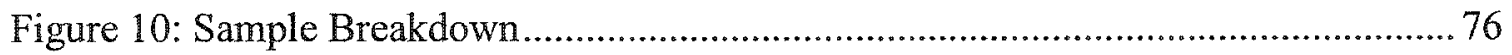

\section{LIST OF APPENDICES}

APPENDIX \# 1: LETTER OF INFORMATION ................................................ 118 


\subsection{INTRODUCTION}

Identifying leadership potential in young people may be one of the most important tasks facing a business today. With technology and globalization pushing markets to change at a rapid pace and with the retirement of the baby boomer population from leadership positions, the challenge to attain and develop quality people for leadership succession at all levels of the organization is even more pronounced. Organizations are searching for emotionally intelligent university students who can meet these challenges and become future business leaders.

The current understanding of leadership has been shaped over the last century by intense research into the topic. The first area of leadership research attempted to define a set of personal traits that could be used to differentiate leaders from the rest of the pack. The results of this research were inconsistent and it was shown that the leader could not be described solely on a set of predefined traits (Stogdill, 1948). Building on trait research, the behaviour of a leader was incorporated into several future leadership models (Blake \& Mouton, 1964; Fiedler, 1967). These behavioural models were also inadequate predictors of leadership due to their lack of flexibility for different leadership situations. Identifying the problem of environmental factors in leadership analysis, situational leadership theory emerged as the dominant area of leadership research for the final quarter of the twentieth century (House, 1971; Hersey \& Blanchard, 1993). Another area of leadership research that developed rapidly in the 1980's and 1990's was transformational leadership research. Within this last body of research, the importance of leadership in transforming organizations has been closely examined. 
Each of the above four main phases of leadership theory (trait, behavioural, situational and transformational) have contributed to the development of a fifth school of leadership theory: emotionally intelligent leadership.

In 1995 Daniel Goleman published the best selling book Emotional Intelligence: Why it can matter more than $I Q$. Since then the idea of emotional intelligence $(\mathrm{EI})$ has been applied to leadership and the implications for businesses are of increasing importance. Researchers such as Goleman (1995; 2002), George (2000) and Bar-On and Parker (2000) have confirmed that EI is a very important measure of leadership potential. Their research has shown that emotionally intelligent leaders have the potential to monitor and control themselves and the people around them. These leaders can adjust their behaviour to different situations and thus are more flexible and efficient. The challenge for businesses therefore, is to identify those individuals who possess the potential to become emotionally intelligent leaders.

Research into the field has developed several models and instruments to test for El. The EI model that has its strongest roots in academic research is the Salovey/Mayer/Caruso model. The development of a way to measure $\mathrm{EI}$ has made further research into the area of emotionally intelligent leadership possible.

To find future leaders, organizations rely on a steady stream of talented university stodents. Recruitment and training of university gradates represents a significant investment for the organization, as these are the individuals who could potentially determine the future success of the company. The idea of succession planning for organizations is an important one. Kessner and Sebora (1997) presented a summary of research surrounding succession planning in their article Executive Succession: Past, 
Present \& Future. In this article the authors discuss the importance of leadership succession for an organization to succeed. To start their succession plans in motion businesses are now recruiting employees who they hope posses the emotional skills to develop into future leaders (Dench, 1997; Langley, 2000). As a result, understanding which university students are developing the skills to become emotionally intelligent leaders is an important task for a business.

The university experience may play an important role in how a student will develop as a potential leader. Students who participate in a varsity sport experience competition, team work and pressure to succeed supplemental to the academic and social challenges of the university experience. To the student athlete who exhibits the self discipline, time management, interpersonal skills and talent needed to succeed as a student and an athlete, the reward is an unforgettable life experience. Research by Ryan (1987) and Debosz and Beaty (1999) have shown positive impacts of athletics on student leadership development. Further research is needed to understand if emotionally intelligent leadership development is related to athletic participation.

The purpose of this research is to examine the relationship between the varsity athletic experience and the level of emotionally intelligent leadership potential in university students. Specifically, this research examines whether students who competed in varsity athletics during their university career possess differing levels of emotional intelligence than those students who did not participate in varsity sport. To further understand the effect of varsity athletic participation on student athletes this thesis will also test two research objectives in relation to overall EI: 
1) How does participation in varsity athletics effect university student scores in each of the four sub-categories of EI (Perceiving, Facilitating, Understanding and Managing)?

2) Are there any gender differences in the effect of varsity athletic participation on EI scores for university students?

Each of the research objectives for this thesis will further enhance the understanding of the relationship between university student's emotional intelligence and participation in a varsity sport. The present research is unique as it is the first research to test the relationship between emotional intelligence and the student athlete's university experience. Previous research has focused on high school sports and the leadership traits developed by students (Debosz \& Beaty, 1999). This research represents a significant extension of existing research. Through the present research, insight into the development of EI through athletic experience will be gained. The findings of this research could prove useful for organizations who seek to improve how they recruit and develops their future leaders. As well, the study may be useful for university administration seeking to ensure that EI development is a valuable part of the university experience. The relationship between university athletic participation and the development of EI leadership theory will also be advanced from the findings of this study.

This thesis is divided into six sections: introduction; literature review, research questions, research methodology, research findings and discussion, and conclusions. The literature review will explore previous literature related to this thesis in the areas of leadership, emotional intelligence and student development. The research objectives section will 
outline the theoretical framework for this study as well as, provide the specific research questions that this study will attempt to answer. In the research methodology section the sample, data collection, research instrument and data analysis procedures will all be discussed. The results of the research, interpretations, limitations and directions for future research from this research will be explained in section five. Finally, the conclusions and lessons to be learned from this research will be summarized in section six. 


\subsection{LITERATURE REVIEW}

The literature review consists of three main sections:

1) Leadership

2) Emotional intelligence

3) The effect of sport on university students

The first section of literature will chronologically examine the development of leadership theory up to but excluding the current theory on EI. This review, while general in nature will put the current research into context as it affects the world of business leadership. The second area of the literature review will deal with the development of emotional intelligence theory. In this section the different models and measures of this construct will be examined. Finally, the literature linking student athletic participation to emotionally intelligent leadership will be discussed. This final section of literature review will contribute to our understanding of how emotionally intelligent leadership development has been studied in terms of the effect of athletics on students.

\subsection{Leadership}

The literature surrounding leadership is one of the most extensive of any topic in business research. While a complete review of leadership theory is beyond the scope of this thesis, it is important that the major areas of leadership research be discussed in order to put current EI theory as it is discussed in this thesis into proper context. To achieve this, the four main areas of leadership literature will be discussed: trait, behaviour, situational and transformational leadership. Each of these stages has furthered our understanding of 
what a good leader is and has helped to shape the theory of emotionally intelligent leadership.

\subsubsection{What is Leadership?}

The definition of leadership is a very difficuit one to agree on because of the variety of examples of both good and bad leaders. For almost every definition of what a leader is, the everyday follower can point out several real life examples that do not fit in that definition. Finding a definition that will include leaders such as Gandhi, the captain of a minor bantam hockey team, a sixth grade teacher and the CEO of Microsoft is very difficult. All of these individuals lead but none of them appear on the outside, to be anything alike. For the purpose of this research the focus will be on providing an explanation on leadership in the business arena.

One of the most important steps to understanding business leadership is to understand the difference between managers and leaders. The most influential paper on this topic was written by Abraham Zaleznik in 1977. This landmark article entitled Managers and Leaders: Are They Different? explains how managers and leaders serve different functions in an organization and must have different capabilities to perform their role. Zaleznik describes managers' duties as being more structured everyday tasks such as controlling, planning, budgeting and staffing. The manager tends to use an impersonal approach to dealing with people. They are concerned with efficiency and problem solving. The manager also serves as an information resource that enables workers to complete their tasks. In contrast, Zaleznik describes leaders as risk takers who have a vision and strive to get others to follow that vision. Leaders take a very upfront and personal approach to achieving their goals. The way they handle themselves and interact 
with others is extremely important for leaders. The leaders' duties include setting a vision for the company, communicating the strategy to employees and motivating others to execute the strategy. Zaleznik writes, "Business leaders have much more in common with artists than they do with managers" (Zaleznik, 1977). He also argues that leaders can be developed with close one on one mentoring. The Zaleznik article has helped to clarify the definition of a leader somewhat, but there still is uncertainty in exactly how to describe a leader. In a very interesting article Parables of Leadership by Kim and Mauborgne (2002), the topic of leadership is explained through ancient Oriental parables. The parables provide some useful messages on leadership. They explain that a leader should have the ability to hear what is unspoken, be humble and committed, know the value of different viewpoints and be able to draw out the unique strengths of every member of the team. This article provides very useful insight into leadership but unfortunately this model does not match well with the North American business definition of a leader.

The truth is that, there still is no accepted definition for a leader. The attempts to define a leader by the academic community have gone through four main stages of development before advancing to emotionally intelligent leadership. These stages include:

1) Trait Theory

2) Behavioral Theory

3) Situational Leadership theory

4) Transformational vs. transactional leadership theory

Details on each of the stages of leadership theory are given in the sections below. 


\subsubsection{History of Leadership}

It is important to understand each of the stages of business leadership theory, as they all contribute significantly to our current knowledge of business leadership. Relevant details are given in the sections that follow.

\subsubsection{Trait Leadership - Early Leadership Theory}

The first stage of research in this area attempted to define a leader through a set of personal attributes. The trait theory of leadership focuses on the idea that leaders have a specific set of traits that allow them to influence and motivate others to increase their

performance. The research in this area represents most of the work on leadership before 1948. This method saw scholars struggle to come up with a list of traits that would define a leader. Researchers tried to find correlations between successful leaders and characteristics such as age, height, weight, physique, energy, appearance, intelligence, scholarship, introversion-extroversion and hundreds of other personality traits. However, seldom could a set of traits be applied across even a majority of leaders. At the peak of the inability to find an acceptable set of leadership traits Ralph M. Stogdill's 1948 article Personal Factors Associated with Leadership: A Survey of the Literature was published in the Journal of Psychology. This research attempted to unify the trait research up to 1948. The results however, showed that there was no evidence that specific personal traits could be used to predict effectiveness as a leader. Stogdill wrote, "a person does not become a leader by virtue of the possession of some combination of traits, but the pattern of personal characteristics of the leader must bear some relevant relationship to the characteristics, activities and goals of the followers" ( Stogdill, 1948: p.64). Stogdill stressed the importance of matching the leader with the correct situation in order to have 
effective leadership. He went so far as to say that the easy part would be to find a good leader; the hard part would be to find a situation that would match the leaders" skills. Despite the shift in leadership research caused by Stogdills' article, research into the trait theory of leadership continued throughout the rest of the century. In 1980 Harry Levinson wrote an article in the Harvard Business Review entitled Criteria for Choosing Chief Executives. Levinson argued that the process of selecting a CEO was an almost impossible task if you did not use a predetermined set of traits to evaluate candidates. He even provided a basic list of twenty attributes that a good CEO should have and a fivepoint scale on which to grade candidates. Levinson advised organizations to use questions about their environment and their organization to revise the list of necessary attributes for the job to fit their business. Using the specific list of traits a selection board could then evaluate potential leaders on acceptable levels of the traits required for their business. The major problem of this research was the fact that a list of traits that would determine the success of the leader in one organization is unlikely to transfer successfully to another organization (Levinson, 1980).

In $1983 \mathrm{McCall}$ and Lombardo brought trait analysis of leadership back into the academic light by identifying traits of ineffective leaders in their article What Makes $A$ Top Executive?. The authors described several traits that would be fatal to anyone trying to lead. Some of these characteristics included insensitivity, arrogance, betrayal of trust, being cold and aloof, impersonal, unable to delegate, unable to think strategically, and being unable to adapt to a boss. This was a very unique type of trait research and it provided a good basis for future research into the trait theory of leadership. 
Kirkpatrick and Locke published one of the most important recent studies on trait research in 1991. The article Leadership: Do Traits Matter? set out to prove that trait research was a valid way to look at leadership. The authors did a literature search and came out with a list of traits common to effective leaders. These included:

- Desire to be a leader (a leader must want to lead)

- Drive to achieve

- Honesty and integrity

- Self-Confidence

- Knowledge

- Cognitive ability

These character traits are very general guidelines for characteristics of leaders however, Kirkpatrick and Locke's research has made it more acceptable for researchers to focus on traits when evaluating leaders and they represent an important challenge to Stogdills' contention that there is no one set of traits that characterize a leader (Stogdill, 1948). Trait based leadership research has the longest history in the leadership area. However, its progress in the last part of century has been plagued by several weaknesses. The main weakness of trait research over the past century is its lack of consensus on a set of leadership traits. Attempts to empirically show the value of trait research have yielded contradictory results (Stogdill, 1948; Judge, Bono \& Remus, 2002). Other weaknesses include the subjectivity of many traits (i.e. integrity does not have the same meaning to everyone), the exclusion of situational factors, the needs of followers and the confusion of cause and effect (i.e. self-confidence brings about good leadership vs. good leadership brings about self confidence (Mauws, 2002). Despite the lack of empirical support for trait research, its effect on emotional intelligence theory has made it very important to our understanding of leadership in this study. Self-confidence, self awareness and selfmonitoring characteristics are all used in Daniel Goleman's EI theory (Goleman, 2002). 
These traits have been identified as being related to leadership and are excellent guidelines for understanding leaders (Goleman, 2002). By contributing to future leadership research as it has to emotional intelligence theory, trait theory will help researchers understand the difficult topic of leadership.

\subsubsection{Behavioral Leadership Theories}

In response to the shortcomings of trait research on leadership, studies began to take a new approach on leadership in the 1950's and early 1960's. Whereas trait theories focused on separating leaders and non-leaders, behavioral theories of leadership focused on the actions of a good leader. This conceptual shift allowed researchers not only to distinguish between leaders and non-leaders but also, to provide insight into how leaders could be trained. If a set of leadership behaviors could be identified then leaders could be taught to perform these duties and the challenge of finding good leadership would disappear.

The first attempt in behavioral analysis of leadership came on the heels of the Stogdill (1948) study. Researchers at the universities of Michigan and Ohio State preformed large-scale studies on different leadership behaviors. At Michigan, researchers identified two different leadership styles: production or task orientation, and relationship or employee orientation (Katz \& Kahn, 1952; Katz, Maccoby \& Morse, 1950; Katz, et al., 1951). Task orientation referred to the extent that a leader believed that employees were simply a means to production. The leader would thus closely supervise them and use position power as the basis for influencing employees. Employee orientation referred to the degree to which leaders believed that it was necessary to create a community for employee development and achievement. This leader believed that in order for the 
company to be successiul, employees must also achieve their goals. Michigan researchers then gave questionnaires to followers who would rate their leaders on these two dimensions (Katz \& Kahn, 1952; Katz, Maccoby \& Morse, 1950; Katz et al., 1951). Unfortunately, these attempts to empirically show an ideal leadership style did not find conclusive evidence that either leadership style was better.

Similar to the Michigan work, Ohio State researchers attempted to measure leaders on two scales by distributing a questionnaire to followers (Hemphill \& Coons, 1957). The first dimension was initiating structure, which looked at leader behaviors that are focused on communicating job descriptions to employees to increase efficiency of production. The second measure was the consideration that leaders gave to interaction with employees. These two measures were very similar to the Michigan study and also did not provide any conclusive empirical evidence supporting leadership behavior that could be used to train leaders. Despite the lack of clear empirical results from these two studies, they represent the corner stones from which behavioral leadership research would build in the future.

Perhaps the best-known behavioral theory of leadership is Blake and Mouton's (1964) managerial grid. The authors provided a questionnaire with a list of statements relating to leadership behaviors. The results from the test were measured in two dimensions; people (the extent to which leaders were focused on people), and task (the extent to which leaders displayed a task focus at work). These two leadership dimensions created a matrix that was divided into five sections, country club (high people, low task), team builder (high people, high task), impoverished (low people, low task), authoritarian (low people, high task) and middle of the road (equal task and people). 
Tigure 1: Blake and Mouton's Managerial Grid

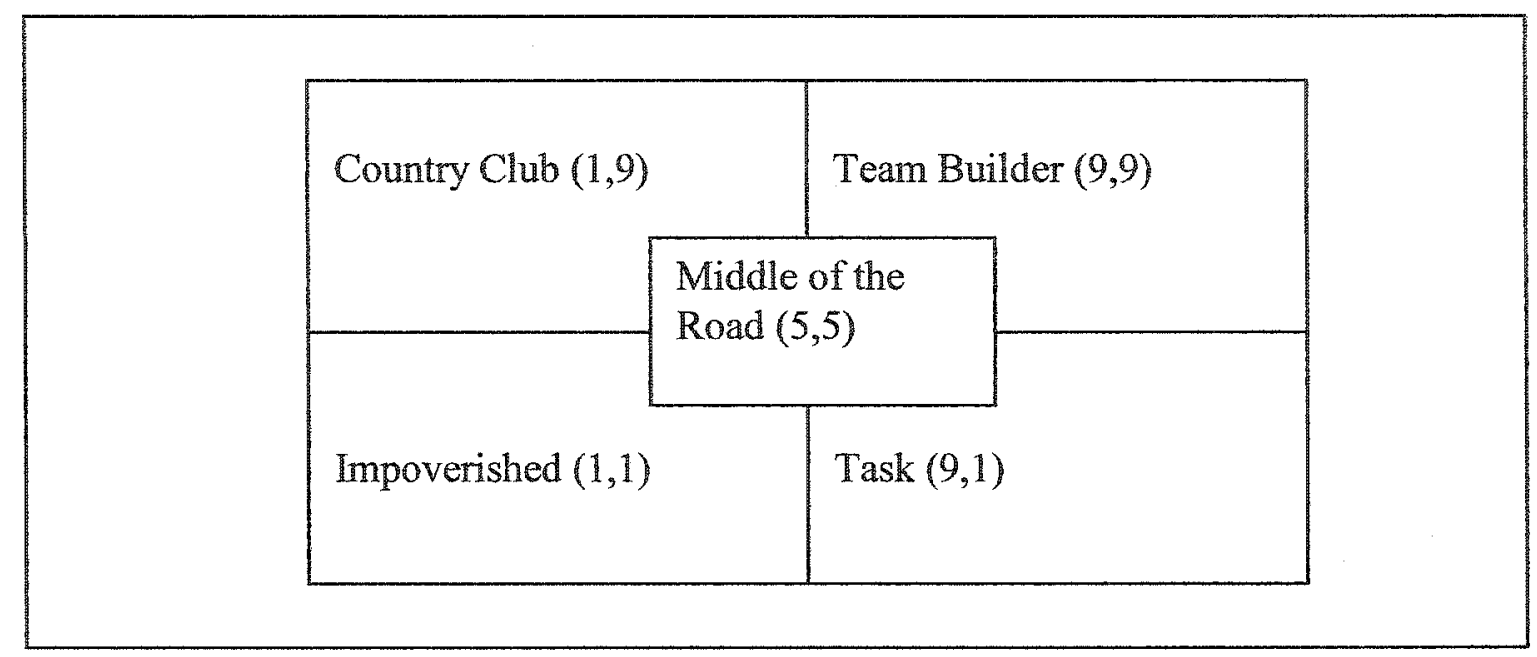

Blake and Mouton's Managerial Grid (1964:10)

By plotting their scores on the grid displayed in Figure 1, a potential leader could see what leadership style they would have. The importance of this study was that Blake \& Mouton identified that the team builder leadership style was the best style. The ideal manager was identified by Blake and Mouton as the Team Builder, with a grid position of 9,9. This meant that effective leaders are both task and people oriented. The grid also provided a tool by which organizations could evaluate leaders.

Research into pure behavioral theories after the 1960's was slowed by a shift in leadership research to situational theories. Behavioral researchers have however, focused on matching leader behavior to sinations and continue to support the behavioral approach to leadership. Shifting away from general people and production behavior analysis, new research has uncovered some of the subtle activities that leaders engage in. Adaptive Self-Regulation: Meeting the Expectations of Leadership and Performance by Sosik, Potosky and Jung (2002), for example, looks at self-monitoring behavior and how it relates to successful leadership. The authors related self-monitoring behaviors to 
effective leadership measures such as the subordinates' belief that the leader deserved the position. Self-monitoring was also shown to affect the extent to which subordinates felt that the leader had a laissez faire attitude and whether employees felt that a manager used management by exception. The study found that self-regulation was positively related to all leadership measures. Self-monitoring has also been shown to be a behavior that emotionally intelligent leaders exhibit (Goleman, 2002). In order to facilitate selfmonitoring Sosik, Potosky and Jung (2002) suggest 360-degree feedback for leaders that would help to ensure that leaders are able to improve their behaviors, as the company requires.

Behavioral research on leadership developed our understanding of leadership and greatly influenced the areas of leadership research which followed it. By studying leader behavior we can develop a training program for leaders. However, like trait research, behavioral leadership literature is plagued by a lack of consensus. Researchers have yet to develop a list of behaviors that will help to ensure the development of a good leader. Also, the styles that leaders can display are heavily influenced by the followers' reactions. For example, a leader who is trying to take a participative leadership style in a situation where followers do not want the responsibility of decision-making will experience frustration and will likely fail (Filley, House \& Ker, 1976). The situation in which leaders perform their activities has such a large impact on the behaviors that can be used that behavioral theories alone cannot be used to describe the recipe for a successful leader (Filley, House \& Ker, 1976). Behavioral theories (similar to trait theories of leadership) have oversimplified the determinants of successful leadership (Filley, House 
\& Ker, 1976). This major shortcoming of behavioral theories led to the third major phase in leadership theory, situational theory.

\subsubsection{Situational Leadership Theory}

Beginning in the 1960 's a more thorough body of leadership research emerged that looked more closely at the different factors such as employees, culture and business environment that would influence the success of a leader. These "situational" theories of leadership sought to identify the characteristics of the situation in which the leader had to act. The main assumption in situational leadership theory is that there is no one best person or behaviors for all leadership roles. Instead, a careful analysis of the situation would allow organizations to select the right person and style of leadership for the job. One of the first situational theories of leadership was written by Tannenbaum and Schmidt (1957), entitled How to choose a leadership pattern. This theory was later refined in 1973 (Tannenbaum \& Schmidt, 1973). In the article the authors stress two important dimensions of leadership, the leaders source of power and the type of subordinate situation that are being led. This leadership model is shown below in Figure 2. 
Figure 2: Tannenbaum and Schmidt - Leadership Model

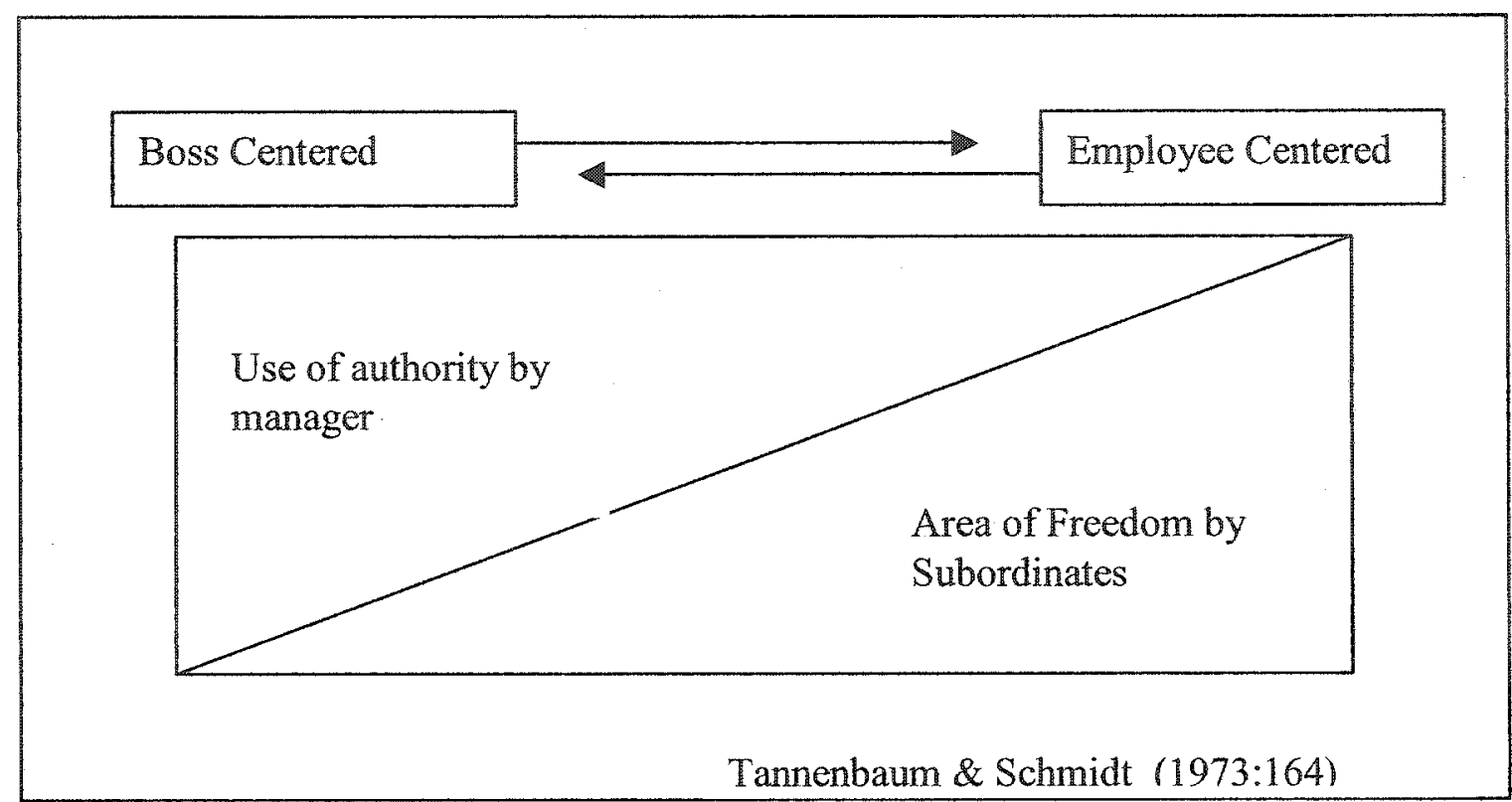

Tannenbaum and Schmidt hypothesized that the range of leadership went from a bosscentered authoritarian style to an employee-centered democratic style. The model does not specify a best leadership style but instead gives a guideline for the appropriate style to be used given the situation. Tannenbaum \& Schmidt's article advanced situational research but was limited, in that it provided a very simple view of leadership (i.e. reduced it to the level of authority that leaders use over followers).

A situational theory that built on Tannenbaums' initial work (Tannenbaum \& Schmidt, 1957 ) is Fiedler's Contingency Model of leadership (1967). In this leadership theory, the leader effectiveness depended on leader-member relations (the degree to which employees accept the leader), task structure (the degree to which the subordinates jobs are described in detail) and position power (the amount of formal authority the leader possesses due to his position in the organization) (Gamnon, 1982). This model postulates that high levels of each of these factors will result in a situation where the relationship style leader will be very effective. If there were low levels in these factors it was argued 
that a task style leader would be better. Fiedler explained that if there is a discrepancy in leadership style and situation a leader is better off to change situations rather then try to adapt his leadership style to fit. One of the main problems with Fiedler's work was the assumption that leadership style was relatively fixed. Factors such as training and experience were not accounted for in this leadership model (Antoine, 2002). Another theoretical weakness of Fiedler's contingency model was that in this model it was assumed that leaders could not attend to both relationships and tasks at the same time. The next major development in situational theory was the Hersey-Blanchard Situational Theory in 1969. This theory used a two-dimensional grid, as shown in Figure 3, with relationship behavior "the extent to which leaders are likely to maintain personal relationships between themselves and members of their groups" (Hersey \& Blanchard, 1993: 129) and task behavior "the extent to which leaders are likely to organize and define the roles of members of their group" (Ibid) as the two dimensions on which leaders would be measured.

Figure 3: Hersey-Blanchard Situational Leadership Model

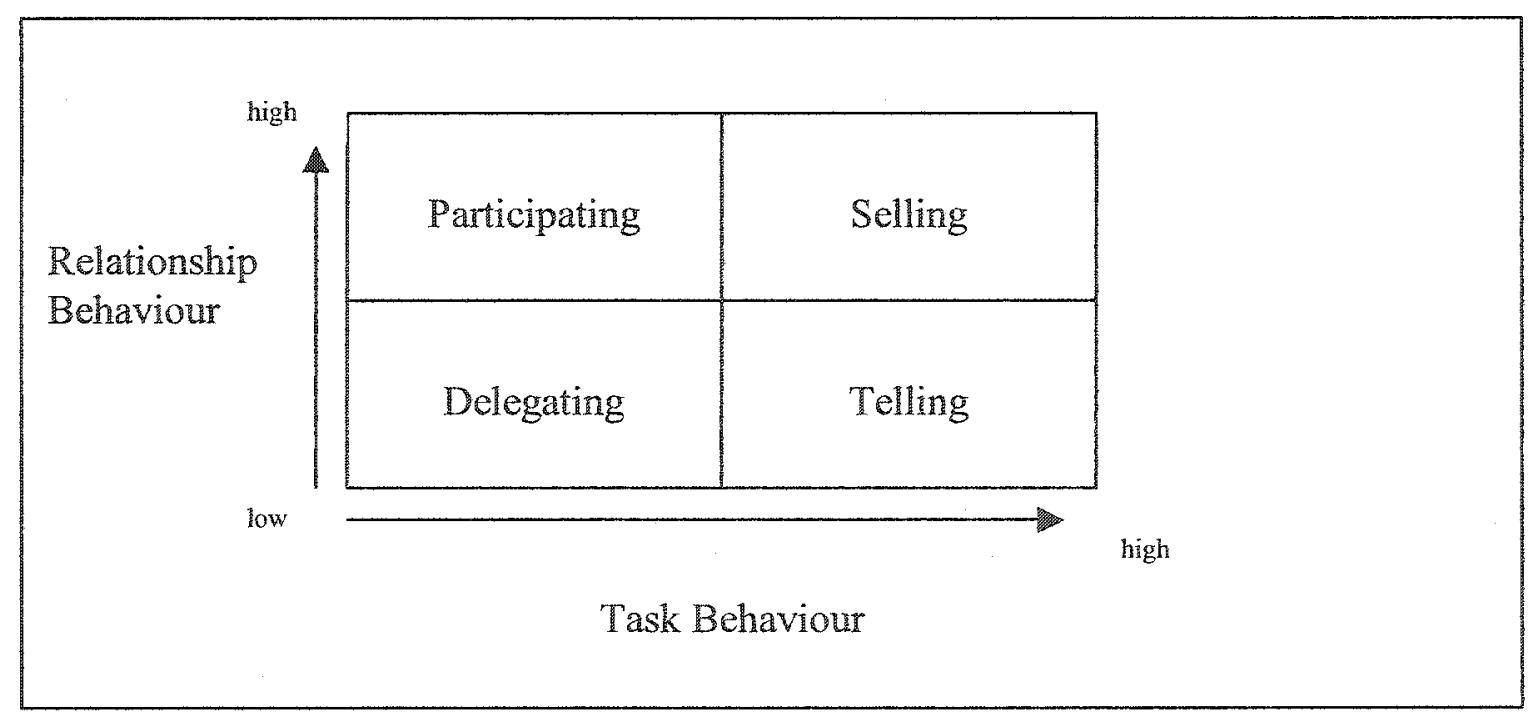

Hersey \& Blanchard (1993) 
The grid divided leadership into four different styles: telling, selling, participating and delegating. This situational leadership theory stated that the subordinates' maturity was the key to applying leadership styles. A leader should gage how able the level of subordinates skill at the task) and willing (how willing a subordinate is to take on responsibility for the task) their subordinates are and then apply the appropriate leadership style. For instance a highly immature follower would be new to a task and unwilling. For this person, a telling leadership style would be appropriate. This research argued that there is no one correct leadership style and leaders should try to develop all four styles so that they can motivate any follower.

The Hersey \& Blanchard situational leadership model represented a development in leadership theory because it called for leaders to select their behavior based on the characteristics of followers. However, this leads to a major flaw of the research; leaders are not always able to measure the maturity and ability of an employee and thus would not know which behavior to select (Strunz \& Dorsch, 2001).

Another influential research paper in situational leadership theory is House's Path Goal Theory (1971). The path-goal theory of leadership suggests that leaders can affect the performance, satisfaction and motivation of a group in three different ways: offering rewards for achievement, clarifying paths to these goals and removing obstacles from these paths. To perform these tasks a leader should adopt a leadership style appropriate to the situation: directive, supportive, participative and achievement-oriented. House (1971) postulated that: 
- supportive behavior increases satisfaction in stressful situations where the follower is unsure of himself,

- directive behavior can reduce uncertainty in ambiguous situations,

- participative behavior will help to clarify the follower's needs and change rewards and; achievement behavior will help to remedy a lack of challenge for the worker

(House, 1971).

This complex model looks carefully at follower characteristics such as locus of control, skill, confidence and experience. By linking the situation, follower characteristics, leader behavior and the impact on the follower this model claimed that a leader can get the outcome of improved effort, satisfaction and performance. This theory relied heavily on expectancy theory (leaders should be able to effect employees expectations), leadership theory (the leaders behaviors are important) and contingency theory (leaders behavior should be contingent on situational factors) (House, 1971).

The strength of the House path-goal leadership model is the close analysis of the leaderfollower relationship and how it affects leadership results. The main weaknesses of the path-goal are its complex nature and the reliance on expectancy and motivation theories for the model to be effective. As well, studies attempting to empirically support the model have been mixed, with several researchers failing to support the model (House, 1996).

Recent leadership research has continued to narrow the focus on business situations which require certain types of leaders and behaviors. Leadership That Gets Results by Daniel Goleman (2000) is an article explaining how effective leaders must select from a collection of leadership styles (like a golfer selects a golf club) at just the right time and 
situation to achieve results. Goleman argues that it is this flexibility to the situation that determines success for leaders. The study used a random sample of 3,871 executives world wide to determine six styles of leadership and the quantitative effect that they have on six drivers of climate. The results showed that affiliative, democratic and coaching leadership styles all had positive impacts on organizational climate. The author discusses the idea that although not all six styles were empirically shown to have long term positive impact on the business climate, all six leadership styles (coercive and pace setting were negative in the long run) have short-term positive impacts on climate if they are applied in the right setting (Goleman, 2000). Goleman then links this research to his previous work on emotional intelligence, stating that emotional intelligence will allow a leader to be more effective at gauging situations and which leadership style to apply. Goleman's article Leadership that gets results (2000) is a good application of situational leadership theory. The empirical support for the six leadership styles given by Goleman is strong. The link to emotional intelligence represented in this paper is mostly theoretical and does not have the same empirical support. Further research is needed to determine the effect of emotional intelligence on a leader's ability to manipulate the six different leadership styles.

The situational theory of leadership which began in the 1960's was the third major attempt to define leadership. The focus on matching a leader and the appropriate behavior to the situation was an important shift in leadership research. Unfortunately, the task of identifying guidelines for leadership in situations is a daunting one and so far has not been able to provide adequate criteria for leadership selection. Researchers such as Tannenbaum and Schmidt (1957), Fiedler (1967) and Hersey and Blanchard (1969) have 
provided simple models of situational leadership but have not been able to give detailed criteria for selecting a leader. The House path-goal theory (1971) of leadership provided a more complex view of leader - follower relations but this model has received mixed support from other research (House, 1996). Despite its shortcomings the situational theory of leadership influenced future leadership research to take close analysis of leaders and how they interact with their followers and their surroundings.

\subsubsection{Transformational Leadership}

One of the most popular applications of the situational theory of leadership in the literature in the past fifteen years has been transformational leadership. Transformational leadership is "the process of influencing major changes in the attitudes and assumptions of the organization's members and building commitment to organizations mission and objectives" (Yukl, 1994: 271). An organization that is in the midst of change, through necessity or plan, is in need of a unique type of leader. Most of the focus in this area of leadership has been on identifying the type of leadership that can influence followers to change (Tichy \& Ulrich, 1984; Fiol, Harris \& House, 1999). Studies on identifying individuals who will be able to influence people best during times of change have been done but have not provided a guideline for selecting leaders who can lead an organization in a new direction for a sustained period of time (Maccoby, 2000).

Most closely linked to transformational change is the concept of charismatic leadership (Bass \& Steidmeier, 1998). Research has shown that charismatic leaders have three main areas in common: they focused on an ideology, emphasized the collective identity, and provided a model for change (House \& Shamir, 1993). Typical characteristics of a charismatic leader include: high self-confidence, high concern for followers' needs, 
strong communication skills and high emotional intelligence (Tichy \& Ulrich, 1984). In The Leadership Challenge-A Call for the Transformational Leader by Tichy and Ulrich (1984), the need for charismatic leaders in transformational change is discussed. The article explains both the organizational dynamic of change and the individual dynamics of change. Tichy and Ulrich explain how charismatic leaders are perfectly suited to communicate a new vision, mobilize workers to commit and then institutionalize the changes.

While many scholars believe that charismatic leadership is necessary for transformational change, there is new research indicating that charismatic leadership might not be the saving grace for any organization undergoing transformational change. Narcissistic Leaders: The Incredible Pros and Cons by Michael Maccoby (2000), profiles the good and bad side of charismatic leaders using Freud's narcissistic personality type. Maccoby (2000) writes that narcissistic leaders are often sensitive to criticism, poor listeners, lack empathy, have distaste for mentoring and are intensely competitive. These faults can be tragic for organizations going through transformation. The lack of mentoring and thirst for competition also mean that these leaders are not likely to leave much of a legacy behind. The main message of the article is that narcissistic leaders can be invaluable in transformational change, but they can also be critically bad if these leaders do not monitor their weaknesses.

Rather than choosing a charismatic leader to bring in transformational change Collins (2001), suggests that quiet, shy and fearless executives are the best ones to lead change. In Level 5 Leadership Collins (2001), describes the level 5 hierarchy shown in Figure 4. 
Figure 4: The Level 5 Hierarchy

Level 5 Executive- Builds Enduring Greatness

Level 4 Effective Leader - Catalyzes commitment to a clear vision

Level 3 Competent Manager - Organizes people and resources

Level 2 Contributing Team Member - works effectively with others

Level 1 Highly Capable Individual - Productive through talent

Collins, 2001:70

Collins would place charismatic leaders at level 4 style of leadership displayed in Figure

4. According to Collins, these leaders lack the enduring qualities that humility and

professional will bring to level 5 leaders. He also notes that level four leaders are well

suited to bring a company from good to great in a short period of time, but they cannot stand the test of time.

Level 5 leadership has many similarities to emotional intelligence. The ability to selfmonitor, exhibit empathy, and to develop meaningful relationships with subordinates were all linked to emotional ability. The future of leadership is being defined by emotions and how leaders use them to motivate and guide their followers (Collins, 2001). While the level 5 theory of leadership is an important development in transformational leadership theory, it requires further empirical testing in order to be considered for practical use. As well, the subjective nature of the levels makes the theory difficult to use 
in training and developing leaders. The long term effects of transformational leaders are studied empirically in a study by Kark, Shamir and Gilad (2003). Using a sample of 888 bank employees and 76 branch managers, the study showed a positive relationship between transformational leadership style and the followers' empowerment and dependence on leadership. This study illustrated highlights the potential dangers of charismatic leaders and shows the need for further research into the long term affects of transformational leadership to ensure long term success for the organization.

\subsubsection{Leadership Literature - Summary}

Each of the major research strains of leadership research has contributed immensely to the current state of business leadership knowledge. Despite over of a century of research into leadership there is still no universally accepted definition or criteria for leadership. Each of the four areas of leadership research (trait, behavioral, situational and transformational) have all come up against significant opposition. Stogdill (1948) showed that a leader could not be defined solely by a set of traits. Behavioral research ran into a similar problem as it attempted to define a leader in terms of behavior (Hemphill \& Coons, 1957; Blake \& Mouton's, 1964). Tannenbaum and Schmidt (1958) argued against such a view of leadership, stating that leadership involved a range of behaviors which must be applied correctly to different situations. Unfortunately, situational leadership theory has also suffered from a lack of consensus and empirical support (House, 1996). As well, the personal traits of leaders have been neglected in this area of research (Stogdil, 1974). Finally, transformational leadership theory has been 
put into question for its long term affects and the dependence on leadership that is associated with it (Collins, 2001; Kark, Shamir \& Gilad, 2003).

The lack of consensus and acceptance for each of the areas of leadership research indicates that a new perspective on leadership is required. The emergent theories in leadership should seek to use this foundation of research in order to define and build an effective method for defining and selecting a leader. The complexity of leadership theory stems from the fact that human interaction and business situations are so turbulent that coming up with matches for a person, behaviors and situation has proved to be a very difficult task. Thus, the challenge for future business leadership research should be to understand how to identify and understand the people, behaviors and situations that make up great business leaders and how they interact with each other. 


\subsection{Emotional Intelligence}

Emotional intelligence (EI) has been one of the most popular topics in business since 1995, when Daniel Goleman wrote his bestselling book Emotional Intelligence: Why it can matter more than IQ (Goleman, 1995). This book caught the attention of organizations struggling to find quality leadership that would give them a competitive advantage. Despite the fact that Goleman's work drew much attention to this field he was not the originator of the concept, as the theory of EI has been developed over several decades by a number of researchers. Leading researchers Mayer, Salovey and Caruso (Mayer \& Salovey, 1990) have developed the most widely accepted definition of EI. They define emotional intelligence as "the ability to monitor one's own and others' feelings and emotions, to discriminate among them, and to use this information to guide one's thinking and action" (Salovey \& Mayer, 1990: 189). Research continues to grow and the work has begun to focus on how EI can determine the success of a leader, be developed in those lacking EI and can be accurately tested to determine gaps in a persons' emotional competency set. EI is a promising new concept in business leadership and organizations can benefit tremendously from it if they understand the theory behind EI and the best way to implement it into their business.

In this literature review, the historical roots of EI research will be examined, followed by a review of modern EI research and finally, a look at different models and measurements. 


\subsubsection{Emotions and Emotional Intelligence}

The study of EI is the most recent and popular face of the attempt to understand the interaction between emotions and reason in the human world. EI represents a small portion of the work being done in the field of emotions, moods and feelings. This section will describe the strengths and weaknesses of EI as a representation of emotion in human relations.

Emotion, mood, affect and feelings are all words that have been used to describe the same concept by many researchers (Batson, Shaw, \& Oleson, 1992). In order to understand where EI fits into emotion literature it is important to define these terms separately and explain their relationship with EI. Fineman (2003) describes emotions and feelings as short-termed and attached to a particular person, object or event. Emotions and feelings come and go quickly and have a wide range of intensity (Fineman, 2003). Fineman contrasts emotions with moods which are lingering and not specifically linked to any one thing (Fineman, 2003). Finally, Fineman describes affect as an all encompassing expression for an individual's personal experience for an emotional activity (Fineman, 2003). Each of these concepts; emotion and feeling, moods, and affect are all related but unique in their relationship to EI.

The concept of EI is one which has been made immensely popular by businesses and consultants searching for a neatly packaged way to manage emotions in the business world. However, EI should not be passed off as a complete measure of emotions in an organization (Fineman, 2003). Fineman explains that EI is has been presented as a solution to the problem of understanding emotion despite its inability to explain many aspects of emotion, mood, feeling and affect. EI is a snapshot of a persons' emotional 
ability. It does not take into account the moods and affects which are involved in a persons' emotional state. The concepts of feeling and emotion are influenced by environmental factors and time. Emotional intelligence, similar to an $\mathbb{Q} Q$ test, simply measures a persons' ability to solve emotional problems in a controlled test setting. It is important to understand where EI fits into emotions, moods and affects in order to better interpret the results of this study. Despite these limitations of EI, it has become a valuable tool for businesses and has provided the most accepted measurement of emotion (Goleman, 1998; Cooper, Robert \& Sawaf, 1997). Therefore, EI is the measure that is used in this thesis to understand the emotional ability of university students.

\subsubsection{History of Emotional Intelligence}

The idea of emotional intelligence (EI) has been studied by researchers for decades. In 1920 a professor at Columbia University teachers college, E.L. Thorndike, was the first researcher to explore the idea of social intelligence. Thorndike described social intelligence as "the ability to understand and manage men and women, boys and girls- to act wisely in human relations." (Thorndike, 1920) In 1937 the topic of "social intelligence" emerged again when Robert Thorndike and Saul Stein attempted to measure social intelligence with their research, An Evaluation of the attempts to measure social intelligence (Thorndike \& Stein, 1937). Unfortunately, these attempis to legitimize and test this new form of intelligence were disregarded when the researchers did not achieve the desired results and research progress in the field was limited for the next thirty years. Daniel Goleman's first book Emotional Intelligence (1995) was essentially a collection and simplification of the work on EI from the past decades of research. Goleman's work has been heavily influenced by several other researchers (Gardner, 1983; Mayer \& 
Salovey, 1990) who had done groundbreaking work in areas related to emotional intelligence. One of the most influential researchers with respect to the conceptualization of EI was David C. McClelland. Throughout the 1970 s McClelland looked at the possibility that traditional intelligence (IQ) was not the best predictor of career and life success. In a paper titled Testing for Competence Rather Than Intelligence (1973) McClelland showed that behavioral traits and characteristics are much more effective than aptitude tests or grades in school in determining who is and is not successful in job performance. The results of the study showed that high performers in terms of leadership and success in business were shown to exhibit behaviors that were independent of aptitude, skill and experience. McClelland suggested that competencies relevant to the job be used as a means for predicting which individuals would be successful in a job (McClelland, 1973). As a consequence of this study a new definition of being "smart" emerged in the literature and opened the door for researchers such as Howard Gardner (1983) to begin to explore the difference between successful and nonsuccessful individuals. The goal was to discover what these differentiators were and measure them, so that they could be used to help hire better employees, assess employees and help them improve their performance. The net result of McClelland's research was that traditional intelligence tests were being set aside and organizations began to look for a new form of intelligence in their employees. 
In 1983 Howard Gardner published Frames of Mind: The Theory of Multiple Intelligences. This book listed seven distinct types of intelligence in human beings

1. Logical-Mathematical Intelligence--consists of the ability to detect patterns, reason deductively and think logically.

2. Linguistic Intelligence-- involves having a mastery of language.

3. Spatial Intelligence-- gives one the ability to manipulate and create mental images in order to solve problems.

4. Musical Intelligence-- encompasses the capability to recognize and compose musical pitches, tones, and rhythms

5. Bodily-Kinesthetic Intelligence-- is the ability to use one's mental abilities to coordinate one's own bodily movements.

6. Interpersonal intelligence -- the ability to understand and discern the feelings and intentions of others

7. Intrapersonal intelligence --the ability to understand one's own feelings and motivations.

(Gardner, 1983).

Gardner hypothesized that every human being has a different amount of each kind of intelligence. The two intelligences most related to the current theory of emotional intelligence are interpersonal intelligence and intrapersonal intelligence. These two intelligences are often grouped together as what is called "Personal Intelligence". (Gardner, 1983) However, emotional intelligence theory has shown that the two should be considered separate (Goleman, 1995). 
Gardner defines intrapersonal intelligence as "the ability to understand one's own feelings and motivations" (Gardner, 1983). This concept is still used today in emotional intelligence theory under the headings of self-awareness and self-management. Goleman has a chapter called "Know Thyself" in Emotional Intelligence (1995) which explains in further detail what Gardner described with his idea of intrapersonal intelligence. Interpersonal intelligence, on the other hand, is defined by Gardner to be "the ability to understand and discern the feelings and intentions of other people: what motivates them, how they work, how to work cooperatively with them" (Gardner, 1983). Gardner goes on to explain that successful salespeople, politicians, teachers, clinicians, and religious leaders are all likely to be individuals with high degrees of interpersonal intelligence (Gardner, 1983). This interpersonal intelligence is also represented in current emotional intelligence work under the headings social awareness and relationship management. The value of Gardner's work to the field of emotional intelligence is considerable. His ideas of interpersonal and intrapersonal intelligence have guided research into EI.

Reuven Bar-On can also be considered a leader in the field of EI since 1988 when he attempted to use what he called emotional quotient (EQ) to explore emotional and social functions that would lead to psychological well-being (Bar-On, 1988). Bar-On also developed the first measure close to the idea of EI, the EQ-i. The EQ-i is more of a measure of a person's emotional condition then a test of emotional ability. Although the self-test instrument was not published until 1997 it stands as the first measure of emotional well-being.

Although all of the authors above contributed to the development of EI theory, it should be noted that none of the studies described referred to the EI construct in its current form. 


\subsubsection{Modern Emotional Intelligence}

Peter Salovey and John Mayer first used the term emotional intelligence in their article Emotional Intelligence (1990). In this article Salovey and Mayer provide a framework for studying EI. They define EI as "the ability to monitor one's own and others' feelings and emotions, to discriminate among them, and to use this information to guide one's thinking and action" (Salovey \& Mayer, 1990: p. 189). In this article, the authors examine how emotions fit into traditional intelligence theories and summarize the work done to recognize emotional intelligence as a legitimate part of intelligence theory. They also provided the first framework for conceptualizing EI, separating it into three processes; appraisal and expression of emotion, recognition of emotion and use of emotion. This article is the basis for most of the subsequent work on EI, including Goleman's popular book in 1995.

Emotional Intelligence: Why it Can Matter More than IQ by Daniel Goleman was published in 1995 and since that time the field of EI has continued to gain popularity in both the public and with academic researchers. Goleman has continued to be the front man for EI and has published two other books that have attracted the attention of the public. The first important book is his 1998 Working With Emotional Intelligence (Goleman, 1998). In this book Goleman applies the theories on EI presented in his first book (Goleman, 1995) to the workplace. He claims that emotional intelligence is what separates the stars in an organization from unproductive employees. Goleman also discusses the contagious effect of emotions in an organization and how to form an emotionally intelligent organization (Goleman, 1998). The book contains several examples from real business cases where EI has helped make businesses successful. In 
this book Goleman also confirms that EI can be leamed by individuals within the organization and that an emotionally intelligent business culture will help employees to develop their emotional skills.

In 2002 Primal Leadership: Realizing the Power of Emotional Intelligence (Goleman, 2002) was released. In this book Goleman linked the theory of emotional intelligence to leadership. The book describes how leadership at a primal level (using emotions to lead) can create a culture of dissonance or a culture of resonance. Primal leadership refers to the tendency of employees to perceive the work place in the same manner that their leaders do. According to Goleman, if leaders are emotionally intelligent their resonant leadership should cause a ripple effect and effective leadership should spread throughout the company.

The concept of emotionally intelligent leadership is based on Goleman's (Goleman, 2002) refined model of EI, shown in Figure 5, which incorporates four distinct domains: self-awareness, self-management, social awareness and relationship management. 
Figure 5: Goleman's Model of Emotiona Intelligence

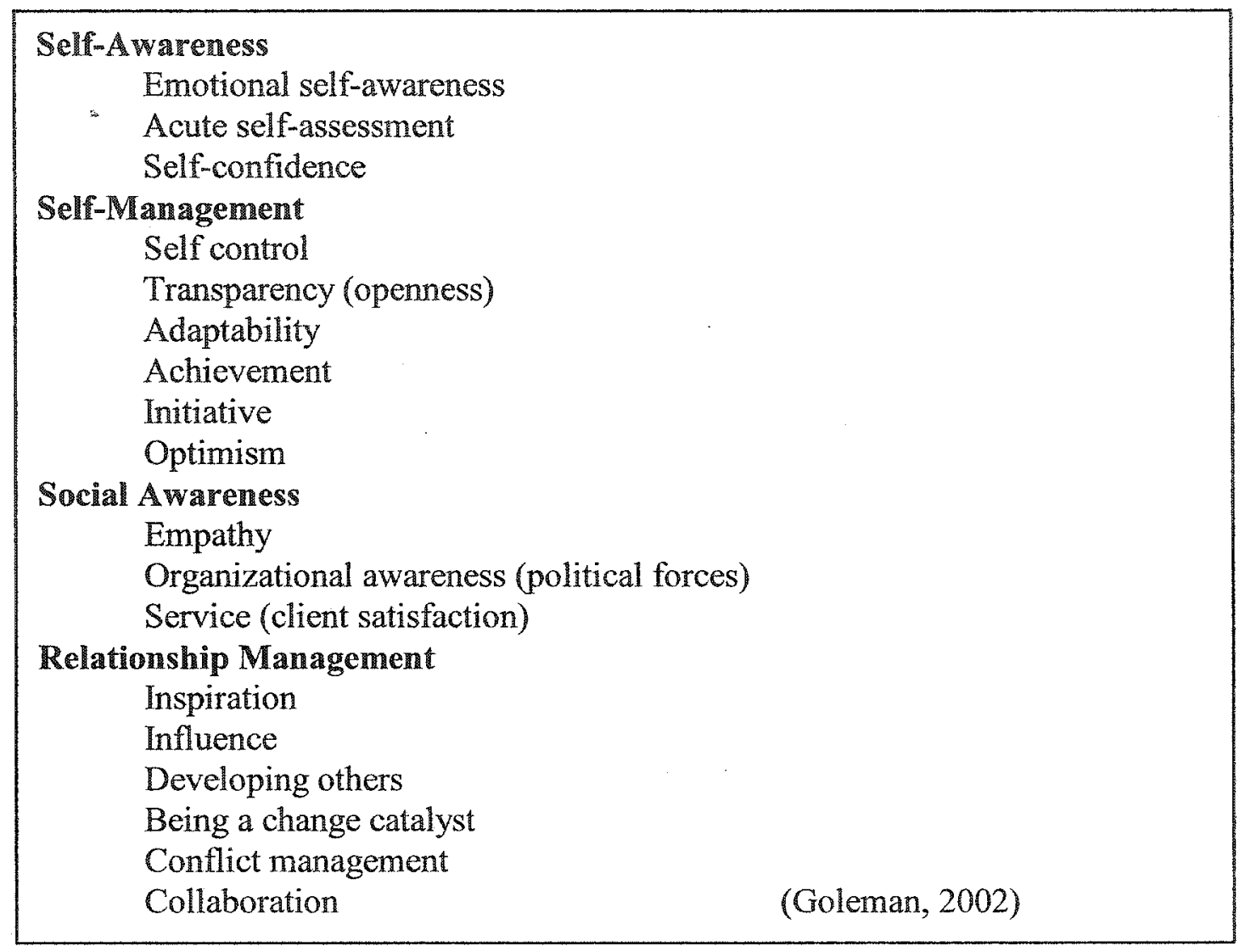

Goleman describes each of these domains, giving examples from the business world, and explains how every person is different in their emotional strengths and weaknesses. This theory of EI has been essentially built on previous research done by other authors (Salovey, Mayer \& Caruso, Gardner, McClelland) but Goleman has done an excellent job of making the research on EI more easily understood and useable by the general public. Goleman's work has however, created a backlash from the researchers such as Salovey \& Mayer, who do not agree with Goleman's treatment of emotional intelligence in the public domain. These researchers also stated concern that many of Goleman's claims 
about EI are not empirically supported and fear that Goleman may discredit the entire field of EI (Mayer, Salovey \& Caruso, 2000).

Much has been made of the effect that EI can have on career development in organizations. Goleman writes in Emotional Intelligence (1995) that IQ contributes to only $20 \%$ of the factors that determine life success, which leaves $80 \%$ to the other forces. Several researchers have disapproved of Goleman's extreme predictions for EI and its power to predict success (Mayer, Salovey, \& Caruso, 2000). At the time Goleman made his claims that EI may contribute twice as much as IQ to a person's future success, there was little academic support for these suppositions. It turns out that Goleman was not completely unjustified in his claims. In 1998 Dulewicz and Higgs found that their measure of emotional intelligence accounted for 36 percent of the variance in organizational advancement whereas IQ accounted for 27 percent (Dulewicz \& Higgs, 1998). These findings suggest that EI contributes slightly more to career advancement than does IQ. As more studies are done to compare the predictive power of EI with that of IQ, it is likely that the importance of EI will remain and organizations will not hire and promote based on intellect alone but rather on a combination of intelligence factors.

\subsubsection{Models of $\mathrm{E}$}

One of the most popular books on emotional intelligence and leadership is Emotional EQ by Cooper and Sawaf (Cooper \& Sawaf, 1997). In this book Cooper and Sawaf propose a slightly different model (shown in Figure 6) of EI, the four-cornerstone model. This model differs from other emotional intelligence models mainly on its focus on the effect 
of external factors on an individual's EI level. As well, states of being such as presence and flow are unique to this model.

Figure 6: Cooper and Sawaf Model of Emotional Intelligence

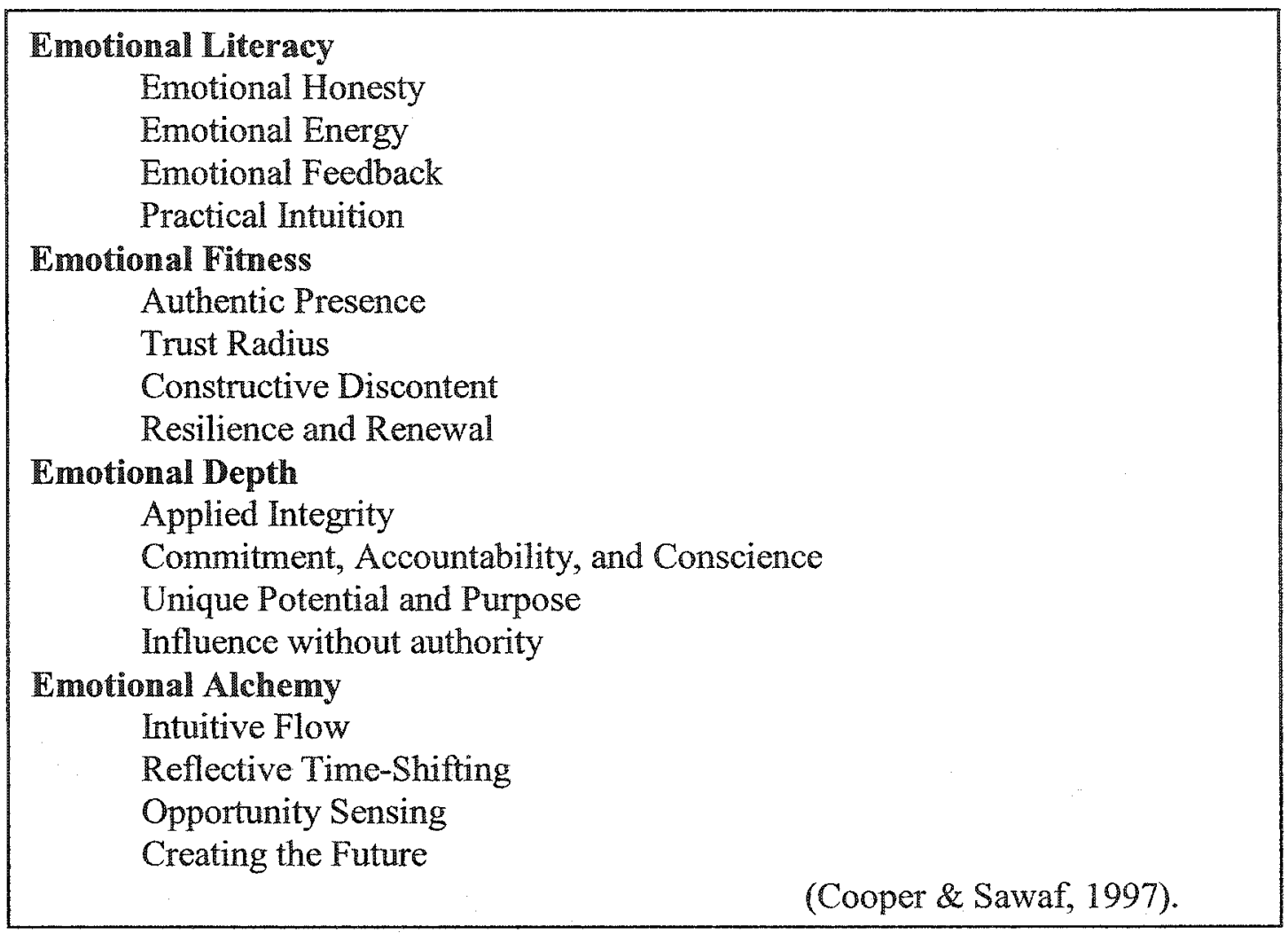

The author's primary purpose for developing this EI model is on how EI can be developed in the organization and how a business cannot be run by traditional analysis alone. While the academic support for this model of EI has been limited, the Cooper and Sawaf model of El and the test that accompanies the theory have been used extensively for practical analysis by businesses (Cooper \& Sawaf, 1997).

Mayer, Salovey and Caruso have been instrumental in the development of EI theory. They are in fact responsible for a large portion of the scientifically accepted work done to legitimize and develop emotional intelligence. Salovey and Mayer's article Emotional 
Intelligence in 1990 is regarded as the first and most influential research on the topic.

While Goleman's name is most often associated with El in the public domain and popular press, Salovey \& Mayer have continued to advance the topic of EI through a more academic approach. These authors teamed up with David Caruso in the late 1990's to provide several influential articles on the subject (Mayer, Caruso \& Salovey, 2000; Mayer, Salovey \& Caruso, 2000a; Mayer, Salovey \& Caruso, 2000c). They have also developed a theoretical model which seeks to explain El conceptually. This model is shown in Figure 7. The model used by these researchers is referred to as a cognitive model because it deals only with the specific mental abilities that a person has to enable them to recognize and manage emotions. The Salovey \& Mayer model (later changed to the Mayer, Salovey \& Caruso (MSC) model) of EI shown in Figure 7 consists of four separate component EI abilities:

\section{Figure 7: MSC Model of Emotional Intelligence}

1) Perceiving and Identifying Emotions - the ability to recognize how you and those around you are feeling.

2) Facilitation of Thought - the ability to generate emotion, and then reason with this emotion.

3) Understanding Emotions - the ability to understand complex emotions and emotional linkages, how emotions transition from one stage to another.

4) Managing Emotions - the ability which allows you to manage emotions in your self and in others.

(Mayer \& Salovey, 1997)

The EI model described by Mayer, Salovey and Caruso is a developmental model where each of the different levels of emotional ability represents a more complex level of 
emotional skill. For instance, in the ability to able to understand emotions requires one to first develop some level of ability in perceiving emotions. The term emotions in the MSC definition of emotional intelligence refer to both moods (longer lasting general states of feeling that are not directly tied to their cause) and emotions (high intensity feelings that are tied to specific causes). Another important aspect of the MSC model is that the different abilities are perceived to be related. For example, in order for a person to be able to successfully manage emotions she must be able to perceive emotions.

Mayer, Salovey and Caruso (2000a) are also responsible for the most widely accepted research in this area which suggests that $\mathrm{EI}$ is intelligence by the criteria of traditional intelligences. Their article Emotional Intelligence meets traditional standards for an intelligence (Mayer, Caruso \& Salovey, 2000a) use empirical evidence from a sample of over 500 participants to argue that EI meets the following three criteria for being considered an intelligence:

1. EI consists of mental abilities,

2. EI abilities meet certain co-relational criteria to standard intelligence measures, 3. El abilities develop with age.

In the tests conducted by Mayer et al (2000a), EI met all three criteria: EI could be deconstructed into a set of mental abilities, EI was shown to co-relate with verbal intelligence, and EI was shown to be positively related to age (Mayer, Caruso \& Salovey, 2000a). 
Of all of the models of EI the Salovey, Mayer and Caruso (MSC) model is argued to be the most solidly based on scientific research (Mayer, Salovey \& Caruso, 2000a). These authors (MSC) argue that other models (Goleman, 1997; Cooper \& Sawaf, 1997) are flawed in that they mix in variables such as motivation, optimism, flow and resilience which have not been scientifically linked to intelligence. They also contend that the EI theories proposed by Cooper and Sawaf (1997), Goleman (1997) and Bar-On (1998) require further empirical analysis in order to be used as the foundation for future work on EI (Mayer, Salovey \& Caruso, 2000b).

\subsubsection{Emotional Intelligence and Leadership}

Over the past five years the field of emotional intelligence has seen rapid growth in the number of researchers who have attempted to link EI to leadership (Goleman, 2002; Cooper \& Sawaf, 1997). As mentioned above, one of the most well-known and influential books on EI and leadership Primal Leadership, was written by Daniel Goleman (2002). In this book Goleman defined EI in terms of business leadership, then applied it to six leadership styles that effective leaders used and then described how business leaders could develop EI. Goleman describes each of the EI domains, giving examples from the business world, and explains how every person is different in their emotional strengths and weaknesses.

The next important theory that comes from Goleman's work is the theory of leadership styles. In Primal Leadership (Goleman, 2002) he explains that good leaders exhibit six main styles of leadership. These leadership styles are listed and described in Figure 8. 
Figure 8: Goleman's Leadership Siyles

Visionary-articulating the groups direction

Coaching- Developing people through one-on-one attention

Affiliating- promoting and collaborating harmony in the organization

Democratic- forges consensus through participation

Pacesetting- sets high performance standards

Commanding- demands complete compliance.

(Goleman, 2002).

Goleman explains that while some styles are preferred in his research (visionary) the real key is being able to adjust your style to the people and situation around you. This is where EI becomes so important to a leader. According to Goleman, the emotionally intelligent leader is more likely to be able to have each of these leadership styles at her disposal and is also more likely to recognize when and how much of each style to use in a given situation. Goleman's work can in this way be linked to the situational leadership theories which began in the 1960's (House, 1971; Hersey-Blanchard, 1969).

Goleman's theory of emotionally intelligent leadership also postulates that $\mathrm{EI}$ competencies may be developed over time (Goleman, 2002). He felt that using the leadership learning agenda, leaders should be able to improve their EI. Goleman (2002) also cautions that this process takes a long time and will only be affective if emotional development becomes a habit.

To begin the leadership leaming agenda Goleman recommends that a person develops a clear picture of both their ideal self (the qualities that they would like) and their real self 
(the qualities that make up who they are). Then the gaps (where there is a difference between the two) and strengths (emotional competencies) can be identified. The leadership agenda should begin by building on strengths and addressing weaknesses in any emotional competencies. The leadership agenda, as described by Goleman, must also fit into the individual's life and be tailored to the person's learning style.

The idea that leaders can learn to become more emotionally intelligent has broad implications for developing and recruiting leaders for the organization. The effect of training programs and life experiences on a leader's emotional development will likely become a priority for organizations in the near future (Goleman, 2002). While Goleman's work (Goleman, 2002) is perhaps the most well known, there have been several other authors (Cooper \& Sawaf, 1997; George, 2000) who have shown a link between leadership success and high EI. Details on this research are given below. In Emotions and Leadership: The role of emotional intelligence George (2000) closely examines the role that $\mathrm{EI}$ plays in the leadership process. George uses the Mayer/Salovey EI model to describe how EI enhances leadership effectiveness. To do this, the article analyzed the leadership literature, and proposed the following five essential elements of leadership: 
1. Development of collective goals and objectives,

2. Instilling in others an appreciation of the importance of work activities,

3. Generating and maintaining enthusiasm, confidence, optimism, cooperation, and trust,

4. Encouraging flexibility in decision making and change, and

5. Establishing and maintaining a meaningful identity for an organization.

(George, 2000)

George also shows how El enables leaders to be more effective at these key leadership elements.

The first leadership element according to George (2000) is the development of collective goals and objectives and a plan to achieve them. George argues that an emotionally intelligent leader will have an advantage because he/she will be able to maintain the emotional control necessary to create the plan and then be able to gauge the followers' reaction to the shared mission.

The second leadership element involves instilling in others an appreciation of work activities. According to George (2000), the emotionally intelligent leader will be able to understand and influence the confidence and commitment that employees feel.

The third element for effective leadership is generating and maintaining enthusiasm, confidence, optimism, cooperation and trust. George believes that a leader's emotions are contagious throughout the organization and that an emotionally intelligent leader will be able to control her emotions and spread confidence, enthusiasm, optimism, cooperation and trust to other workers. Along this same vein, a good leader must be able to understand followers' real emotions. Theoretically this can be done through using the perceiving ability incorporated in EI (Mayer \& Salovey, 1997). 
The fourth leadership element proposed by George is encouraging flexibility in decision and change. George argues that the emotionally intelligent leader has the ability to identify and adjust the moods that can make employees more flexible in decisions. For example, negative moods can often limit creativity and cause people to be too critical of new ideas. Positive moods, on the other hand, and emotions can cause a leader to become carried away with a course of action. Knowing how to identify and balance emotions should allow the leader to maintain an open mind and the necessary internal state to create a plan for change (George, 2000).

The final leadership element is establishing and maintaining a meaningful identity for an organization. The culture of an organization is largely shaped by the collective emotions of the employees. According to the author, the EI leader can better attune to the direction that the organizations culture is going and will be able to shape and build that identity (George, 2000).

As mentioned in the modern theories of EI section of this report, one of the most popular books on emotional intelligence and leadership is Emotional $E Q$ by Cooper and Sawaf (Cooper \& Sawaf, 1997). Cooper and Sawaf propose a slightly different model of EI, the four-comerstone model, which was outlined earlier in Figure 6. In this model, the authors focus on how EI can be developed in the organization and how a business cannot be run by traditional analysis alone but that rather requires emotionally intelligent workers to make key decisions (Cooper \& Sawaf, 1997). Perhaps the most important aspect of Executive EQ is the EQ Map that is included with the book. The EQ map represented one of the most widely used $\mathrm{EQ}$ measures when it was released in 1997. This self report tool, which has been widely used by organizations seeking to measure the 
El of their leaders (Cooper \& Sawaf, 1997), will be discussed further in the section on measuring EI.

The combination of leadership and EI in the workplace is a very appealing to organizations seeking to maximize the potential of their leadership (Mayer, Salovey \& Caruso, 2000b). However, Mayer, Salovey and Caruso raise concerns in their article Emotional Intelligence as Zeitgeist, as Personality, and as a Mental Ability that the EI theories being written for the business world are not representative of the scientific research being done to support EI (Mayer, Salovey \& Caruso, 2000b). Mayer et al (2000b) argue that the EQ map (Cooper \& Sawaf, 1997) and Goleman's EI model in his 1997 book Working with Emotional Intelligence (Goleman, 1997) include variables which have not been scientifically proven to be related to EI. The authors stress that it is important that the use of the term EI be confined to that which has been scientifically shown to be EI (Mayer, Salovey \& Caruso, 2000a), even if it is not as appealing as other descriptions for EI which are designed for the workplace.

\subsubsection{Measuring Emotional Intelligence}

One of the biggest challenges of testing the current models of EI theory has been the development of an accurate instrument to measure the concept. To test the models and to implement the ideas associated with El in organizations, there must be a valid and reliable way to measure $\mathrm{EI}$. The challenge of finding an accurate instrument has been further hindered by the multitude of different models available.

The first attempt to measure emotions was the Bar-On EQ-i (Bar-On, 1997). This test was designed by Dr. Reuven Bar-On over a nineteen year period and represents the 
historical roots of emotional testing. The purpose of this test was to clinically examine the emotional well-being of the individual rather than an intelligence level. The EQ-i consists of 133 items and takes approximately 30 minutes to complete. It provides an overall EQ score as well as scores based on 5 subscales (intrapersonal, interpersonal, adaptability, stress and general mood). The EQ- $\mathrm{i}$ is a self-report test where subjects rate themselves according to the questions and an EQ score is generated. There is a distinct contrast between Bar-On's EQ measure and the other current EI tests such as the Mayer, Salovey \& Caruso test (MSCEIT). This can be attributed to the fact that Bar-On is much wider in its focus on emotions than other EI models and includes general mood, stress and adaptability sections (Bar-On, 1997). In other words, it may be that the EQ-I is not measuring the same construct as other EI tests (Mayer, Salovey \& Caruso, 2000b). Another well known test for El is the Emotional Competence Inventory 360 (ECI 360) designed by David Goleman and Richard Boyatzis to assess the competencies in the EI model first proposed in Daniel Goleman's Working With Emotional Intelligence (Goleman, 1998) and later refined in Primal Leadership (Goleman, 2002). The ECI is in part a self-report report test like the Bar-On EQ-i, where subjects assess themselves on various emotional competencies. The other part of the test involves an observer report on the subject. A colleague, supervisor or someone in close contact with the subject rates the person on their emotional competency. The ECI 360 provides a way to determine the strengths and weaknesses of people so they can focus on honing the competencies that will enable them to meet career objectives. The ECI 360 provides feedback on the subjects' performance according to Goleman's model of emotional intelligence. In research done by the Hay Group/McClellend Centre for Research (2000) the ECI 360 
scored an overall internal consistency rating of .85 for the others rating section of the test (observer ratings) and a .75 internal consistency coefficient for self rating section of the test (Hay Group, 2000). The research of the Hay Group (2000) also indicates both construct and content validity (Hay Group, 2000). The Hay Group did not report testretest reliability for the $\mathrm{ECI} 360$.

The third widely used test of emotional abilities (although not necessarily EI) is the EQ Map from Executive EQ by Cooper and Sawaf (1998). The EQ map enables someone to identify her individual and interpersonal emotional strengths and weaknesses by plotting performance strengths and vulnerabilities, using 21 scales. The authors of the EQ Map claim that it is a non-judgmental test where the goal of mapping is personal discovery and self-learning. The EQ Map is self-administered and involves five areas of self-report related to emotional well-being: current environment, awareness, competencies values and attitudes, and outcomes (Orioli, 2003). Similar to the Bar-On EQ-I, the EQ Map covers a much broader definition of EI than that given by Mayer, Salovey and Caruso (MSC), as it includes environment, life outcomes and values (Mayer, Salovey \& Caruso $2000 \mathrm{~b}$ ). For this reason this test is not widely used by academic researchers interested in measuring EI. This tool, however, has been widely used by business managers and business leaders to assess their emotional state.

The final test of El is the Mayer/Salovey/Caruso Emotional Intelligence Test (MSCEIT). The MSCEIT test is an ability test based on the Mayer/Salovey definition of emotional intelligence (Mayer \& Salovey, 1997). The MSCEIT tests the subjects' ability with respect to four specific emotional abilities; 
1) Perceiving and Identifying Emotions

2) Facilitation of Thought

3) Understanding Emotions

4) Managing Emotions

The MSCEIT tests subject's emotional ability through such tasks as, correctly identifying the emotions expressed by a face or in designs, defining the causes of different emotions, understanding the progression of emotions and determining how to best include emotion in our thinking in situations that involve yourself or other people. Subjects are scored based on the combination of consensus best answer from all the tests taken and the experts scoring system. The results from the test show the subjects emotional abilities as well as their overall EI score.

The EI model that has its strongest roots in academic research is the Mayer, Salovey \& Caruso model and test of EI. MSC contend that the other tests (Bar-On EQ-I, ECI 360 and EQ Map) all are self-report (or in the case of the ECI 360 part self report, part observer rating) measures of a person's emotional capability. Rather than reporting the true ability, they report the perceived ability by either the person themselves or their peers. In contrast the MSCEIT determines the ability of the subject through a series of tests where the subject must use his emotional ability to solve problems. Another problem with existing measures discussed by Mayer and Salovey is that Goleman and Bar-On's models are "mixed models" because they mix in variables that have not been scientifically validated as being related to intelligence (Mayer, Salovey \& Caruso, 2000b). Robert R. McCrae also critiques these mixed models of $\mathrm{El}$ in an article contained in Bar-On's The Handbook of Emotional Intelligence arguing that the mixed 
models have broadened the concept of EI to include desirable motivational, interpersonal, and intra-psychic attributes that resemble personality traits more than traditional abilities (McCrae, 2000).

The MSCEIT test has been shown to be a reliable and valid test of EI. As such, it was the one selected for use in this thesis. The psychometric properties of this measure are discussed in the methodology section of this report.

\subsubsection{Emotional Intelligence - Summary}

Emotionally intelligent leadership theory has burst on the business scene and changed the way that leaders are judged (Goleman, 2002; Cooper \& Sawaf, 1997). Such researchers as McClelland, Gardner, Bar-On, Mayer, Salovey and Caruso, and Goleman have developed the theory of emotional intelligence. It has been shown that $\mathrm{EI}$ is a measurable intelligence (Mayer, Caruso \& Salovey, 2000), EI can be developed (Goleman, 2002) and that $\mathrm{EI}$ is as important as or more important than IQ in determining an individual's success in an organization. (Dulewicz \& Higgs, 1998; Goleman, 1995) Emotional competency can also be measured by a number of tests such as the Bar-On EQ-I, the EQ Map, the ECI 360 and the MSCEIT. 


\subsection{Development of University Students: The Role of Varsity Athletics}

One of the main challenges facing businesses is ensuring that they have a pool of high quality leaders to form the foundation for their organization into the future (Kesner \& Sebora, 1994). In order to implement a quality leadership succession plan, organizations must understand the key markers of leadership in the students they have. It has been proposed that one of the most influential experiences that a university student can participate in is intercollegiate athletics (Ryan, 1989). Student athletes can face rigorous training schedules and intense competition on top of the normal demands of university life. Unfortunately, there has been limited research into the effect of this important influence on a student's leadership potential. One area of research that has received attention is the comparisons of athletics to business and the potential for transference of knowledge between the two areas (Liu, Srivastava \& Woo, 1998; Burdett, 1997). The theory behind the research relating business and athletics is that athletics and business parallel each other in key areas such as teamwork, competition, performance standards and intense pressure on individuals (Liu, Srivastava \& Woo, 1998). This research into athletics and business similarities has encouraged a few researchers to examine student athlete development, and the benefits of athletic participation (Ryan 1989; Dobosz \& Beaty, 1999). More recently, EI has entered the research picture and is now being considered in leadership identification (Goleman, 2002; Tucker et al, 2000). The purpose of this section is to understand the possible link between the participation in university athletics and emotionally intelligent leadership potential. To accomplish this goal, this literature search will show the similarities of athletics and business as cited in 
both the popular press and in academic literature. Next, the literature surrounding leadership potential and athletics will be discussed. Finally, what has been studied regarding the effect of varsity athletics on $\mathrm{EI}$ in university students will be examined.

\subsubsection{Athletics and Business - Similarities}

The link between business and athletics is a natural one. Both are intensely competitive, team-based arenas where hard work, talent and a little luck are all needed to succeed. Popular literature has shown a fascination with this connection between athletics and business (Weber, 1987; Parcells, 2000; Perry \& Jamison, 1998). Successful coaches and players often write books or give interviews about how they successfully lead their team to victory (Weber, 1987) and articles using successful athletes and coaches to provide lessons for the world of business. For example, in Red Auerbach on Management (Weber, 1987) Alan M. Webber interviews the legendary Boston Celtics basketball coach on his techniques for a winning basketball team and how they apply to the business environment. Coach Auerbach preaches selfless attitude and a passion for your work. The entire interview is treated as a potential lesson for business executives. In a similar article by New York Jets coach Bill Parcels, The Tough Work of Turning Around a Team (Parcels, 2000) the athletic lessons for business leaders continue. Coach Parcels uses his success at tuming around failing football teams to explain how the same principles can be applied to business. To make change he explains that you must make it clear that you are in charge and are willing to work very hard to succeed. He also writes that to turn around a failing organization you are going to need to confront people. Finally, Parcels advises new leaders to set small goals, and make sure you hit them. Both of these articles exemplify how the business community has attempted to learn from athletics. 


\subsubsection{Academic Research-Similarities between Sport and Business}

The world of high performance athletics has also been compared to the business world in the academic literature (Webber, 1987; Liu, Srivastava \& Woo, 1998; Burdett, 1997). A complete review of the literature identifies that the following crossovers between sport and business have been made:

- High Pressure, highly competitive environment

- Importance of leadership

- Mental, physical and spiritual preparation may be necessary in both areas

- Individual development is important to group success

- Expectations often determine outcomes

- Customer relationships are important

Each of these areas has been argued to be similar for both sport and business. The details of these arguments are given below.

The high pressure, competitive nature of both business and sport is one of the most important similarities identified by these authors. Another similarity cited by researchers is the importance of leadership and teamwork in both areas (Burdett, 1997), especially in the situation where a team or business must undergo a strategic transformation (Tichy \& Ulrich, 1984). As well, the fact that both team and individual performances are needed to have success is a similarity between the two areas. Finally, both the athletics and business arenas require its players to constantly adjust and preserve in their surroundings if they hope to succeed.

The article Transference of skills between sports and business by Liu, Srivastava and Woo (1998) provides a very thorough literature review of this topic and outlines how the two fields (business and sport) can benefit from understanding each other. An important section in this paper outlines the transferability of coaching, training and management techniques used in sport to the world of business. Liu, Srivastava and Woo's summary of 
the research shows that sports environment teaches such lessons as: the importance of a shared objective, the ability to follow a game plan, the importance of communication and the value of practice. The article also provides a summary of some of the lessons from the player-coach relationship common in sports that could be applied to business. For example, the importance of performance standards and reviews in sports is applied to the business setting. According to the authors, sport teaches the athlete to constantly strive for higher performance levels and how to gauge his/her progress against specific standards. They then go on to argue that such practices are very useful in business and have already been implemented in many organizations. The authors summarize their work by writing that, "there is not only a link that exists between these two mediums (sport and business), but also a healthy one" (Liu, Srivastava \& Woo, 1998:17). Another article that links the world of sport to business is Going for the Gold by John Burdett (1997). In this article, Burdett discusses the importance of player development, leadership, player's assumptions and relationships with customers. The author then compares this to the importance of all of these factors for an employee to be successful in business. According to Burdett, player (employee) development is necessary for both a sports team and an organization to remain successful and deal with changing environments. Burdett also concludes that leadership is also necessary for both sport and business to succeed, for without leadership teams/organizations will consistently underachieve. Another similarity listed in the article is the power of players' (employee's) assumptions. The author explains that the collective expectations and beliefs of employees (players) will determine the ultimate potential of the organization. In short, a team or business can only go so far as its players or employees believe it can 
go. Following this logic it would appear that managing expectations and assumptions is critical to the success of an organization in both sport and business. Finally, Burdett explains why the most valuable players or employees in an organization are those who form relationships with customers. The players must give the fans value (wins or entertainment). Similarly, employees must provide service and knowledge for customers. This article is a valuable discussion and has implications for the development of students through sports. The lessons listed by Burdett are certainly available to university athletes and could help to develop them into better business leaders. Another key similarity between sport and business is the importance of leadership. As mentioned in Going for Gold (Burdett, 1997) and Transference of Skills between sport and business (Liu, Srivastava \& Woo, 1998) leadership is a necessary criterion for success in both business and sport. Carling (1995) argued that leadership is the main factor in enhancing human potential in the article Winning through Leadership. The article describes how leadership in both sport and business involves being optimistic and realistic at the same time. Leaders provide an atmosphere of integrity and trust that may spread throughout the organization or team. Leaders are also visible and help followers on a day-to-day basis to discover their true potential. This article illustrates how athletes can learn the importance of quality leadership from sports experience, and transfer the knowledge to the business environment.

The demands on business executives involve striving to achieve a continuously rising high level of performance. To achieve this high performance Loehr and Schwartz explain that executives must learn from high performance athletes. In The Making of a Corporate Athlete (Loehr \& Schwartz, 2001) the authors describe their theory of the Ideal 
Performance State (IPS) and the high performance pyramid. According to Loehr and Schwartz, business executives must develop their physical, emotional, mental and spiritual capacities in order to achieve their IPS. The authors explain that business practice has mostly focused on mental capacity, neglecting the physical, emotional and spiritual capacities. Athletes provide a great example for how to develop the physical and emotional capacities. Athletes use strict routine to develop control over their physical ability and emotional states. Loehr and Schwartz contend that business executives must work out regularly, balance their diet and use mental imagery just as athletes do in order to prepare for competition. The authors explain that this physical and emotional development is needed to renew and recover energy that is required to achieve in the business world. This article describes routines of high-level athletes as not only valuable, but also necessary for success in the business world (Loehr \& Schwartz, 2001). Following this argument, the student athlete would therefore, have a considerable advantage towards developing the physical and emotional capacity described in this article.

The literature search shows that the world of business has many similarities with athletics. Furthermore, it suggests that there are several valuable habits and techniques used in sport that could give a person an advantage in the business world. This research suggests that it is important to understand and further test how athletics can help develop an individual for success in business. In particular, the development of leadership and emotional intelligence through athletic participation should be examined, as they are both very important issues in today's business world. 


\subsubsection{Leadership Development through Athletics}

Research in this area indicates that athletic participation has a positive impact on the leadership development of university students (Ryan, 1989). One of the main similarities between sport and business has been suggested to be the importance of leadership (Burdett, 1997). The experience of working with a team to reach the highest level of performance has the potential to be instrumental in developing leadership qualities in athletes. The impact of participation in intercollegiate athletics on student leadership development is an important topic for both educational institutions (Ryan, 1989) and organizations who recruit students to become a part of the succession planning for their business. University administration may benefit from a better understanding of the effect of athletics on their students in order to ensure that student athletes are properly prepared for their career after university. It may also be necessary for an organization hoping to recruit the best possible leaders for their company to understand whether student athletes are more likely to show leadership potential than non-athletes.

Despite the potential benefits to both university administration and business recruiters, the research in the area of leadership development through athletic participation is limited and divided in opinion. One valuable research article Participation in Intercollegiate Athletics: Affective Outcomes (Ryan, 1989) uses empirical study (a sample of almost 400 American schools and almost 12000 students) to argue that university athletics had a positive effect on overall satisfaction with the college experience, motivation to earn a degree, and the development of interpersonal skills and leadership abilities. The study done by Ryan (1989) took data from a national (USA) follow up survey by the CIRP (Cooperative Institutional Research Program) in 1985 of freshmen who entered university 
in 1981. The students rated themselves in each of the four developmental areas; overall satisfaction with the college experience, motivation to earn a degree, interpersonal skills and leadership abilities. The results showed that those students who participated in a varsity sport rated themselves higher in each of the four developmental areas. The importance of this study is that it suggests that athletic participation is having a positive impact on the development of students. For students considering trying out for an athletic team this study (Ryan, 1989) would argue that the sacrifices in time and energy that are needed to play a varsity sport are being rewarded in personal development. One of the main weaknesses of this research is the fact that it is a self-report test on general areas of student development. The students self-report shows how much they feel that they have improved in their four years at university and not the actual abilities that were developed at university. Therefore, it may be a better indication of how much the student's confidence in their abilities improved throughout their time at university rather than actual improvement itself. Ryan (1989) also discusses the need for further research into the topic, including an examination of the specific benefits that sports provide and the identification of other student experiences that could also generate the similar positive effects of athletics for students.

Another article that illustrates the leadership development value of athletic participation is The Relationship between Athletic Participation and High School Students' Leadership Ability, by Dobosz and Beaty (1999). This study examined 60 suburban high school students, to find out if athletes exhibited greater leadership ability than non-athletes. The results of a leadership ability evaluation showed that athletes outscored their peers in leadership ability. The study is important to business leadership because it suggests that 
athletic participation promotes leadership development at an early age. If students in high school are able to retain leadership lessons that are learned through sport then there is potential for the same learning and development to take place in a university setting. It is important that future researchers develop the work of Dobosz and Beaty using university students rather than high school students, because the ability to predict business leadership skills within a business setting based on high school sports experience is very difficult due to the high number of years between the experience and the workplace. There are still considerable life experiences ahead of a high school student before he/she will become a business leader. The transition from high school to university and the university years that follow offer a significant time period for students to change. Unfortunately, the academic research in this area is very limited and few studies have been done to determine whether high level athletic experience in university is an effective way to develop key leadership abilities.

One study which has argued against the benefits of varsity athletic participation is College Experiences and Managerial Performance by Ann Howard (1986). In this study the author tested the relationship between various college experiences and management potential, using two AT\&T longitudinal samples of managers. The mangers were measured on promotions and assessment center performance. The results were reported as varied for the category of extracurricular activities but the report suggested that participation in athletic activities showed no relationship to managerial performance. These results are not explained in the report and there is no further discussion of the role of athletics as a predictor of managerial success. For the most part the study simply discusses athletics under the term extracurricular activities. No distinction is made as to 
whether athletic participation refers to varsity competition or intramural or simply leisure participation in sports. This study represents a challenge to previous research (Ryan, 1989) but it requires further testing in order to be accepted as evidence discounting the effect of athletic participation on leadership potential.

The lack of research done to study the effect of varsity athletic participation on leadership potential is the single biggest weakness of this area of literature. The few studies which have been done have not used EI as a measure of leadership potential. As well, results of these studies are inconclusive as to whether athletics has a positive effect on leadership potential. These weaknesses are particularly disturbing considering that the university student-athlete lifestyle can attract talented, hard working students out of high school. Athletes balance studies while participating in or training for, athletic competitions that can both challenging and rewarding life experiences.

In the article by Loehr and Schwartz (2001), The Making of A Corporate Athlete, the authors write that business executives can learn from athletes. The article explains that business executives must find their ideal performance state and also should learn how to balance their mental and physical performance needs. Similar to athletes, business leaders can learn how to control their emotions in pressure situations. These lessons are learned by athletes as they go through training and competition. This comparison of business executives to athletes further demonstrates the need for research that will shed light on the value of varsity athletic participation as an indicator of leadership potential. 


\subsubsection{Development of Emotional Intelligence in Students}

The field of emotional intelligence is a relatively new one in relation to leadership theory and it has yet to be applied to the development of student-athletes during their time at university. There has been however, considerable debate about the value of trying to develop EI within the general student population (Schmidt, 1997; Tucker et. al., 2000). Tucker et. al. (2000) suggest that a student who is high in emotional intelligence is a much more attractive recruit to business firms. In Training Tomorrow's Leaders: Enhancing the Emotional Intelligence of Business Students (Tucker et. al., 2000) the idea that educational institutions have over emphasized the importance of intellectual development in favour of logical and linguistic development is discussed. The paper proposes a new model of education for business students, one which involves regular emotional experience exercises and assessments.

The model for integrating EI into business curriculum at universities involves an initial testing phase where students are provided with feedback as to their EI level. From there educators would develop the student's emotional abilities through activities designed at improving EI. The authors go on to explain that the educational institution must reward and support emotional development in students in order for the development to be successful. Finally, they note that an evaluation of EI at the end of the students training should allow for continuous improvement of the curriculum. The model proposed is a good step toward enhancing the EI of university students. Educational institutions however, should look at the entire student experience and draw from potential areas of emotional development for students, before any curriculum is designed. 
The need for emotional development in students is further discussed in two articles Changing skill needs: what makes people employable (Dench, 1997) and Emotional Intelligence- a new evaluation for management development? (Langley, 2000). In Changing skill needs, the author explains how employers are now focusing on interpersonal and intrapersonal skills as criteria for hiring new employees. They note that companies are finding it easier to train job specific skills than to train employees to be better team players or to communicate more effectively. Dench (1997) argues that individuals who possess these personal skills are better able to cope with change and adjust to pressures on an organization. The implication of this article is that recruiters will be searching for university students who have developed the personal skills to go along with their technical training during their studies.

The second article Emotional Intelligence- a new evaluation for management development? (Langley, 2000) looks at emotional intelligence and how it can be used to measure the potential management ability and "promotion readiness" of an individual. The author stresses that emotional intelligence is now and will continue to be, a valuable measure of potential leadership qualities. The main issue discussed in both of these articles is that the criteria for evaluating potential leadership ability are changing. El has been argued to be an important indicator of leadership potential (Goleman, 2002; Dench, 1997; Langley, 2000) and consequently, businesses are adjusting their recruitment practices to take advantage of this. This would suggest that the number of businesses that will be searching out those students who have the training and experience that helps to develop the desired emotional abilities will increase in the future. If a 
specific university experience can be shown to better develop student's EI, then both recruiters and students will be able to take advantage of this knowledge.

The idea that students will be better prepared for life and work if they are taught emotional skills along with their intellectual training is also agreed upon by theorists (Goleman, 2002; Dench, 1997). Future research into student development and training methods used in schools to increase EI in students should include the extracurricular activities that are available for students. For example, if athletics can be shown to increase the emotional development in students then appropriate resources should be allocated to ensure that students get the opportunity to benefit from these activities. EI has captured the attention of students, school administration and businesses seeking leadership. There is a clear need to understand how EI is developed in students and how businesses can better identify those students with higher emotional intelligence abilities. The future will likely see this area of student development be explored in detail and the result will be a framework for developing and identifying emotionally intelligent future leaders. This thesis provides a step in this direction.

\subsubsection{University Student Athlete Experience - Summary}

The study of the impact of athletic participation on leadership potential is still very much in its infancy in terms of its ability to contribute to the knowledge surrounding the development of future leaders. The similarities between the sports and business world have been demonstrated by several researchers and athletes. More recently studies have looked at the importance of leadership in both sports and business and used this as a way for business to learn from lessons and techniques used in sport. With respect to 
leadership development, the idea that athletic participation will help to develop leadership has been tested by Ryan (1989) and Dobosz and Beaty (1999). Both of these studies showed a positive relationship between athletic participation and a perceived increased leadership. However, this finding is contradicted by Howard (1986) and there is a need for further assessment of the effect of varsity athletic participation on the leadership potential. Finally, studies by Dench (1997) and Langley (2000) have suggested that businesses may focus on EI when recruiting at universities.

The literature review of student development through athletics reveals a need for research which will examine the effect of varsity athletic participation on EI in students. This research will determine the value of using varsity athletic participation as an indicator for leadership potential. The research reported in this thesis has implications for university administrators and students who are seeking to provide the best opportunity to develop emotional intelligence at university. As well, there are implications for organizations seeking to improve their recruitment and succession plans. 


\subsection{RESEARCH QUESTIONS}

The purpose of this thesis research is to examine the effect that participation in varsity athletics has on the EI levels in university students. The results of this thesis will then be applied to leadership theory and used to determine the value of varsity athletic participation as an indicator of leadership potential. By understanding how athletics is associated with emotional development in students the potential exists to enhance the development of future leaders. The link between EI and leadership is supported by work done by researchers such as Goleman (2002), Macaleer and Shannon, (2002) and Dench (1997).

\subsection{Theoretical Framework}

The research done in this thesis is based on the theoretical framework described in Figure

9. The literature review on leadership suggests that EI is one the most important qualities for a leader (Goleman, 2000; Cooper \& Sawaf, 1997; Langley, 2000). The challenge faced by organizations and individuals is to understand which activities will aid in developing EI. This research proposes to test a model which links participation in university athletics to El levels in university students. 


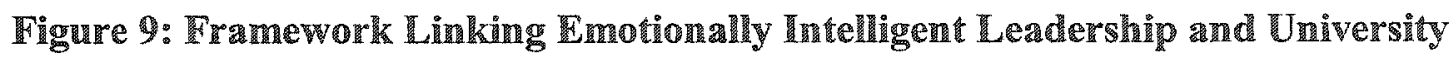
Athletic Participation

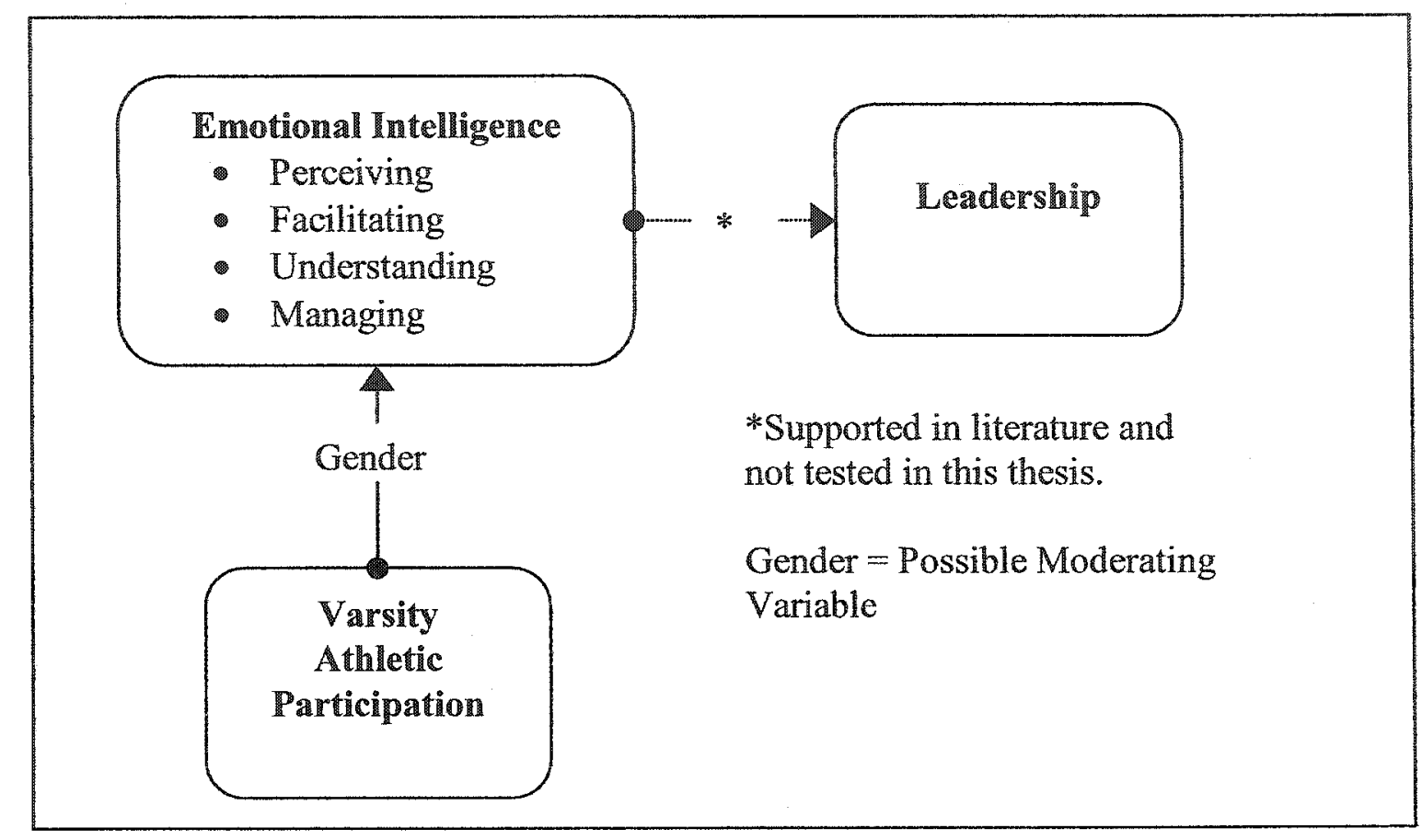

The current research will build on research in the fields of leadership, emotional intelligence and student development. Leadership theory has developed over the last century and in the past fifteen years EI has emerged as a defining element in predicting leadership success (Goleman, 2000; Langley, 2000). Research has discovered measurable emotional abilities that can be tested to show an individual's overall EI and also their ability to perceive, facilitate, understand and manage emotions (Mayer, Caruso \& Salovey, 2000). In order to isolate the relationship between varsity athletic participation and EI, gender is controlled for in the framework shown above. Previous research has shown the females typically score slightly higher than males on the MSCETT (Mayor, Salovey \& Caruso, 2002). Finally, student development research has only begun to understand the effect of athletic participation on student athlete development. Research by Ryan (1989) and Dobosz and Beaty (1999) has shown that athletics does 
have a positive impact on student's leadership ability however, neither of these studies shows the effect of varsity athletics on the emotional ability of student athletes. 


\subsection{Objectives}

The primary objective for this thesis is to determine the relationship between athletic participation and EI. In order to understand the main effect of varsity athletic participation on EI it is first necessary to look at any interaction effect between the gender of the respondents and varsity athletic participation. The following research question addresses any difference in effect of varsity athletics on EI for female athletes versus male athletes:

1: Is the relationship between varsity athletic participation and the EI scores of university students different for males and females?

The second research question looks specifically at the link between $\mathrm{EI}$ and varsity athletic participation:

2: What is the relationship between varsity athletic participation and overall emotional intelligence among university students?

A third objective for this research involves an examination of the difference between varsity athletes and non-athletes scores for the four different emotional abilities described in the Mayer, Salovey and Caruso model of EI (Figure 7). The following research questions test the relationship between varsity athletic participation and the four branches of EI:

3: a) What is the relationship between varsity athletic participation and a student's ability to perceive and identify emotions?

b) What is the relationship between varsity athletic participation and a student's ability to facilitate and use emotions? 
c) What is the relationship between varsity athletic participation and a student's ability to understand emotions?

d) What is the relationship between varsity athletic participation and a student's ability to manage emotions? 


\subsection{Relevance}

Based on the literature review there is a need for research into the impact of athletic participation on the EI level of university student athletes. Business recruiters are looking for emotionally intelligent leaders (Dench, 1997; Langley, 2000). If organizations can identify the students who are more likely to have high EI then recruiting would improve and they could identify more easily the desired future employees for their leadership succession programs.

The relevance of this study also applies to the university community, in particular the university administration and its students. One of the main goals of university administrators is to provide students with the best possible training for their future. As noted earlier, EI is increasing as a measure of leadership potential for employers seeking to implement and execute successful succession plans. If the link between EI and varsity athletic participation is established then the university has further justification to allocate the appropriate resources to such activities. Students who have leadership ambitions are also interested in knowing whether or not the benefits of varsity participation outweigh the associated costs (Dench, 1997; Langley, 2000).

The effect of varsity participation on the EI of both males and females will also be relevant to university administration. By determining if varsity athletics has the same impact, regardless of gender, students and administration will better be able to assess the gains from the varsity athletic experience.

Finally, this thesis will attempt to add to the fields of leadership, emotional intelligence and student development. By understanding how university student's leadership potential (as shown by EI) is affected by athletics, leadership development will be better 
understood. The field of EI is still searching to better understand how emotional intelligence is developed. The implications of this study will be influential in designing future development models for individuals seeking to improve their emotional abilities. Lastly, the study of student development will be furthered by this study, due to the large number of students who participate or consider participation in athletics during their time at university. 


\subsection{RESEARCH METHODOLOGY}

This chapter will outline the methodology used to test the objectives for this thesis. The first section of this chapter will examine the research instrument used in this thesis, the MSCEIT. The second part of the methodology deals with the sample used for this research. The third section in this chapter deals with data collection and the final section of the chapter explains the data analysis techniques used in this thesis.

\subsection{Research Instrument}

The MSCEIT is a test of emotional intelligence used in this study to determine the effect of university athletic participation on the development of emotional intelligence in university students. The following explains the rational behind the use of MSCEIT for this research.

\subsubsection{Selecting a Definition and Measure of Emotional Intelligence}

The field of EI has several definitions, models and tests which all claim to be the most reliable and accurate tools for an individual wishing to understand and assess their EI level. For the purpose of this thesis, it was necessary that the EI model and test selected for research had a strong scientific grounding. The EI model that has its strongest roots in academic research is the Salovey/Mayer model and test of EI. The MSCEIT determines the ability of the subject through a series of tests where the subject must use his emotional abilities to solve problems. The fact that the MSCEIT test had also been shown to be a reliable and valid test of El provides further support for its use as a research tool for this thesis. The first measure of the reliability of the MSCEIT is the 
internal consistency (the extent to which each of the questions in the test is measuring the same thing). It was found that for a normative sample the internal consistency of the overall MSCEIT scores is .93 for the general scoring measure of the total MSCEIT (Emotional IQ, 2003). Robbins (2002) also reports that the four scales of the MSCEIT have internal consistency alphas ranging from .81 to .96 with a full-scale alpha of .96 (Robins, 2002). Another measure of reliability is the test-retest measure of the MSCEIT. Regarding test-retest reliability of the MSCEIT (the extent to which test measures are consistent for the same individual over time) Brackett \& Mayer (2001) found a test-retest reliability for the full-scale MSCEIT V2.0 of .86, based on a sample of 62 people. The MSCEIT has also been shown to be a valid test of EI. In order to have content validity a test should measure what it is supposed to measure, in this case, EI according to the Mayer, Salovey \& Caruso definition and model of EI. The MSCEIT test is designed to measure an individual's ability to identify emotions in persons and objects; to generate emotion and use it to solve problems; to understand emotional causes and complexity; and, the ability to manage emotion to enhance growth, it can, therefore, be said to possess content validity. (Emotional IQ, 2003) The authors of the MSCEIT also maintain that the test has face validity (the extent to which a test appears to measure what it is supposed to measure) (Caruso, 2003). Finally, a test should posses discriminant validity (i.e. it should not test anything outside what it is designed to test) in order to be considered a valid test. The MSCEIT test did not correlate highly with measures such as IQ, Emotionality, Mood Scales (TTMS), Bar-On EQ-I (a measure of emotional well-being) and personality inventory (NE). Therefore, it is accepted as unique measurement of emotional ability (Caruso, 2003). 
Each of these psychometric properties supports the decision to use the MSCEIT for this thesis. The complete details of the comparison of the MSCEIT to the other available tests of $\mathrm{EI}$ can be found in the previous section on measuring $\mathrm{EI}$ (refer to section 2.2.5).

\subsubsection{Interpreting MSCEIT Scores}

The MSCEIT (Mayer Salovey Caruso Emotional Intelligence Test) is designed to test the four branch ability based model of emotional intelligence supported by Dr. John Mayer, Dr. Peter Salovey and Dr. David Caruso (Mayer, Salovey \& Caruso, 1997). The authors of the test (Mayer, Salovey and Caruso) define emotional intelligence as "the ability to monitor one's own and others' feelings and emotions, to discriminate among them, and to use this information to guide one's thinking and action" (Salovey \& Mayer, 1990: 189). The test measures how well people perform tasks and solve emotional problems, which means that the scores are relatively unaffected by self-concept, response set, emotional state, and other confounds (Mayer, Salovey \& Caruso, 2002). The MSCEIT yields an overall EI score and four branch scores; perceiving, using emotions, understanding emotions and managing emotions. The MSCEIT scores in this research were scored using general consensus scoring. This means that a person's responses were scored based on the normative database of over 5000 respondents (Mayer, Salovey \& Caruso, 2002) who have taken the test. The MSCEIT results are computed as empirical percentiles, then placed on a nomal curve with a mean score of 100 and standard deviation of 15 (Mayer, Salovey \& Caruso, 2002). Table 4.1.2 shows the guidelines for interpreting the ranges of MSCEIT scores obtained by respondents. A respondent who scores 100 would be in the average range of emotional intelligence. 
Table 4.1.2 Guidelines for Interpreting MSCELT Scores

\begin{tabular}{|c|c|}
\hline ElQ Range & Qualitative Range \\
\hline 69 or less & Consider Development \\
\hline $70-89$ & Consider Improvement \\
\hline $90-99$ & Low Average Score \\
\hline $100-109$ & High Average Score \\
\hline $110-119$ & Competent \\
\hline $120-129$ & Strength \\
\hline $130+$ & Significant Strength \\
\hline
\end{tabular}

(Mayer, Salovey \& Caruso, 2002).

The overall EI score provided by the MSCEIT is a global score and is the starting point for understanding a person's MSCEIT scores. The overall EI score acts as a summary for the four branches of the EI model. The first branch of the model is perceiving emotion. The perceiving emotion score represents a persons "ability to perceive emotions in oneself and other, as well as in objects, art, stories, music and other stimuli" (Mayer, Salovey \& Caruso, 2002: 7). The second scored branch of EI is facilitating, which represents "the ability to generate, use and feel emotion as necessary to communicate feelings, or employ them in other cognitive processes" (Mayer, Salovey \& Caruso, 2002: 7). Understanding emotions is the third branch score provided by the MSCEIT and it shows "the ability to understand emotional information, how emotions combine and progress through relationship transitions, and to appreciate such emotional meanings" (Mayer, Salovey \& Caruso, 2002: 7). The final score used in this research was the managing emotions score which measures "the ability to be open to feelings and to modulate them in oneself and others so as to promote personal understanding and 
growth" (Mayer, Salovey \& Caruso, 2002: 7). The overall EI score and the four branch scores used in this research were used to define the El of the respondents in this study.

\subsection{The Sample}

The data measuring the emotional intelligence levels of university students was collected between September, 2003 and March, 2004. The population for this research consisted of Ontario university students who had completed three or more years of university studies. The students selected for study were required to be attending university or have just graduated university in the past semester. All respondents were between the ages of 20 and 28 years old in order to control for the effect of age on EI scores in this study (it will be revealed that research has found $\mathrm{EI}$ to increase with age). The student athlete population consisted of those students who have competed in varsity athletics for a minimum of three seasons. Operational definitions for these two groups are as follows:

Non-athletes: -completed three or more years university education -still attending university or have just graduated in the past semester -between the ages of 20 and 28 years old

Athletes: -completed three or more years university education -still attending university or graduated in the past semester -having participated in three or more years of varsity athletics -between the ages of 20 and 28 years old

The criteria for the operational definitions of both the non-athlete and athlete groups were chosen in order to control for several factors outside the scope of this research. The age range of 20-28 represents a best effort to control for age in the sample. Each respondent was required to have a minimum of three years of university experience in order to control for the number of years a students' EI could be developed in university. As well, 
the respondents to the study were required to be either in school or graduated in the past semester in order to control for any influence of post education activities on emotional development. Finally, in order to control for the affect academic program type, the nonathlete portion of the sample was matched as closely as possible to the athlete sub sample with respect to area of study for the respondents.

\subsubsection{Sample Size}

The research sample consisted of 120 students from Ontario Universities. The following grid (Figure 10) explains the breakdown of the sample.

\section{Figure 10: Sample Breakdown}

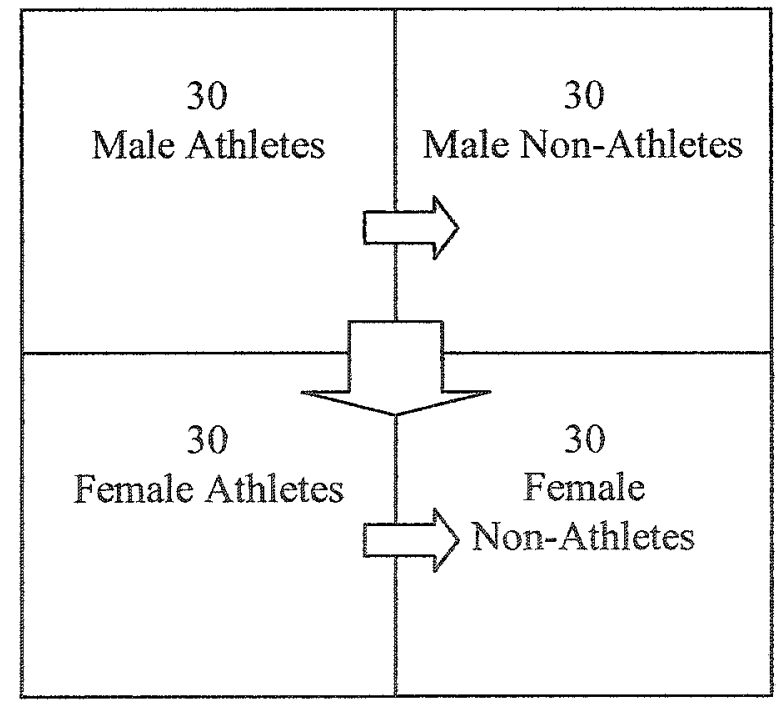

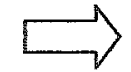

Arrows indicate comparisons.

\subsubsection{Recruitment}

The research sample was obtained by distributing information flyers to various student groups with a request to participate in a study based on EI. Potential subjects were 
instructed to contact the researcher, at which point they received further information regarding the test. The researcher informed the subject of any risks involved and the voluntary nature of the test. Consent was also obtained to use the subjects test scores for the purpose of this research. Subjects were requested to give information regarding name, year in school, program, age, sex and sport played before taking the MSCEIT. The researcher then gave them a unique identifier which was used to link demographic information to the MSCEIT. The athletes sample was obtained first as this group is much smaller population and it would be more difficult to match athletes to non-athletes than vice versa. Where possible the researcher tried to recruit non-athletes who were in similar programs to the athletes sample in order to minimize the possible confounding effects of the program of study on EI.

\subsection{Data Collection}

The data collection was performed by an online emotional intelligence service for the MSCEIT (www.emotionalia.org). Each subject took the MSCEIT on-line. They entered a user name and password at the MHS web site. The results of the test were then summarized in a report and a data file. This data was linked through a unique identifier to a file containing demographic information on each respondent.

\subsubsection{Test Procedure}

The subject was given an identification number which ensured the confidentiality of their data with the administrators of the test, Multi-Health Systems, Inc (MHS) of Toronto, Canada. MHS provided a secure website which subjects accessed using their id number 
and a password supplied by the researcher. Subjects then took the online MSCEIT test and their results were stored by id number in a database which was only accessed by the primary researcher.

\subsubsection{Test Results}

The results of the test were used by MHS for research purposes. For the MHS research, subjects of this research study were not identified. The research was summarized by MHS according to subject's name, age, gender, ethnicity, total EI, perceiving EI, facilitating EI, understanding EI, managing EI (Caruso, 2003).

\subsection{Data Analysis Procedures}

All statistical analysis for this thesis was conducted using SPSS. The main statistical tests used for this research are described below and are summarized in Table 4.4:

1. T-Test: The t-test is an assessment of the differences between the means of two independent samples.

2. ANOVA: Analysis of variance. The ANOVA is a test used to uncover the main and interaction effects of categorical independent variables on a dependent variable. A two way ANOVA was used in this analysis with athletic participation (yes/no) and gender (male/female) as the independent variables and overall EI as the dependent variable. The underlying assumptions of the two-way ANOVA include: the groups formed by the independent variables are similar in size and there is a normal distribution of variance for 
the dependent variable in each of the groups formed by the independent variables (homogeneity of variance). In order to test the homogeneity of variance assumption Levene's test of homogeneity of variance as computed by SPSS was used.

3. MANOVA: Multiple analysis of variance. MANOVA is used to test the main and interaction effects of one or more independent variables on multiple dependent variables. A two way MANAOVA was used in this research, with the four branches of EI; perceiving, facilitating, understanding, and managing, as the dependent variables in the analysis and, athletic participation (yes/no) and gender (male/female) as the independent variables.

The key underlying assumptions for the MANOVA are:

- Observations are independent of one another - selection of one observation should not depend on the selection of earlier ones.

- Similar group sizes.

- Adequate sample size

- Residuals are randomly distributed

- Homogeneity of Variance - within each categorical group formed by the independent variables, the variance of each of dependent variables should be similar.

Statistical analysis was preformed to test the validity of these assumptions. The independence of the observations, similar group size and adequate sample size assumptions are all dealt with in the demographic data section. To test the random distribution of the residuals, a standardized residual plot was examined. To test the homogeneity of variance assumption, Levene's test statistic was observed for each of the 
four dependent variables. As well, the data was checked for outliers in the sample as this can alter the accuracy of MANOVA.

The following sections describe the data analysis techniques and statistical tests that were used to analyze the demographic data and answer the research questions in this thesis.

\subsubsection{Demographic Data}

The demographic data which was collected for this thesis is outlined in section 4.3.

Below are the statistical analyses used to ensure that the sample specific factors of this research allow for accurate and reliable testing of the three research questions listed in section 3.2

The sample size required to test the research questions was selected according to the formula $n=16 \sigma^{2} / d^{2}$. This formula is for a two-sided test (testing for $\mathrm{H}_{0}: \mu=\mu_{0}$ ) with $\alpha$ (type I error) and $\beta$ (type II error) fixed at $5 \%$ and $20 \%$ respectively. This put the probability of incorrectly rejecting the null hypothesis at 0.05 and the power $(1-\beta)$ of the study at 0.80 . In order to select the appropriate sample size the type I and II error rates ( $\alpha$ and $\beta$ ), the variability of the data $\left(\sigma^{2}\right)$, and the effect size (d) were all estimated. According to Mayer, Salovey \& Caruso (2002) a reasonable standard deviation for the sample was 15 scoring points for mean EI scores. Given these estimates of $(\alpha, \beta, d$ and $\sigma^{2}$ ) the sample size $N=120$ is large enough to detect an effect size five points on the $E$ I scores. This effect size was chosen based on the Mayer, Salovey and Caruso scales which report changes in EI levels at intervals of ten points on the EI scale (Table 4.1.2). The sample was then examined for any differences in the sample with regards to age, years attended university and years playing a varsity spont (athletes only). The 
comparisons that were done were based on athletic participation (varsity athletes compared to non-athletes) and gender (males compared to females). To test for these differences, t-tests were done at a significance level of 0.05 .

Each of the statistical analyses on demographic data listed above allow for meaningful conclusions to be drawn from the statistical analysis of the research questions, as they give confidence that any differences observed in EI scores are due to varsity athletic participation and not other possible determinants of EI.

\subsubsection{Research Question 1: Gender Analysis}

Research question 1 examined the interaction effect of varsity athletic participation and gender on EI scores for university students. As this is the most complex relationship, it was looked at first, as a significant interaction would mean that we could not look at the main effects of varsity athletics on EI scores. In order to test this relationship MANOVA was preformed with varsity athletic participation and gender being the independent variables and perceiving EI, facilitating/using EI, understanding EI, managing $\mathrm{EI}$ as the dependent variables in the analysis. As well, ANOVA was preformed with varsity athletic participation and gender as the independent variables and overall EI as the dependent variable. To interpret the interaction effect of varsity athletics and gender in both the MANOVA and ANOVA, the F statistic was observed and a $\alpha<0.05$, was deemed to be significant. 


\subsubsection{Research Question 2: Overall EII}

The main measure of EI used in this thesis is the MSCEIT overall EI score. In order to test the relationship between overall $\mathrm{EI}$ scores and varsity athletic participation a two way (gender by athletic participation) ANOVA (Analysis of Variance) was used (research question 1). Overall EI was the dependent variable for this analysis.

If the gender by varsity athletics interaction is not significant then research question 2 can be answered by looking at the main effect of varsity athletic participation on the dependent variable, overall EI, as listed in the between-subjects test report. Using the SPSS output, the F statistic and corresponding significance level was used to test the null hypothesis. The relationship between varsity athletic participation and overall EI was tested for significance using with $\alpha<0.05$ again being considered significant.

\subsubsection{Research Question 3a-d: Four Branches of Emotional Intelligence}

To examine research question 3, a two-way (gender by athletic participation) MANOVA (Multiple Analysis of Variance) was performed using SPSS. In this analysis the four subcategories of EI; Perceive EI, Facilitate/Use EI, Understand EI and Manage EI were used as the dependent variables in the analysis. Gender and varsity athletic participation were used as the independent variables in the MANOVA.

Again, if the interaction effect of gender is not significant, one can look at the main effects of varsity athletics on the four branches of EI scores to answer research question 3. Interpretation of the MANOVA is a two step process. In the first step the multivariate F-test and its p-value was used to test the null hypothesis that there is no difference in between the means of the dependent variables (the four branches of ED) for the different groups formed by the categories of the independent variables (gender and varsity athletic 
participation). The Wilk's lambda score was the multivariate significance test used due the fact that there were four dependent variables in the analysis. The second phase of the analysis was the between-subjects effects test. The SPSS output listed the degrees of freedom, F statistic and p-value for each of the independent variables in the model. Differences between varsity athletes and non-athletes were tested for significance using $a$ $<0.05$. The statistical analysis above tested the relationship between varsity athletic participation and each of the four branches of EI; perceiving, facilitating, understanding, and managing.

Table 4.4 - Summary of Analysis of Data

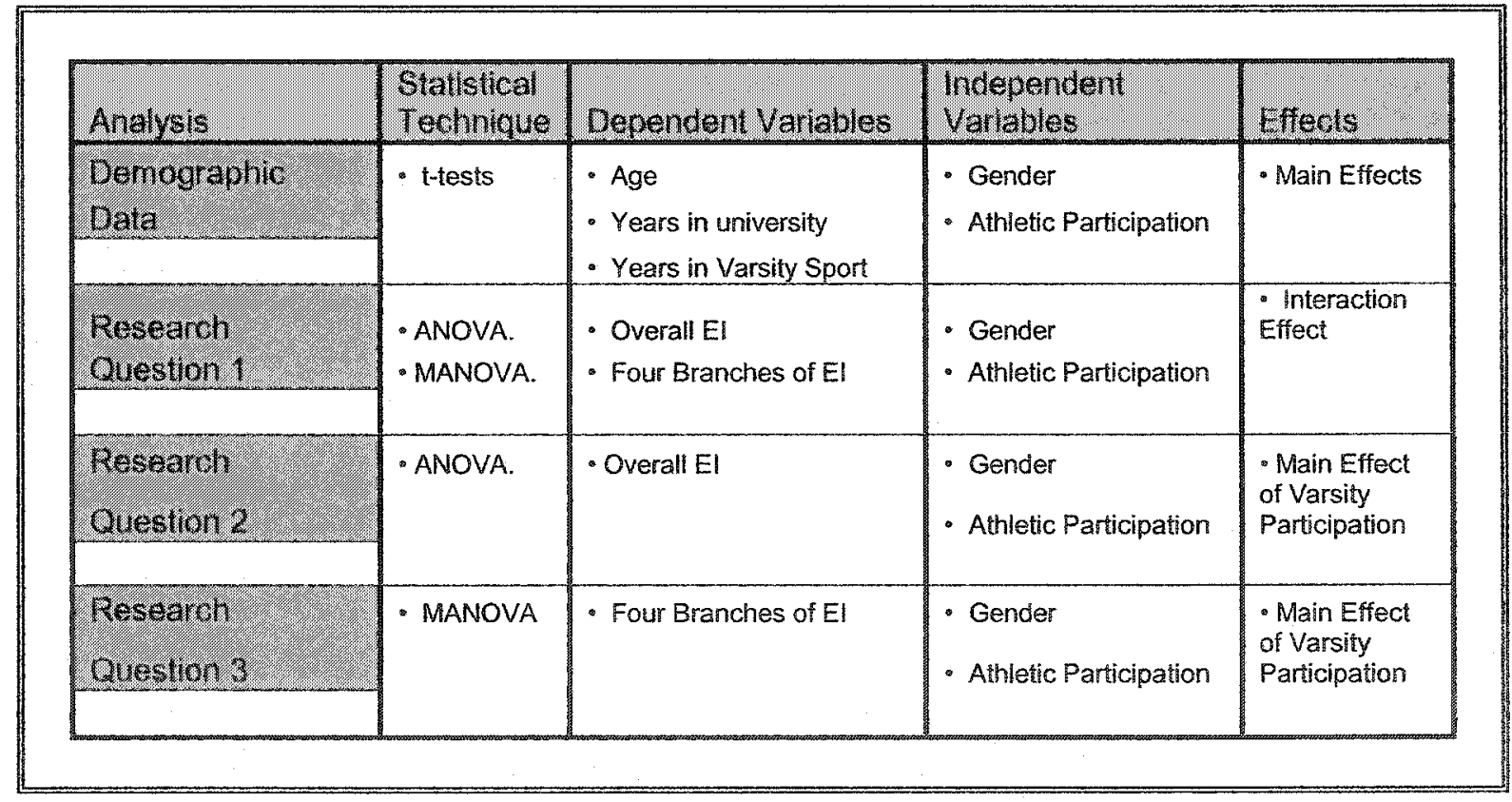




\subsection{RESEARCH FINDINGS \& DISCUSSION}

Section five presents and discusses the major findings of this research on varsity athletic participation and emotional intelligence levels in university students. The goal of this section will be to describe the sample characteristics and present the results of the statistical analysis related to the research questions outlined in the objectives section of this research. To accomplish this task the chapter is divided into six sections. The first section will describe the demographic characteristics for the sample. These sample characteristics will be analyzed in terms of gender and varsity athletic participation in order to ensure that any significant findings can be attributed to a difference in EI levels and not to sample characteristics. The second section of this chapter will provide an overview of the data results on the overall EI scores and four branches of EI: perceiving, facilitating, understanding, and managing.

Section three presents the results of the analysis of the interaction effect between varsity athletic participation and gender on overall EI and the four branches of EI (research question 1). The main effects of varsity athletic participation on overall EI are reported in section four (research question 2). In section five, the results of the analysis of the effect of varsity athletic participation on the four branches of EI (perceiving, using, understanding, and managing) are reported (research question 3). Each of the results from the above sections will then be discussed in terms of the limitations, implications and directions for future research, at the end of this chapter, in section six. 


\subsection{Sample Characteristics}

The following section will describe the survey sample according to five key

characteristics: gender; age; university attended; program of study; and sport information.

Table 5.1 shows the complete sample breakdown and the sample sizes for each subject group. As required by the research, design the four major subject groups (males, females, athletes and non varsity athletes) all had a group size of sixty respondents. The four minor groups (male athletes, female athletes, male non varsity athletes and female non varsity athletes) all had a group size of thirty.

Table 5.1 Complete Sample Breakdown

\begin{tabular}{|c|c|c|c|c|}
\hline \multirow{5}{*}{$\begin{array}{l}G \\
E \\
N \\
D \\
E \\
R\end{array}$} & \multicolumn{4}{|c|}{ Varsity Athletic Participation } \\
\hline & & Yes & No & Total \\
\hline & Male & 30 & 30 & 60 \\
\hline & Female & 30 & 30 & 60 \\
\hline & Total & 60 & 60 & $N=120$ \\
\hline
\end{tabular}

\subsubsection{Age}

The age breakdown for the sample is displayed in table 5.1.1. The overall average age for the sample was 23.1 years with a standard deviation of 1.41 years. Consistent with the methodology section, all of the subjects were below the age of 28 years old. The major group with the highest average age was the non-athletes (23.27 years) and the lowest group average age was the athletes (22.93 years). In the minor groups, the highest 
average age belonged to the female non athletes (23.53 years) and the lowest group average was the female athlete group with an age of 22.73 years.

Table 5.1.1 Age Breakdown

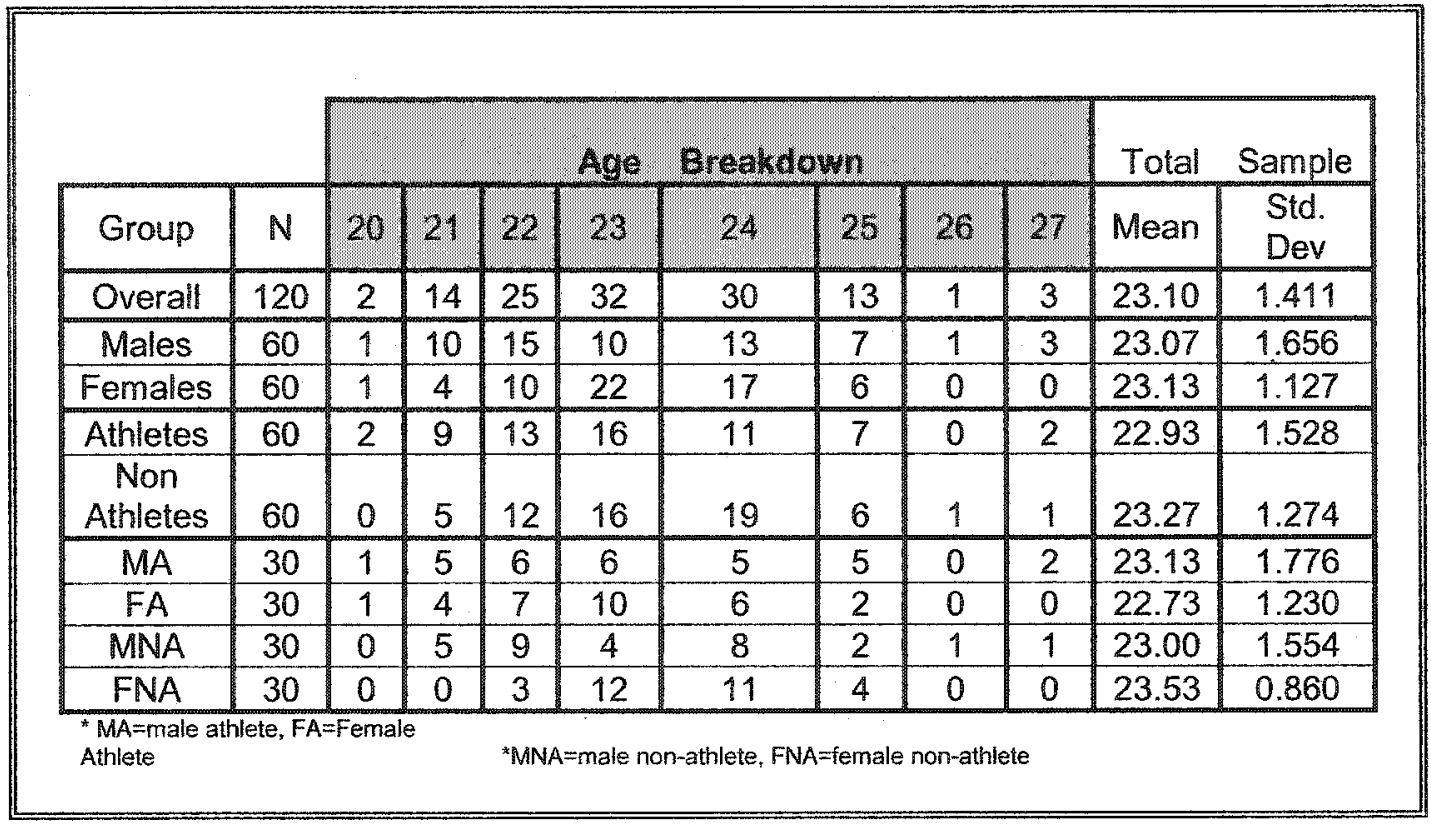

The median age for the entire sample $(\mathrm{N}=120)$ was 23.10 years. To test for a difference between the mean age for males and females a t-test was preformed as described in the methodology section. The result of the t-test indicated that there was no significant between the mean age for male respondents and the mean age of females for this research $\left[\mathrm{t}_{2,118}=0.258 ; \mathrm{p}>0.05\right]$. The t-test comparing the mean age for athletes to non-athletes yielded $a t_{2,118}=1.298$ and a significance level of $\mathrm{p}=0.197$. This also indicated that there was no significant difference between the mean age of a respondent who played a varsity sport and one who did not. 


\subsubsection{University}

The sample was taken from six Ontario Universities; Guelph, Queen's, Carleton,

Western, Lakehead and Ottawa. As table 5.1.2 shows, the majority of subjects were from Carleton University (53), Guelph University (39) and University of Western Ontario (17).

Table 5.1.2 University

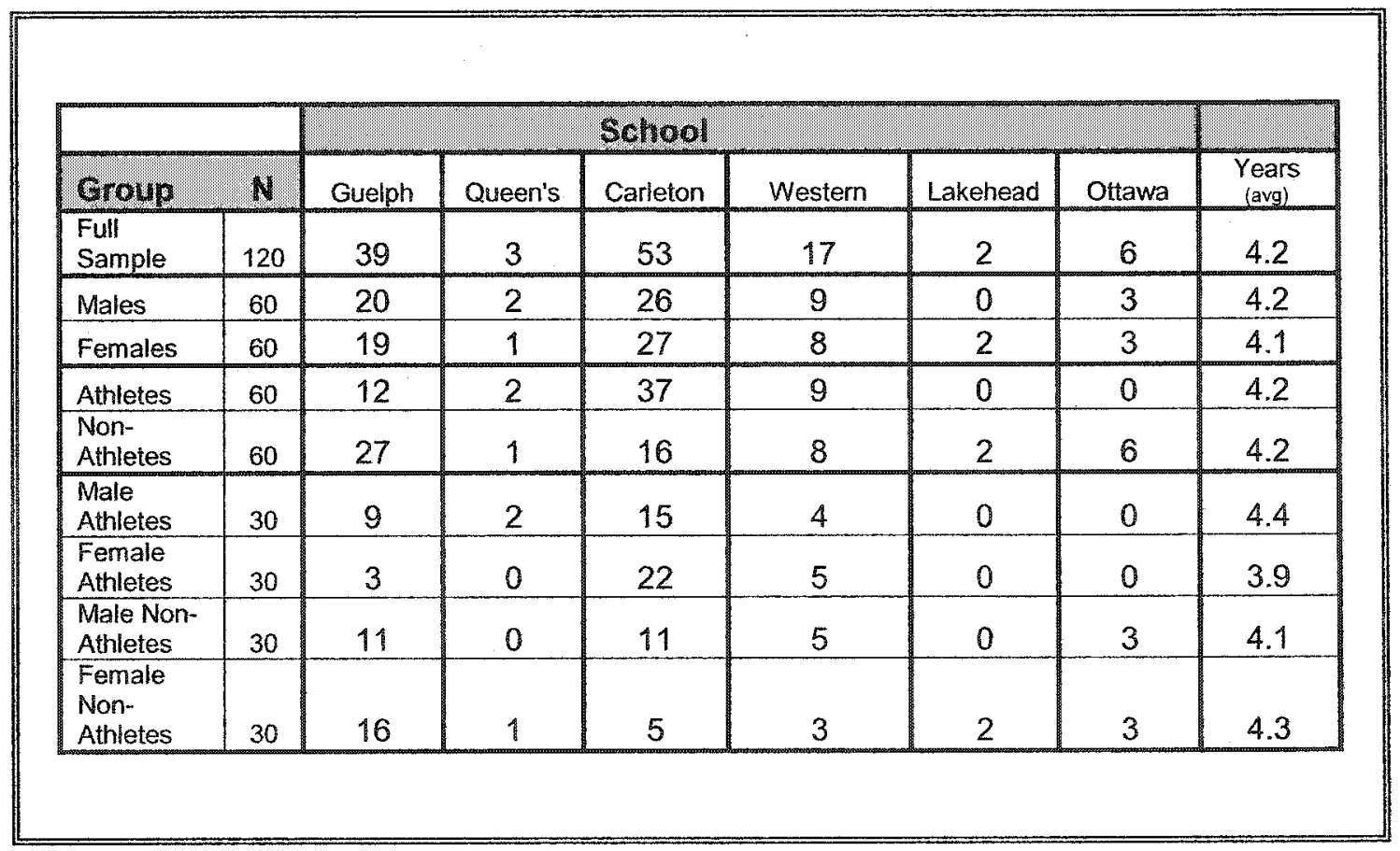

The statistical analysis of the years of university experience reveals an overall sample average of 4.2 years. The average number of years in school for athletes and non varsity athletes was 4.2 years. This analysis also revealed that the average number of years of experience at university was 4.2 years for males and 4.1 years for female subjects. To test for a difference in mean years of university experience for males and females in the sample a t-test was preformed as described in the methodology section. The result of the t-test comparing the mean years of school experience for males and females in the 
sample was a t statistic $\left(t_{2,118}=0.705\right)$ and a significance level of $p=0.482(p>0.05)$.

This indicated that there was no significant difference between in the mean years of experience for the two genders. The t-test comparing the mean number of years in university for athletes to non-athletes yielded a $t_{2,118}=0.390$ and a significance level $\mathrm{p}=0.763(\mathrm{p}>0.05)$. This also indicated that there was no significant difference between athletes and non-athletes in terms of years of university experience.

\subsubsection{Program of Study}

Table 5.1.3 provides the statistical breakdown of the academic program for the subjects in the study. The six major program categories were: business, math/science, arts, engineering, humanities/social sciences and other. The most common program for the full sample was math/science (38), followed by humanities (27) and business (21).

Table 5.1.3 Program Breakdown

\begin{tabular}{|c|c|c|c|c|c|c|c|}
\hline & & & & & ogram & & \\
\hline group & N. & Business & Math/Science & Arts & Engineering & Humanities/Soc. & Other \\
\hline $\begin{array}{l}\text { Full } \\
\text { Sample }\end{array}$ & 120 & 21 & 38 & 14 & 19 & 27 & 1 \\
\hline Males & 60 & 14 & 21 & 7 & 10 & 8 & 0 \\
\hline Fernales & 60 & 7 & 17 & 7 & 9 & 19 & 1 \\
\hline Athletes & 60 & 9 & 18 & 8 & 10 & 15 & 0 \\
\hline $\begin{array}{l}\text { Non- } \\
\text { Athletes }\end{array}$ & 60 & 12 & 20 & 6 & 9 & 12 & 1 \\
\hline $\begin{array}{l}\text { Male } \\
\text { Athletes }\end{array}$ & 30 & 6 & 12 & 5 & 4 & 3 & 0 \\
\hline $\begin{array}{l}\text { Female } \\
\text { Athletes }\end{array}$ & 30 & 3 & 6 & 3 & 6 & 12 & 0 \\
\hline $\begin{array}{l}\text { Male } \\
\text { Non- } \\
\text { Athletes } \\
\end{array}$ & 30 & 8 & 9 & 2 & 6 & 5 & 0 \\
\hline $\begin{array}{l}\text { Female } \\
\text { Non- } \\
\text { Athletes }\end{array}$ & 30 & 4 & 11 & 4 & 3 & 7 & 1 \\
\hline
\end{tabular}


According to the sample selection methodology outlined in section 4.2 the program frequencies for athletes compared to non-athletes represents a best effort to recruit equal numbers for all of the programs. This was done to try to control for the effect of program of study on EI scores. Each of the program categories had the same number of athletes and non-athletes within $+/$ - three subjects. It should be noted that there was a gender difference in the number of respondents who were enrolled in humanities and also in the business category. This result reflected the fact that this study matched participants according to varsity athletic participation and not gender. It also means that any gender differences observed in EI might reflect differences associated with the program of study (i.e. people with higher EI are more likely to be enrolled in the humanities) rather than gender.

\subsubsection{Varsity Sport Information}

The data regarding participation in varsity sport is summarized in table 5.1.4. Consistent with the sampling framework the number of sample participants who did not participate in a varsity sport is $\mathrm{n}=60$ (table 5.1 ). The sixty subjects who did participate in sport all participated in at least three years of varsity sport with an overall average of 3.7 years of experience playing their sport. The male athletes had an average of 4.1 years of experience and their female counterparts had an average of 3.4 years of experience. 
Table 5.1.4 Varsity Spont Breakdown

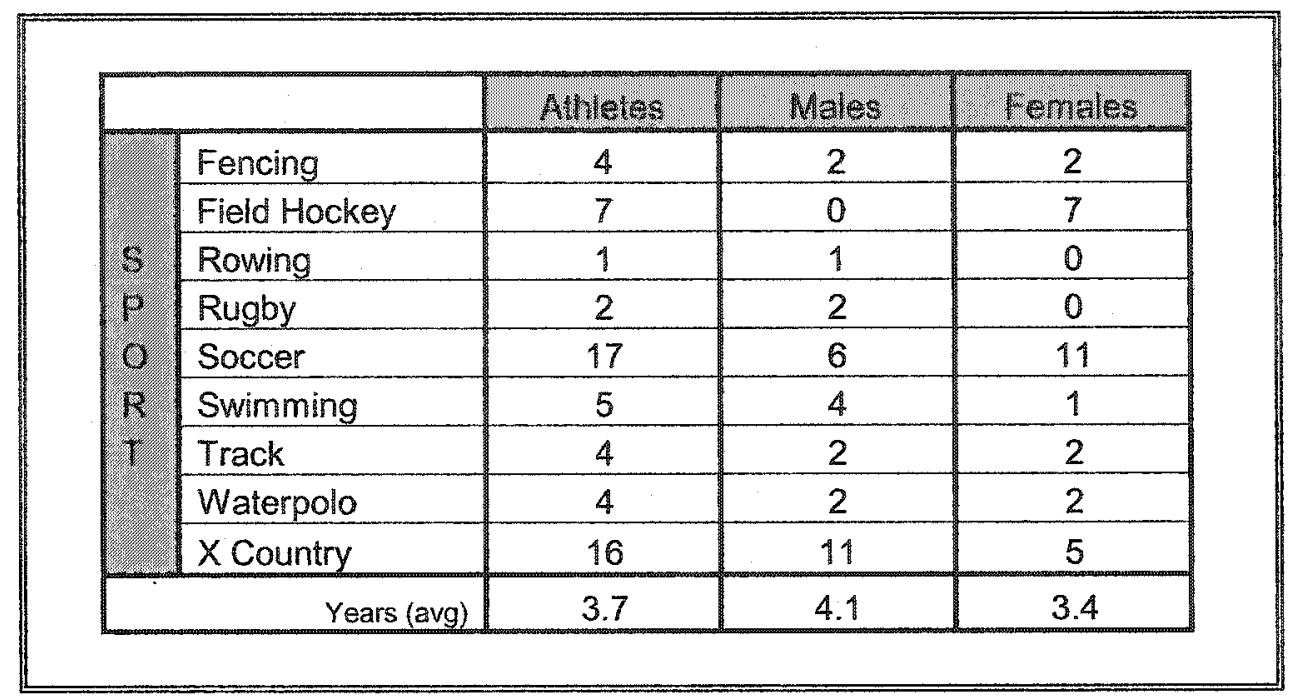

The most common sport played was soccer ( 17 athletes), followed by cross country running (16 athletes) and field hockey ( 7 athletes). Male athletes reported cross country running (11 athletes), soccer ( 6 athletes) and swimming ( 4 athletes) as the most played sports. The varsity sports most played by the female athletes in the sample were soccer (11 athletes), field hockey ( 7 athletes) and cross country running ( 5 athletes). To test for a difference in the mean number of years that males and females played a varsity sport a $\mathrm{t}$-test was preformed. The results revealed that the number of years playing a varsity sport was significantly greater in males than in females $\left(t_{2,58}=0.771 ; p<0.05\right)$. This result was taken into consideration when analyzing research question 1. 


\subsection{Data Analysis - Overview}

This section provides an overview of the data analysis for the MSCEIT emotional intelligence (EI) scores that were observed in the research. The summary of data analysis provides an accurate overall picture of the results for this research. Table 5.2 shows the data analysis for the full sample means by group. The mean overall EI for the full sample was $96.7 \pm 12.1$ (mean $\pm \mathrm{sd}$ ). The full sample mean score for perceiving emotions was $96.7 \pm 12.8$. The mean using emotions score for the full sample was 99.9 \pm 14.8. The highest branch mean was the understanding emotion category, which had a mean score of $104.1 \pm 14.3$. Finally, the full sample data analysis showed a managing emotion mean score of $97.6 \pm 12.4$

Table 5.2 Full Sample Mean EI Scores by Group

\begin{tabular}{|c|c|c|c|c|c|c|c|c|c|c|c|}
\hline & vi & $\begin{array}{l}\text { Percelve: } \\
\text { enotion }\end{array}$ & $\begin{array}{l}\text { sed } \\
\text { dev }\end{array}$ & $\begin{array}{l}\text { Using } \\
\text { emolion }\end{array}$ & $\begin{array}{l}\text { ste } \\
\text { dev }\end{array}$ & $\begin{array}{c}\text { Undersianoing } \\
\text { emotion }\end{array}$ & $\begin{array}{l}\text { sid } \\
\text { dey }\end{array}$ & $\begin{array}{l}\text { Manage } \\
\text { emovion }\end{array}$ & $\begin{array}{l}\text { swis } \\
\text { dev }\end{array}$ & $\begin{array}{c}\text { Orerail } \\
\mathrm{EI}\end{array}$ & $\begin{array}{l}\text { sid } \\
\text { dev }\end{array}$ \\
\hline \multicolumn{12}{|l|}{ Athlete } \\
\hline Male & 30 & 93.7 & 12.8 & 98.3 & 15.1 & 104.2 & 20.1 & 97.2 & 14.8 & 92.9 & 12.1 \\
\hline Female & 30 & 98.1 & 9.9 & 99.6 & 14.4 & 103.6 & 12.8 & 97.5 & 6.8 & 98.4 & 10.4 \\
\hline Overall & 60 & 95.9 & 11.6 & 98.9 & 14.6 & 103.9 & 16.7 & 97.4 & 11.4 & 95.7 & 11.5 \\
\hline \multicolumn{12}{|l|}{$\begin{array}{l}\text { Non } \\
\text { Athlete }\end{array}$} \\
\hline Male & 30 & 95.8 & 14.0 & 98.4 & 16.6 & 105.3 & 13.9 & 99.0 & 17.8 & 95.3 & 14.4 \\
\hline Female & 30 & 99.1 & 13.8 & 103.3 & 13.1 & 103.3 & 9.0 & 96.7 & 6.5 & 100.0 & 10.4 \\
\hline Overall & 60 & 97.5 & 13.9 & 100.8 & 15.0 & 104.3 & 11.7 & 97.8 & 13.3 & 97.6 & 12.7 \\
\hline \multicolumn{12}{|l|}{ Mate } \\
\hline Overall & 60 & 94.8 & 13.3 & 98.3 & 15.7 & 104.7 & 17.1 & 98.1 & 16.3 & 94.1 & 13.3 \\
\hline \multicolumn{12}{|l|}{ Female } \\
\hline Overall & 60 & 98.6 & 12.0 & 101.4 & 13.8 & 103.5 & 11.0 & 97.1 & 6.6 & 99.2 & 10.3 \\
\hline $\begin{array}{l}\text { Fuif } \\
\text { Sample }\end{array}$ & 120 & 96.7 & 12.8 & 99.9 & 14.8 & 104.1 & 14.3 & 97.6 & 12.4 & 96.7 & 12.1 \\
\hline
\end{tabular}


Table 5.2 shows that the students who participated in this research had lower than average levels of overall $\mathrm{EI}$, perceiving emotions, using emotions and managing emotions. Students in this study had higher than average levels of understanding emotion. The levels of standard deviation observed were also consistent for each of the groups on all of the measures of EI.

The general data analysis for this research provides an overview for understanding the effect of varsity participation on EI scores in university students. The results are further examined and tested for significance in the next three sections, where each research question is analyzed individually. 


\subsection{Results Associated with Research Question 1: Is the relationship between varsity athletic participation and the CI scores of university students different for malles and females?}

The interaction effect of varsity athletic participation and gender on emotional intelligence levels in university students was the subject of research question 1 . This was the most complicated interaction in the statistical analysis and therefore, was examined before the main effects of varsity athletic participation in the model. Table 5.3a shows the mean MSCEIT scores and confidence intervals for overall EI and the four sub groups of the sport*gender interaction. The four groups that help define the interaction between varsity sport and gender are: female non-athletes, female athletes, male non-athletes, and male athletes. To test this research question the interaction term was used (table 5.3b) from both the ANOVA, which was done to test for overall EI levels (research question 2) and the MANOVA, which was done to test for the four branches of EI (research question 3). Both tests were preformed using SPSS software.

In order to use the ANOVA for the interpretation of these results, tests were done to ensure that the underlying assumptions of the ANOVA were not violated. Levene's test for homogeneity of variance, which tests the assumption that the error variances of the dependent variable are normally distributed and independent across groups, was found to have a significance level of $p=0.589$. This meant that the ANOVA assumptions were not violated.

The key underlying assumptions for the MANOVA were then tested to ensure for accurate interpretation. The sample design was selected such that the observations are independent of each other, the group sizes are similar and the sample size is adequate 
$(\mathrm{N}=120)$. In order to test the assumption that the residuals for the dependent variables are randomly distributed the standardized residual plots were examined and were found to be random for each variable. As well, the data was checked for outliers in the sample as this can alter the accuracy of MANOVA. Finally, to test the homogeneity of variance assumption, Levene's test statistic was observed for each of the four dependent variables. The results showed that Levene's test statistic is not significant for perceiving emotions, using emotions, and understanding emotions, indicating that homogeneity of variance was maintained for all three of these dependent variables. The managing emotions dependent variable had a Levene"s score of 0.03 . Although this indicates a violation of the assumption of equal variance, the violation is not severe and the because the multivariate test showed no relationship for the model and each of the four branches of also showed no significant relationship from varsity athletic participation, the MANOVA remains valid.

The mean analysis (table 5.3a) showed that the group with the highest mean overall EI score was the female non-athletes with an average score of 100 . The lowest mean overall EI score belonged to the male athletes with a score of 92.9 . The standard error on each of the overall EI scores was 2.178. Table $5.3 \mathrm{a}$ also shows the confidence intervals for each of the MSCEIT scores. 
Table 5.3a MSCEIT Mean Scores - Sport * Gender

\begin{tabular}{|c|c|c|c|c|c|c|}
\hline \multirow[b]{2}{*}{ E: Measure } & \multirow[b]{2}{*}{ Gerver } & \multirow[b]{2}{*}{ Sport } & \multirow[b]{2}{*}{ Mean } & \multirow[b]{2}{*}{$\begin{array}{l}\text { Std: } \\
\text { Error }\end{array}$} & \multicolumn{2}{|c|}{$\begin{array}{l}95 \% \text { Confidence } \\
\text { Interval }\end{array}$} \\
\hline & & & & & $\begin{array}{l}\text { Lower } \\
\text { Bound }\end{array}$ & $\begin{array}{l}\text { Upper } \\
\text { Bound }\end{array}$ \\
\hline \multirow[t]{2}{*}{ Perceiving } & $F$ & $\begin{array}{l}\text { NA } \\
Y\end{array}$ & $\begin{array}{l}99.1 \\
98.1\end{array}$ & $\begin{array}{l}2.327 \\
2.327\end{array}$ & $\begin{array}{l}94.5 \\
93.5\end{array}$ & $\begin{array}{l}103.8 \\
102.7\end{array}$ \\
\hline & $\bar{M}$ & $\begin{array}{l}\text { NA } \\
Y\end{array}$ & $\begin{array}{l}95.8 \\
93.7\end{array}$ & $\begin{array}{l}2.327 \\
2.327\end{array}$ & $\begin{array}{l}91.2 \\
89.1\end{array}$ & $\begin{array}{l}100.5 \\
98.3\end{array}$ \\
\hline \multirow[t]{2}{*}{ Using } & $\bar{F}$ & $\begin{array}{l}\text { NA } \\
Y\end{array}$ & $\begin{array}{l}103.3 \\
99.6\end{array}$ & $\begin{array}{l}2.713 \\
2.713\end{array}$ & $\begin{array}{l}97.9 \\
94.2\end{array}$ & $\begin{array}{l}108.6 \\
105.0\end{array}$ \\
\hline & $\bar{M}$ & $\begin{array}{l}\text { NA } \\
Y\end{array}$ & $\begin{array}{l}98.4 \\
98.3\end{array}$ & $\begin{array}{l}2.713 \\
2.713\end{array}$ & $\begin{array}{l}93.1 \\
92.9\end{array}$ & $\begin{array}{l}103.8 \\
103.6\end{array}$ \\
\hline \multirow[t]{2}{*}{ Understanding } & $\mathrm{F}$ & $\begin{array}{l}\text { NA } \\
Y\end{array}$ & $\begin{array}{l}103.3 \\
103.6\end{array}$ & $\begin{array}{l}2.647 \\
2.647\end{array}$ & $\begin{array}{l}98.0 \\
98.4\end{array}$ & $\begin{array}{l}108.5 \\
108.9\end{array}$ \\
\hline & $M$ & $\begin{array}{l}\text { NA } \\
Y\end{array}$ & $\begin{array}{l}105.3 \\
104.2\end{array}$ & $\begin{array}{l}2.647 \\
2.647\end{array}$ & $\begin{array}{c}100.0 \\
98.9\end{array}$ & $\begin{array}{l}110.5 \\
109.4\end{array}$ \\
\hline \multirow[t]{2}{*}{ Managing } & $F$ & $\begin{array}{l}\text { NA } \\
Y\end{array}$ & $\begin{array}{l}96.7 \\
97.5\end{array}$ & $\begin{array}{l}2.280 \\
2.280\end{array}$ & $\begin{array}{l}92.1 \\
93.0\end{array}$ & $\begin{array}{l}101.2 \\
102.0\end{array}$ \\
\hline & $M$ & $\begin{array}{l}\text { NA } \\
Y\end{array}$ & $\begin{array}{l}99.0 \\
97.2\end{array}$ & $\begin{array}{l}2.280 \\
2.280\end{array}$ & $\begin{array}{l}94.5 \\
92.7\end{array}$ & $\begin{array}{l}103.5 \\
101.7\end{array}$ \\
\hline \multirow[t]{2}{*}{ Overall El } & $F$ & $\begin{array}{l}\text { NA } \\
Y\end{array}$ & $\begin{array}{l}100.0 \\
98.4\end{array}$ & $\begin{array}{l}2.178 \\
2.178\end{array}$ & $\begin{array}{l}95.7 \\
94.1\end{array}$ & $\begin{array}{l}104.3 \\
102.7\end{array}$ \\
\hline & $M$ & $\begin{array}{c}\text { NA } \\
Y\end{array}$ & $\begin{array}{l}95.3 \\
92.9\end{array}$ & $\begin{array}{l}2.178 \\
2.178\end{array}$ & $\begin{array}{l}91.0 \\
88.6\end{array}$ & $\begin{array}{l}99.6 \\
97.3\end{array}$ \\
\hline
\end{tabular}

Female non-athletes also reported the highest MSCEIT scores in perceiving emotions (99.1), and using emotions (103.3). Male non-athletes had the highest scores in both understanding emotions (105.3) and managing emotions (99.0). Male athletes scored lower than male non-athletes on each of the five measures of EI. Finally, female athletes did not report either the high or low mean score on any of the five MSCEIT EI scores used for this research.

The interaction effect is shown in Table 5.3b for the MSCEIT overall EI score and the four branch scores (perceiving, using, understanding and managing). 
Table 5.3b Gender * Varsity Athetic Participation Interaction Cffect

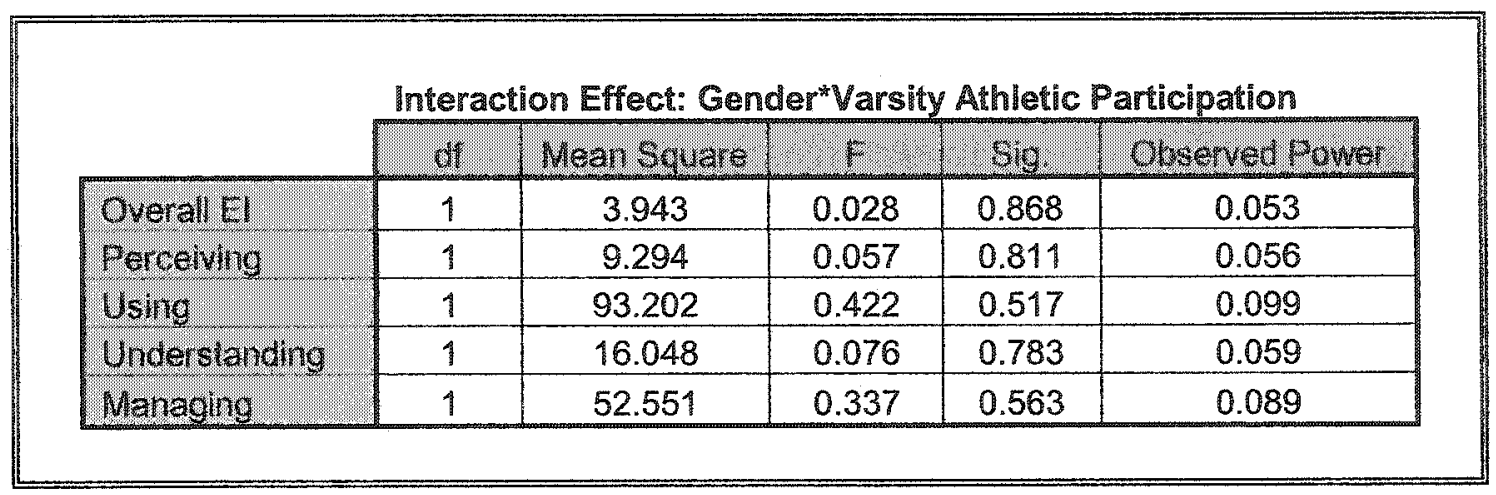

Using the F statistic and significance value, each of these dependent variables was examined in order to determine the significance of the interaction between gender and varsity athletic participation. The analysis showed no significant interaction between gender and varsity athletic participation with regards to either overall EI or the four branch scores. This analysis indicates that any significant effects of varsity athletic participation on EI scores are not influenced by gender. 


\subsection{Results Associated with Research Question 2: What is the relationship between varsity athletic participation and overall emotional intelligence among university students?}

The primary purpose of this research is to test the effect of varsity athletic participation on EI levels in university students. The relationship which best shows this effect is the relationship between athletic participation and overall EI scores. Mayer, Salovey and Caruso define overall EI as "the ability to monitor one's own and others" feelings and emotions, to discriminate among them, and to use this information to guide one's thinking and action" (Salovey \& Mayer, 1990: p. 189). The data analysis procedure for this research question was laid out in section 4.4.3. The first step was to examine the means and mean differences associated with this research questions.

Table 5.2 lists the overall EI mean scores for both athletes and non-athletes in the sample. The athletes $(n=60)$ had a mean score of 95.7 , one point below the mean overall EI for the full sample and 1.97 points below the mean overall EI score for non-athletes $(n=60)$. Both groups have similar standard deviation scores to the mean of the full sample. To test the significance of the relationship between varsity sport and overall El, ANOVA was done using SPSS with overall EI as the dependent variable and gender and varsity sport as the two independent variables (table 5.4). As mentioned in section 5.3, the underlying assumptions for the ANOVA were not violated.

The F statistic and corresponding significance level is also given in table 5.4. 
Table 5.4 Research Question 2: ANOVA

\begin{tabular}{|c|c|c|c|c|c|}
\hline \multicolumn{6}{|c|}{ Tests of Between-Subjects Effects } \\
\hline \multicolumn{6}{|c|}{ Dependent Variable: Overall El } \\
\hline Source & df & $\begin{array}{l}\text { Mean } \\
\text { Square }\end{array}$ & $\mathrm{F}$ & Sig. & $\begin{array}{c}\text { Ohserved } \\
\text { Power: }\end{array}$ \\
\hline \multicolumn{6}{|l|}{ Main Effects } \\
\hline Gender & 1 & 779.9 & 5.48 & 0.021 & 0.641 \\
\hline Sport & 1 & 116.4 & 0.818 & 0.368 & 0.146 \\
\hline
\end{tabular}

Differences were considered to be statistically significant at the level of $\alpha=0.05$. It should be noted that there was a significant main effect of gender on overall EI scores $\left[\mathrm{F}_{1}\right.$, $116=5.48 ; \mathrm{p}<0.05]$. These findings are consistent with the finding of Mayer, Salovey and Caruso (2002).

The ANOVA main effect showed that varsity sport participation had no significant effect on overall EI scores $\left[\mathrm{F}_{1,116}=0.818 ; \mathrm{p}>0.05\right]$. The observed power (the probability of correctly rejecting the null hypothesis) for this analysis was small (0.146). This data analysis indicates that varsity athletic participation does not have a significant effect on overall EI scores in university students. The results from this analysis show that although the non-athlete group in this sample has a slightly higher average mean overall EI (1.97 points higher than the athlete group), this mean difference is not statistically significant. Therefore, based on the data analysis for this research, the null hypothesis for question number one cannot be rejected. The results of this analysis show that there is no statistically significant difference between the overall EI scores for university students who participated in varsity sports and the overall EI scores for university students who did not participate in varsity sports during their time at university. 


\subsection{Results Associated with Research Question 3}

In order to further examine the effect of varsity athletic participation on EI for university students the four branches of EI; perceiving, using, understanding, and managing, are examined in research question 3 . The data analysis procedure for this research question is outlined in section 4.4.4. The first step of analysis for each of the four branches of EI involved the analysis of the mean and mean difference between athletes and non-athletes in the sample. The mean scores for the varsity athletes and non-athletes in the sample are described in table 5.5a. Scores are listed for all four branch measures of EI and the sample size for both athletes and non-athletes is $n=60$.

Table 5.5a MSCEIT Four Branches of EI Mean Scores

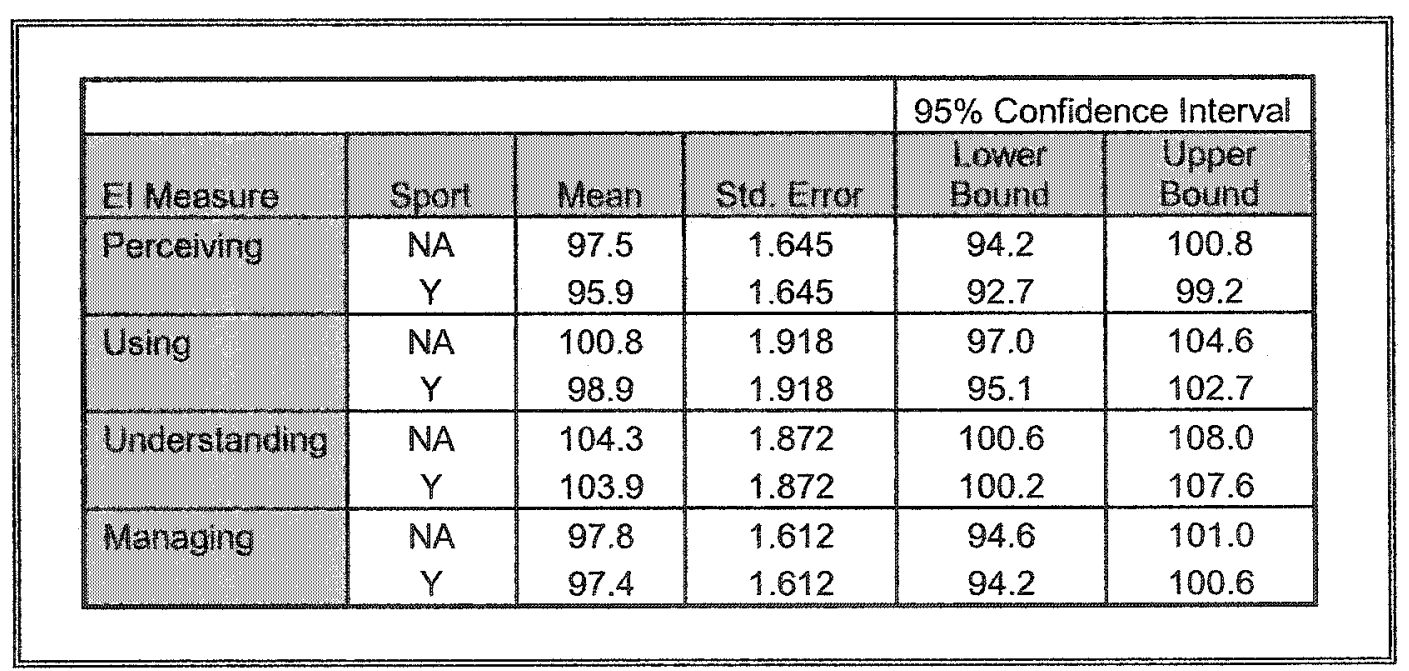

The non-athletes in the sample had a higher mean score in each of the four branches of EI as well, with the largest branch score difference being in the using emotions score. The lowest mean score difference took place in the understanding emotions branch which had a mean difference of 0.364 . Overall, the mean scores for each of the measures of EI are similar for both athletes and non-athletes. 
The next stage of the analysis was the MANOVA (table 5.5b). For the MANOVA, the dependent variables were the four branches of EI as mentioned above. The independent variables were gender (male/female) and varsity sport participation (yes/no).

Table 5.5b Research Question 3: MANOVA Main Effects

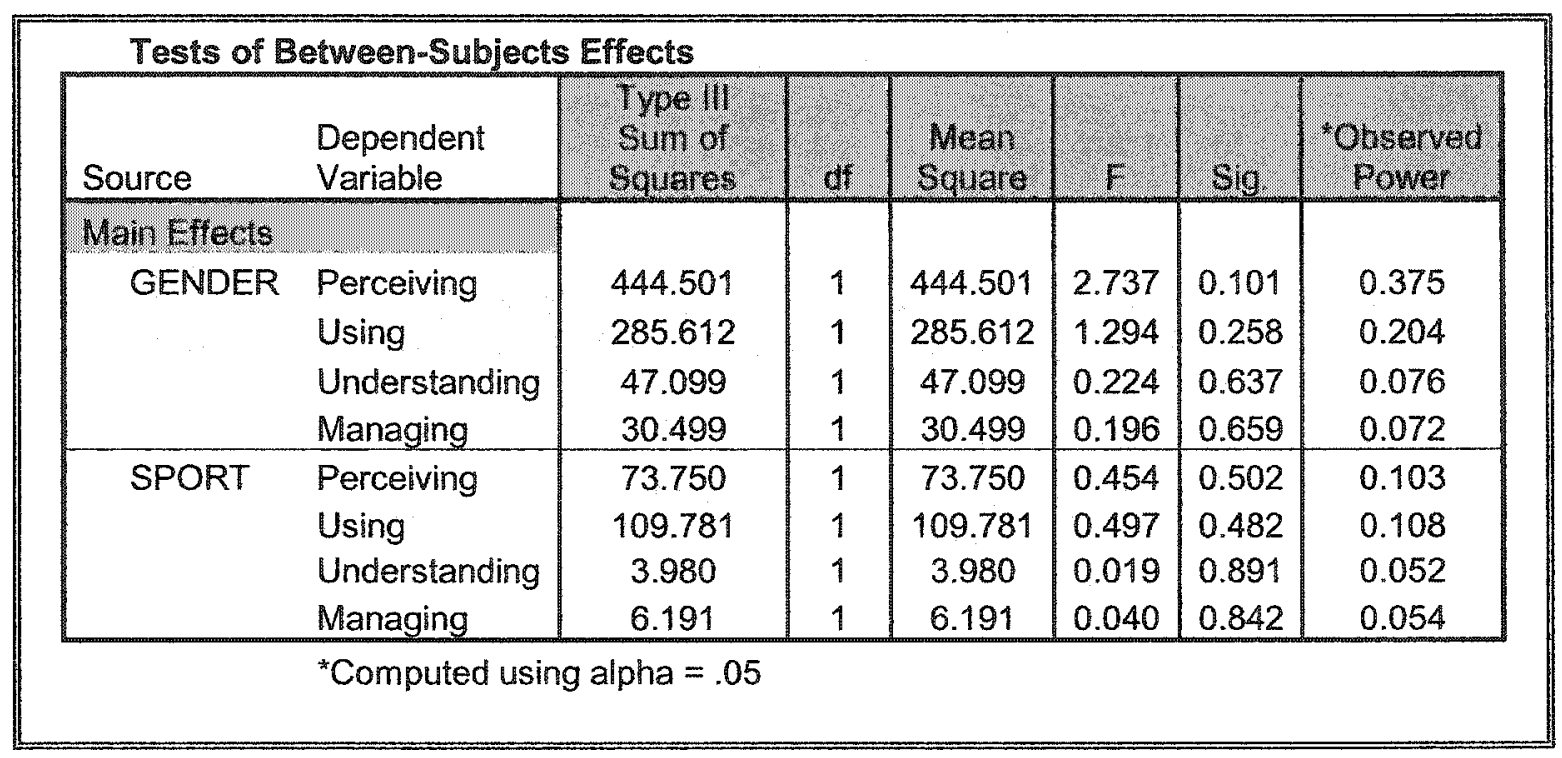

The key underlying assumptions for the MANOVA were then tested to ensure for accurate interpretation. As discussed in section 5.3, the each of the underlying assumptions of the MANOVA were adequately met and thus allow for meaningful interpretation of the results.

The Wilk's lambda score was the multivariate significance test used to test for significance because there were four dependent variables in the analysis. The Wilk's lambda from the MANOVA output showed that varsity sport participation did not significantly affect the four branches of EI tested $(p>0.05)$.

The main effects of the MANOVA and the rest of the statistical analysis testing the relationship between varsity athletic participation and each of the four branches of EI; 
perceiving, facilitating, understanding, and managing is continued in the following subsections.

\subsubsection{Results Associated with Research Question 3a: What is the relationship between varsity athletic participation and a student's ability to perceive and identify emotions?}

Research question 3 a examines the relationship between varsity athletic participation and a student's ability to perceive and identify emotions. The mean perceiving emotion scores for athletes and non-athletes were reported in table 5.5a. The difference between the perceiving scores for varsity athletes and non-athletes were then tested for significance using the MANOVA output shown in table 5.5b. The analysis reveals that varsity sport participation does not have a significant effect on perceiving emotion scores in university students $\left[F_{1,116}=0.454 ; p>0.05\right]$. The observed power of this effect was 0.103.

The perceiving emotion score for the MSCEIT test represents the ability to perceive and identify emotions. The results from the data analysis show that although the non-athlete group in this sample has a higher average mean perceiving emotion score, this mean difference was not statistically significant. Therefore, based on the data analysis for this research, the null hypothesis for question 3 a camnot be rejected. The analysis failed to find any statistically significant difference between the perceiving emotion scores for university students who participated in varsity sports and the perceiving emotion scores for university students who did not participate in varsity sports during their time at university. 


\subsubsection{Results Associated with Research Question 3b: What is the relationship between varsity athletic participation and a student's ability to facilitate and use emotion?}

The relationship between varsity athletic participation and a student's ability to perceive and identify emotions is examined in research question $3 \mathrm{~b}$. The mean using emotion scores for both athletes and non-athletes are listed in table $5.5 \mathrm{a}$. This analysis revealed a mean difference of +1.91 on using emotions score for non-athletes compared to athletes. To test the significance of this relationship, MANOVA was done to observe the using emotion mean scores for athletes and non-athletes in the research sample (table 5.5b). Differences were reported to be statistically significant at the level of $\alpha=0.05$. The analysis revealed the significance of the relationship between sport participation and using emotion scores.

The using emotion score for the MSCEIT test is the second branch score of the EI test. It represents the ability to facilitate and use emotions. Varsity sport participation did not have a significant effect on using emotion scores in university students $\left[F_{1,116}=0.497 ; p\right.$ $>0.05]$. Therefore, the null hypothesis for question $3 \mathrm{~b}$ could not be rejected. The research analysis revealed that the answer to research question $3 b$ is that there is no significant difference between the using emotion scores for university students who participated in varsity sports and the using emotion scores for university students who did not participate in varsity sports during their time at university. 


\subsubsection{Results Associated with Research Question 3e: What is the relationship between varsity athetic participation and a student's ability to understand emotions?}

The ability of university students' to understand emotions was examined in research question $3 \mathrm{c}$. The mean analysis for this research question is summarized in table $5.5 \mathrm{a}$. The non-athletes $(n=60)$ had a mean understanding emotion score of 104.3 while the athletes in the sample $(n=60)$ had a mean score of 103.9 . The standard deviations for the athletes mean score was five points higher than that the standard deviation for the nonathletes (table 5.2). This means that there was increased variance for the athletes understanding scores means. Aside from the different standard deviations of the two groups, they were very similar to each other (mean difference $=0.36$ ).

The analysis reveals the significance of the relationship between sport participation and understanding emotion scores. These findings show that varsity sport participation had no significant effect on understanding emotion scores in university students $\left[F_{1,116}=0.019\right.$; $p>0.05]$. Therefore, based on the data analysis for this research, the null hypothesis for question $3 c$ cannot be rejected and it cannot be said that there is any significant difference between the understanding emotion scores for university students who participated in varsity sports and the understanding emotion scores for university students who did not participate in varsity sports during their time at university. 


\subsubsection{Results Associated with Research Question 3d: What is the relationship between varsity athletic participation and student's ability to manage emotions?}

The effect of varsity athletic participation while studying at university on the ability to manage emotions is examined in research question $3 \mathrm{~d}$. The effect of varsity sport participation on managing emotion scores was summarized in table 5.5b. This table summarizes the observed power, the F statistic and the corresponding significance level from the MANOVA. These findings show that varsity sport participation did not have a significant effect on managing emotion scores in university students $\left[F_{1,116}=0.04 ; p>\right.$ $0.05]$.

The data analysis for understanding emotions reveals a similar conclusion to the previous three branch EI scores. Despite having a slightly higher mean managing emotion score, there was no significant difference in scores for athletes and non-athletes. Therefore, based on the data analysis for this research, the null hypothesis for question $3 \mathrm{~d}$ cannot be rejected. There was no significant difference between the managing emotion scores for university students who participated in varsity sports and the managing emotion scores for university students who did not participate in varsity sports during their time at university. 


\subsection{Discussion of Results}

This section provides a discussion of the data results presented above, in the context of the theoretical and empirical literature surrounding the topic of emotional intelligence in university student athletes. This thesis addressed the need for further research into this topic (Ryan, 1989), including an examination of the specific benefits that participation in sport provides to university students. The results of this thesis indicate that there is no significant relationship between varsity athletic participation and emotional intelligence scores for male or female university students.

These results can be interpreted to in two main ways. The first interpretation assumes that the findings of this study are accurate and there is no relationship between varsity athletic participation and El levels in university students. These findings support research done by Howard (1986) who reported that athletics was not a predictor of managerial success. It is possible that other experiences may have a much larger influence on a university student's emotional intelligence than varsity athletic participation. It is important to note that the non-athlete participants may be gaining emotional development in areas that athletes are not. Analysis of the experience of nonathletes compared to varsity athletes could give a possible explanation for the results of this research.

Another possible explanation for the results in this thesis is that the lack of significant relationship between varsity athletic participation and EI scores is not an absence of impact from varsity athletic participation but rather a canceling out of positive and negative influences on a student's EI. For example, the time taken away from schooling and socializing with students outside of athletics while playing a sport could be a 
negative factor which negates any gains in EI that are derived from training and competing with teammates. Further analysis of the university sport experience and the different aspects which contribute or take away from a student athletes' development would be a valuable supplement to this research.

Finally, the results from this study could be limited in that they ignore several more important factors in a varsity athlete's emotionally intelligent leadership potential. For instance, personality (measured by the Big Five personality dimensions) has been shown to exhibit a significant effect on leadership emergence and effectiveness in individuals (Judge, Bono, Ilies and Gerhardt, 2002). In a study by Law, Wong and Song (2004), EI was found to be related to yet distinct from the Big Five personality dimensions (neuroticism, extraversion, openness, agreeableness and conscientiousness). Controlling for the Big Five personality dimensions in this study may have allowed this research to more accurately isolate the affect of varsity athletic participation on emotionally intelligent leadership potential.

The second way to discuss the results of this thesis is to assume that there is a relationship between varsity athletic participation and EI but this research failed to detect it. The power obtained in this study was very small for each of the research questions. The power of a study can be interpreted as how likely a study is to correctly identify any significant differences even if they were present. By increasing the sample size the power of this research would increase and so would the confidence in the results of the research. As well, the measure of EI used for this thesis (MSCEIT) may not have measured the emotional qualities in university students which are influenced by varsity athletic participation. EI measures such as the EQ-i (Bar-On), the ECI 360 (Goleman) or 
the EQ Map (Cooper \& Sawaf) each test different definitions of emotional intelligence. As well, the MSCEIT (as mentioned in section 2.2.1) provides only a snapshot of a student's emotional health and this narrow view of the emotional potential may have missed some emotionally intelligent leadership characteristics in the respondents to this study.

There are several other limitations of this research which may have contributed to masking the relationship between varsity athletic participation and EI. A main limitation of this research revolves around the fact that within the varsity athletic experience there is a range of different experiences that individuals can have. For example, playing on winning teams vs. losing teams could affect the type of experiences that students have. As well, a player's role on a team may affect her athletic experience. A player who plays a supporting role vs. a main role may have different factors influencing their emotional development. The fact that this study did not take into account these variations in athletic experience is a limitation and represents a valuable extension of this research.

Another factor which may have affected the ability of this research to correctly uncover any relationship between varsity athletic participation and EI was the decision to exclude high profile sports from the sample. The exclusion of basketball and football athletes from the sample may have influenced the performance of athletes on the test. The higher profile sport experience (football and basketball), while different in nature than some other sports, could also contribute to a better understanding of varsity sport participation and its relationship to emotional intelligence development.

There were two sample specific characteristics which may have influenced the results of research question 1. First, the fact that the females in the sample were found to have a 
significantly lower mean number of years of varsity sport experience compared to the males in the sample. The effect of this difference is likely to be minimal due to the fact that the mean difference was 0.4 years, which equates to less than half a season of experience in varsity sport. However, it may have impacted the results of research question 1 by altering the impact of gender on EI scores. The second characteristic of the sample in this research which may have influenced the results of research question three is the program breakdown of the respondents. Although a best effort to control for university and program was done to help isolate the effect of varsity sport participation on EI scores, it should be noted that the sample showed nearly twice as many female to male respondents who were enrolled in humanities. Similarly, there were nearly twice as many male to female respondents in the sample who were enrolled in a business program. This imbalance can be attributed to how the sample was selected (i.e. the focus of the thesis on testing the effect of varsity sport participation and not gender on EI scores). Another limitation of this study is the difference in varsity athletic experience between the NCAA (US university athletics) and the CIS (Canadian Interuniversity Sport). The sample consisted of university students from six Ontario schools and thus, the results are applicable to Ontario Universities. However, the NCAA universities are allowed to have athletes on full athletic scholarship and also, the sports represent a much larger financial gain for a university then at the Canadian Universities. Therefore, research beyond that proposed in this thesis is required in order to determine if the results of this study are applicable to American Universities.

Finally, this study does not attempt to determine whether it is necessarily the varsity athletic experience which determines the student's relative EI levels or whether varsity 
athletics simply attracts students with a different $\mathrm{E}$ level. This thesis was a cross sectional examination of varsity athletes $\mathbb{E I}$ levels. In order to test the developmental effects of varsity athletic participation it would be necessary to perform a longitudinal study starting when students entered university and ending after their playing career is finished. This was also is beyond the scope of the proposed research but represents another potential extension of this research. 


\subsection{CONCLUSIONS}

This research has examined the relationship between varsity sport participation and emotional intelligence levels in university students. The results of this research have shown no significant relationship between overall EI scores and playing a varsity sport. The research also examined the effect of varsity participation on university student levels in the four branch scores of EI. The research findings showed no significant relationship between varsity sport participation and a university students' ability to perceive, use, understand or manage emotion. Finally, this research looked at effects of varsity sport participation on EI for males and females. The findings of this research showed no significant effect on EI scores for males or female athletes. These findings support previous work done by Howard (1986) which reported that extracurricular activities had no positive effect managerial effect. However, the results of this thesis also support research (Ryan, 1989) that called for further research into the effects of varsity athletic participation.

Despite the fact that this research study did not identify a significant relationship between university athletics and EI, it did however provide lessons which can guide future research in the area and can be used by business practitioners. The first potential benefit is to any organization seeking to understand how to recruit students and develop its future leaders. The results from this study would advise caution in using athletic participation as a predictor of emotional intelligence. Further research is needed to better understanding this relationship. The second area of implication for this research is for the university administration. Equal gender representation and funding is an important issue in the managing of university athletic departments. The findings of this report, while they show 
no significant results, point to further study which may examine the benefits of varsity sports for females in particular.

This study shows the need for researchers to conduct "grass roots" investigation on the potential benefits or costs of varsity sport participation for students. By understanding the positive and negative influences of varsity sport on a student's emotional development results of this research will be better understood.

Extensions of this research include the effect of varsity athletic participation on emotional intelligence in higher profile sports such as basketball and football. As well, a study of the influence of sport participation on EI scores at American universities would be a valuable area of research. Finally, further research into the development of a students' emotional intelligence through university experiences other than varsity sport would be extremely valuable to researchers, students, employers and university administrators. 


\subsection{REFERENCES}

Antoine, P. (2002), Fiedler's Contingency Theory of Leadership.

www.stfrancis.edu./ba/ghkickul/stuwebs/btopics/works/fied.htm. ref- 12/11/02

Badaracco, Joseph L. Jr. (2001), "We don't need another hero", Harvard Business Review, Sept, 121-128.

Bar-On, R. (1988). The development of a concept of psychological

well-being. Unpublished doctoral dissertation, Rhodes University, South

Africa.

Bass \& Steidlmeier (1998), Ethic, character, and authentic transformational leadership, Center for Leadership Studies, School of Management

http://cls.binghamton.edu/BassSteid.html. site visited-09/07/03.

Batson, Shaw, \& Oleson (1992) Differentiating Affect, Mood and Emotion: Toward Functionality based Conceptual Distinctions.

Bennis, Warren G. \& Thomas Robert J. (2002), "Crucibles of Leadership", Harvard Business Review, Sept, 39-45.

Blake, Robert R. \& Mouton, Jane S. (1964), The managerial grid. Houston, TX: Gulf Publishing.

Brackett, M., \& Mayer, J. D. (2001). Comparing measures of emotional intelligence. Paper presented at the Third Positive Psychology Summit- October 2003, Washington, DC.

Burdett, J. (1997), "Going for the gold", Management Decisions, Vol. 35, Issue 2.

Caruso, David R.,(2003), Emotional IQ, www.emotionaliq.org, ref- June 2003.

Collins, $\operatorname{Jim}(2001)$, "Level 5 Leadership: The triumph of humility and fierce resolve", Harvard Business Review, Jan, 67-76.

Clark (2002), Blake \& Mouton's Managerial Grid, www.nwlink.com/ donclark/leader/bm model.html, Last update - 24/02/02, Ref24/11/02.

Cooper, Robert K. \& Sawaf, Ayman (1997), Executive EQ: Emotional Intelligence in Leadership and Organizations, published by Putnam. 
Dench, Sally (1997), "Changing Skill needs: what makes people employable", Industrial and Commercial training, Vol. 29, Issue 6.

Dulewicz, V., and Higgs, M. (1998), "Emotional intelligence: can it be measured reliably and validly using competency data?" Competency, 6(1).

Fiedler, Fred (1967), A theory of leadership effectiveness. New York: McGraw Hill.

Filley, House \& Kerr (1976), Managerial Process and Organizational Behavior, Scot, Foresman and Company.

Fineman (2003), Understanding emotion at work. London: SAGE Publications Ltd.

Fleishman, E.A., Harris, E.F., \& Burtt, H.F. (1955), Leadership and supervision in industry. Columbus, Ohio: Ohio State University, Bureau of Educational Research.

Fiol, M., Harris D., House R. (1999), "Charismatic leadership. Strategies for effecting social change", The Leadership Quarterly 10 (3), 449-482.

Foil, Harris \& House (1999), "Charismatic Leadership: Strategies for Effecting Social Change", C. Marlene Fiol.

Gannon, M.J. (1982), Management: An Integrated Framework. Boston: Little Brown.

Goffee \& Jones (2000), "Why Should Anyone Be Led By You", Harvard Business Review, Sept-Oct, 63-70.

Goleman, Daniel (1995), Emotional Intelligence, New York, NY: Bantam Books York, NY.

Goleman, Daniel (1998), Working With Emotional Intelligence, New York, NY: Bantam Books.

Goleman, Daniel (1998), "What makes a leader?", Harvard Business Review, Nov-Dec, 93-102.

Goleman, Daniel (2000), "Leadership that gets results", Harvard Business Review, MarApr, 78-90.

Goleman, Boyatzis, \& McKee (2002), Primal Leadership: Realizing the Power of Emotional Intelligence. Cambridge, MA: Harvard Business School Press.

George, J.M, (2000) "Emotions and Leadership: The role of Emotional Intelligence", Human Relations, Volume 53(8). 
Hay Group (2000), Emotional Competency Inventory (ECI): Technical Manual, http:/www.eiconsortium.org/research/ECI Tech Manual.pdf, ref: 14/07/03.

Hemphill, J. K. and Coons, A. E. (1957). "Development of the leader behavior description questionnaire" In Leader Behavior: Its Description and Measurement. Stogdill, R. M., and Coons, A. E. (eds.) Columbus, OH: Bureau of Business Research of Ohio State University.

Hersey, Paul \& Blanchard, Kenneth H. (1993) Management of organizational Behavior, $6^{\text {th }}$ Edition. Englewood Cliffs, NJ: Prentice-Hall.

House, R.J. (1971) "A Path-Goal Theory of Leader Effectiveness", Administrative Science Review. 16, p.321-339.

House (1996), "The Path Goal Theory of Leadership: Lessons, Legacy and a Reformulated Theory", Leadership Quarterly, 7(3), 323-352.

House \& Shamir, 1993. "Toward an integration of transformational, charismatic and visionary theories of leadership". Leadership: Perspectives and Research directions: 81 107. New York: Academic Press.

Howard, Ann (1986), "College Experiences and Managerial Performance", Journal of Applied Psychological Monograph, Vol. 71, No.3, 530-552.

Judge, Bono, Ilies \& Gerhardt (2002), "Personality and Leadership: A Qualitative and Quantitative Review", Journal of Applied Psychology, Vol. 87, No.4, 765-780.

Judge, Bono \& Remus (2002) "Personality and Leadership: A Qualitative and Quantitative Review", Journal of Applied Psychology, v. 87 no4, Aug, p.765-80.

Kark, Shamir \& Gilad (2003), "The two faces of transformational leadership: Empowerment and Dependency", Journal of Applied Psychology; Apr2003, Vol. 88 Issue 2, p246

Katz, D., and Kahn, R. L. (1952) "Some recent findings in human relations research" Readings in Social Psychology. Swanson, E., Newcomb, T., and Hartley, E. (eds.) New York: Holt, Rinehart \& Winston.

Katz, D., Maccoby, N., Gurin, G., and Floor, L. (1951). Productivity, Supervision, and Morale among Railroad Workers. Ann Arbor, MI: Survey Research Center, University of Michigan.

Katz, D., Maccoby, N., and Morse, N (1950). Productivity, Supervision, and Morale in an Office Situation. Ann Arbor, MI: Institute for Social Research. 
Kesner \& Sebora (1994). "Executive Succession: Past, Present \& Future", Journal of Management, Vol.20(2), 327-372.

Kim, W. Chan \& Mauborgne, Renee A. (1992) "Parables of Leadership", Harvard Business Review, July-Aug, p.123-128.

Kirkpatrick, Shelley A. \& Locke, Edwin A. (1991), "Leadership: Do traits Matter?" Academy of Management Executive, 5(2), 48-60.

Kotter, John P. (1999), "What Effective General Managers Really Do", Harvard Business Review, March.

Law, Wong \& Song (2000), "The Construct and Criterion Validity of Emotional Intelligence and Its Potential for Management Studies", Journal of Applied Psychology, Vol. 89 , No. 3, 483-496.

Langley, A. (2000), "Emotional Intelligence: A new evaluation for management development?", Career Development International, Vol. 5, issue 3.

Levinson, Harry (1980), "Criteria for choosing chief executives", Harvard Business Review, July-Aug, p.113-120.

Liu, Srivastava \& Woo (1998), "Transference of Skills between sports and business", Journal of European Industrial Training, Vol.22, Issue 3

Maccoby, Michael (2000), "Narcissistic Leaders: The incredible pros and cons", Harvard Business Review, Jan-Feb, 69-77.

Mayer, Salovey \& Caruso, MSCEIT User's Manual, Multi-Health Systems, Toronto Ont. 2002

Mayer, J.D., Caruso, D.R, and Salovey, P. (2000a). Emotional intelligence meets traditional standards for an intelligence. Intelligence, 27(4), 267-298.

Mayer, J.D., Caruso, D. R., \& Salovey, P. (2000b). Selecting a measure of emotional intelligence: The case for ability testing. In R. Bar-On \& J. D. A. Parker (Eds.). Handbook of emotional intelligence (pp. 320-342). New York: Jossey-Bass

Mayer, J. \& P. Salovey. (1993). "The intelligence of emotional intelligence". Intelligence, 17, $433-442$.

Mayer, J.D., \& Salovey, P. (1997). What is emotional intelligence? In P. Salovey \& D. Sluyter (Eds.), Emotional development and emotional intelligence: Implications for educators (pp. 3-31). New York: Basic Books. 
Mayer, J.D., Salovey, P., \& Caruso, D. (2000a). Models of emotional intelligence. In R.J. Sternberg (Ed.), The handbook of intelligence (pp. 396-420). New York: Cambridge University Press.

Mayer, Salovey \& Caruso (2000b), "Emotional Intelligence as Zeitgeist, as Personality, and as a Mental Ability", Chapter in: R. Bar-On, \& J. D. A. Parker (Eds.) The Handbook of Emotional Intelligence.

McCall, Morgan W. \& Lombardo, Michael M. (1983) "What Makes a Top Executive" Psychology Today, February 1983, 26-31.

McClelland, D.C. (1973), "Testing for Competence rather than Intelligence." American Psychologist, 28: 1-14.

McCrae, Robert R. (2000), "Emotional Intelligence from the Perspective of the FiveFactor Model of Personality" Chapter 12 - Handbook of Emotional Intelligence, Edited by Reuven Bar-On and James D. A. Parker

Mauws, M.K (2002), Leadership, www.per.ualberta/mmauws, cite visited 2002/12/06.

Macaleer \& Shannon, (2002) Emotional Intelligence: How does it affect leadership.

Orioli, Esther M. (2003), Q Metrics, http://www.qmetricseq.com/, site visited - June $10^{\text {th }}, 2003$.

Perry \& Jamison (1998), In the Zone: Achieving Optimal Performance in Business-as in Sports, N T Contemporary Publishing Company

Robins, S. (2002). "A consultant's guide to understanding and promoting emotional intelligence in the workplace", In Lowman, R. (Ed), Handbook of Organizational Consulting Psychology. John Wiley \& Sons, Inc.

Reichheld, Frederick (2001), "Lead for Loyalty", Harvard Business Review, Jul-Aug, 7684.

Ryan (1989), "Participation in Intercollegiate Athletics: Affective Outcomes", Journal of College Student Development, March Vol. 30, 122-128.

Schmidt, D.C. (1997), Organizational change and the role of emotional intelligence. Paper presented at the Academy of Management Meeting, Boston.

Sosik, Potosky \& Jung (2002), "Adaptive Self-Regulation: Meeting others expectations of Leadership and Performance", Joumal of Social Psychology, Apr, 142 no2, 211-232.

Salovey, P., \& Mayer, J.D. (1990). Emotional intelligence. Imagination, Cognition, and Personality, 9, 185-211. 
Strunz, H. \& Dorsch, M.(2001), Management, Oldenbourg Verlag Muchen Wien

Stogdill, R.M. (1948), "Personal Factors associated with Leadership. A survey of the literature.", Journal of Psychology 25:35-71.

Stogdill, Ralph (1974) Handbook of Leadership. NY: Free Press

Tannenbaum, Robert \& Schmidt, Warren H. (1957/1973) 'How to choose a leadership pattern." Harvard Business Review, May-June 1973. Updated from 1957.

Thorndike, E.L. (1920). "Intelligence and its uses". Harper's Magazine, 140, 227-235

Thomdike, R.L., and Stern, S. (1937). "An evaluation of the attempts to measure social intelligence", Psychological Bulletin, 34, 275-284.

Tichy \& Ulrich (1984), "The leadership challenge- A call for the transformational leader", Sloan Management Review, Fall p.59-68.

Tucker, M., Sojka, J., Barone, F., McCarthy, A. (2000), "Training tomorrow's leaders: Enhancing the emotional intelligence of business graduates", Journal of Education for Business, v75 i6, 331-338.

Weber, A.M (1987), "Red Auerbach on Management", Harvard Business Review, MarchApril, p.84-91.

Yuk1, G. (1994). Leadership in Organizations (3rd ed.). Englewood Cliffs, NJ: PrenticeHall.

Zaleznik, Abraham (1977), "Managers and Leaders: Are they different?", Harvard Business Review, May-June, p.126-135. Reprinted in 1992 


\section{APPENDIX \# 1: LETTER OF INFORMATION}

\section{Letter of Information}

Research to study the affects of athletic participation in varsity sport on the emotional intelligence of University students will be conducted by Robert Smart with supervisor Dr. Linda Duxbury and in cooperation with Multi-Health Systems, Inc. (MHS) of Toronto. The study will be conducted in affiliation with the graduate School of Business at Carleton University, as part of a graduate course requirement.

The purpose of this research is to determine the relationship between varsity athletic participation and emotional intelligence levels in university students. The subject will be given an identification number that will ensure confidentiality of their data with the administrators of the test, Multi-Health Systems, Inc (MHS) of Toronto, Canada. MHS will provide a secure website which subjects will access using their id number and a password supplied by the researcher. Subjects will then take the online MSCEIT test, which will take approximately 40 minutes and their results will be stored by id number in a database. Only the researchers listed on this page can access this data.

A possible risk for this study is that participants may feel uncomfortable answering some questions regarding emotional intelligence. For this reason, participants may choose to decline answering any of the questions or remove themselves from the study and have data withdrawn at any time without reprisal. The benefits of this research are of an academic nature and participants may not benefit from their participation in the study.

The participants will have anonymity and confidentiality with regard to their data being used by MHS. Participants will give their name, program and year in university for the purpose of the thesis research being done by Robert Smart. Only the researchers listed on this page will have access to this data, which will be kept indefinitely. The findings of the study will be available, when completed, in the main office of the Eric Sprott School of Business.

This project has been reviewed and received ethics clearance through Carleton University's Research Ethics Committee, and those concerned or with questions about their involvement in the study may contact the ethics committee chair, Prof. Klaus Pohle (613) 520-2600 ext. 7434.

Rob Smant

nob smartahotmalcom

(613) $738-7779$

Dr. Linda Duxbury

520-2385

Linda dusbury@carleton.ca 